\title{
Experimental characterization of the mechanical consequences of a debonded total hip stem with an unsupported distal tip
}

\author{
Keith Thomas Hustosky \\ West Virginia University
}

Follow this and additional works at: https://researchrepository.wvu.edu/etd

\section{Recommended Citation}

Hustosky, Keith Thomas, "Experimental characterization of the mechanical consequences of a debonded total hip stem with an unsupported distal tip" (2002). Graduate Theses, Dissertations, and Problem Reports. 2440.

https://researchrepository.wvu.edu/etd/2440

This Dissertation is protected by copyright and/or related rights. It has been brought to you by the The Research Repository @ WVU with permission from the rights-holder(s). You are free to use this Dissertation in any way that is permitted by the copyright and related rights legislation that applies to your use. For other uses you must obtain permission from the rights-holder(s) directly, unless additional rights are indicated by a Creative Commons license in the record and/ or on the work itself. This Dissertation has been accepted for inclusion in WVU Graduate Theses, Dissertations, and Problem Reports collection by an authorized administrator of The Research Repository @ WVU.

For more information, please contact researchrepository@mail.wvu.edu. 


\title{
Experimental Characterization of the Mechanical Consequences of a Debonded Total Hip Stem with an Unsupported Distal Tip
}

\author{
Keith T. Hustosky \\ Dissertation submitted to \\ The College of Engineering and Mineral Resources \\ at West Virginia University \\ in partial fulfillment of the requirements \\ for the degree of \\ Doctor of Philosophy \\ in \\ Mechanical Engineering
}

Timothy L. Norman, Ph.D., Chair

J. David Blaha, M.D.

Thomas A. Gruen, M.S.

Victor H. Mucino, Ph.D.

Charles F. Stanley, Ph.D.

Department of Mechanical and Aerospace Engineering

Morgantown, West Virginia

2002

Keywords: Bone Cement, Creep, Hip Arthroplasty, Taper Lock, Mechanical Testing 


\title{
ABSTRACT \\ Experimental Characterization of the Mechanical Consequences of a Debonded Total Hip Stem with an Unsupported Distal Tip
}

\author{
Keith T. Hustosky
}

Cemented total hip arthroplasty (THA) has enjoyed widespread success since its introduction over thirty years ago. Despite the successes, there are threats to the long term stability of THA, chief among them aseptic loosening of the femoral stem. Femoral component loosening is a significant problem because it prevents the efficient transfer of hip joint forces through the cement to the proximal femur. This may cause pain in the patient severe enough to warrant surgery to replace the loose component.

The predominant approach to preventing loosening of cemented THA femoral components focuses on improving the bond between the prosthesis stem and the acrylic bone cement. This is done by using a stem with a rough surface or by pre-coating the stem with bone cement. An alternative approach is to incorporate stem-cement interface debonding into prosthesis design. A stem of this type is the subject of this study.

This study has two components. First, bulk specimens of Simplex P bone cement were subjected to compressive creep tests. Second, polished, tapered, cemented stems were implanted in cadaveric femora and subjected to physiologic loads. During loading, cement mantle hoop strains and axial displacement of the stem within the cement mantle were measured. Stem pull-out tests were performed before the specimens were loaded and after each load case. Finally, the cement mantles were examined for damage.

The compressive creep tests of Simplex P bone cement indicate that this cement has a relatively high resistance to creep. Measurement of bone cement hoop strains, stem subsidence and pull-out strength indicate that the stem debonds from the cement, that the cement mantle will experience creep under physiologic loading and boundary conditions and that the stem will undergo distally directed axial displacement within the cement mantle. The combined effects of this behavior lead to a mechanical taper lock between the stem and cement mantle that provides a means of stable fixation. Analysis of the cement mantles from the tested specimens indicates that cement mantle damage varies between formulations of bone cement. This indicates that choice of bone cement may be an overlooked variable in total hip arthroplasty. 


\section{DEDICATION}

This dissertation is dedicated to my mother, Virginia Hustosky. Her love and support are the foundation upon which all of my achievements have been built. 


\section{ACKNOWLEDGEMENTS}

Rarely is the completion of any significant task the result of individual effort. My doctoral research is no exception. I would like to take this opportunity to express my gratitude to those who have helped me achieve this goal:

Dr. Timothy Norman, my research advisor, for giving me the opportunity to work under him, for his guidance and his patience.

Dr. J. David Blaha for his contagious enthusiasm for research and for the hours he spent with me in the lab.

Mr. Thomas Gruen for always being willing to share with me some of his insights into hip prosthesis performance, for his critical review of my manuscripts and for his efforts to keep me informed of the latest developments in the field.

Dr. Victor Mucino and Dr. Charles Stanley for taking the time to serve on my committee and for their interest and valuable input into my research.

Mr. Vincent Kish for the countless hours spent working with me and teaching me about specimen preparation, fixture fabrication and troubleshooting the experimental setup.

Ms. Nina Clovis and Ms. Suzanne Smith for teaching me how to conduct research in the lab and making sure that I had access to the supplies and equipment I needed.

All of my fellow graduate students I have had the pleasure of working with in the Musculoskeletal Research Center for their support and friendship, especially Christopher Brown for all of his encouragement and Srinivas Nivargikar for the orientation he gave me to life in the lab.

Mr. James Dalton of the Department of Industrial and Management Systems Engineering for allowing me use of the surface profilometer and sandblaster in the Manufacturing Processes Laboratory.

Everyone at West Virginia Assistive Technology System for their support and friendship, especially my supervisors Jack Stewart and Jeanne Grimm for a flexible work schedule that allowed me to fulfill my academic responsibilities. 


\section{TABLE OF CONTENTS}

ABSTRACT ........................................................................................................................ ii

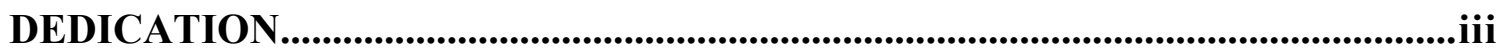

ACKNOWLEDGEMENTS .............................................................................................iv

TABLE OF CONTENTS ......................................................................................................

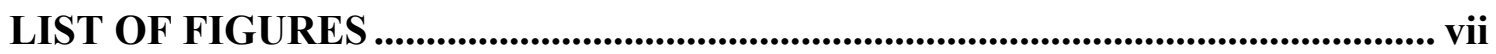

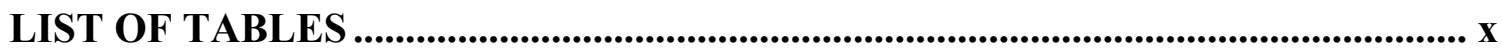

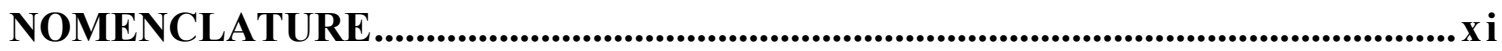

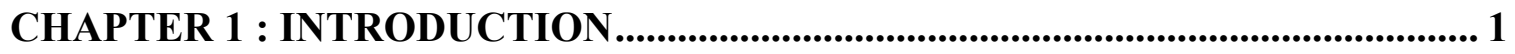

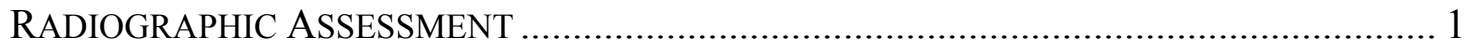

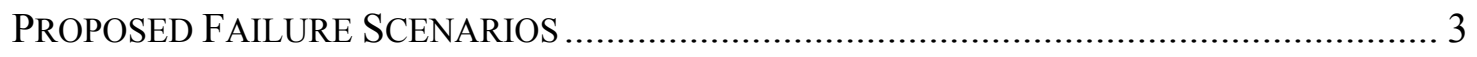

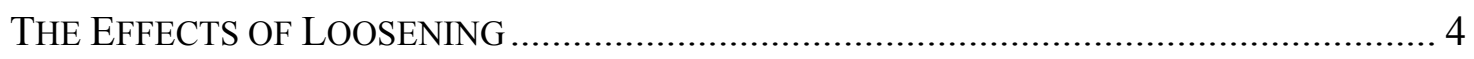

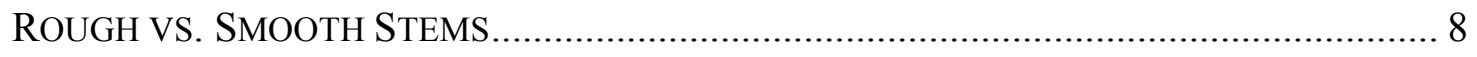

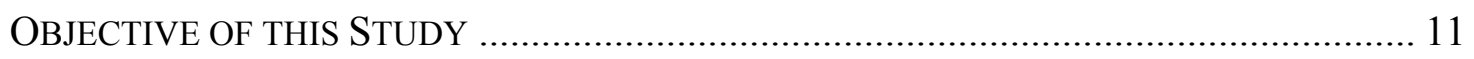

CHAPTER 2: ANATOMY................................................................................................. 13

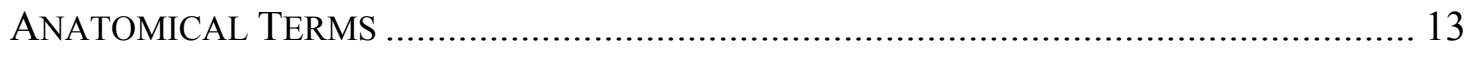

BONE STRUCTURE AND CLASSIFICATION ……………………………………….... 14

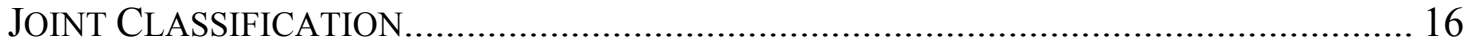

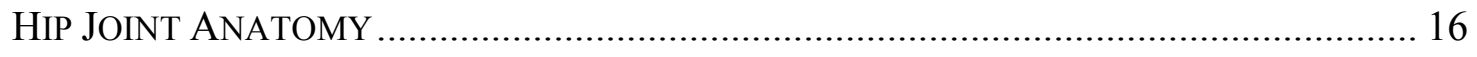

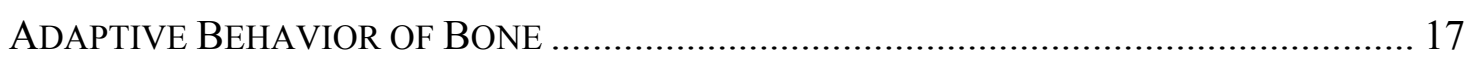

CHAPTER 3: THE ROLE OF BONE CEMENT IN THA …….................................... 22

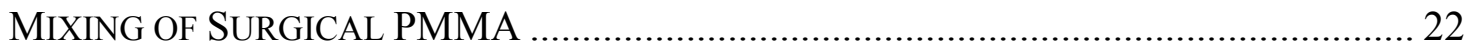

VISCOELASTIC BEHAVIOR OF PMMA BONE CEMENT …………………………...... 23

CHAPTER 4: EXPERIMENTAL METHODS.................................................................... 34

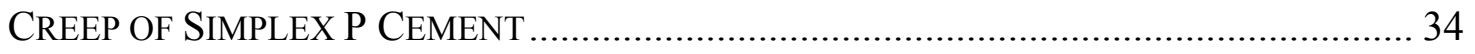


EXPERIMENTAL APPLICATION OF PHYSIOLOGIC HIP LOADS.................................. 36

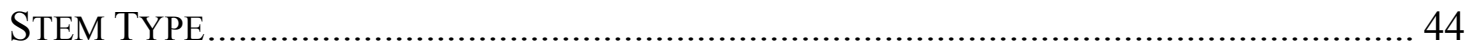

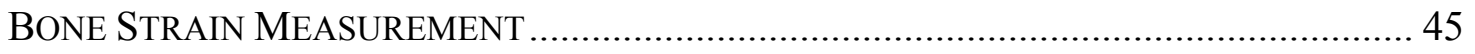

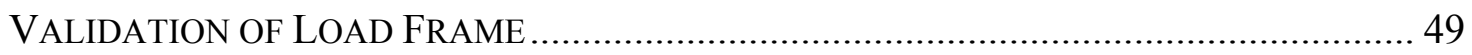

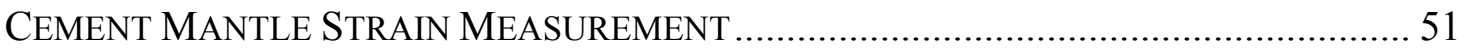

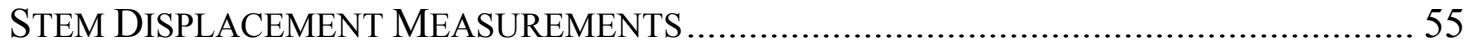

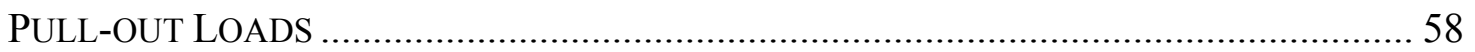

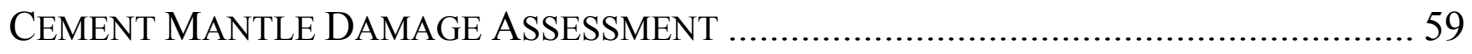

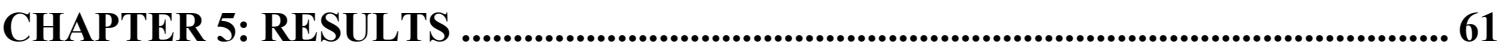

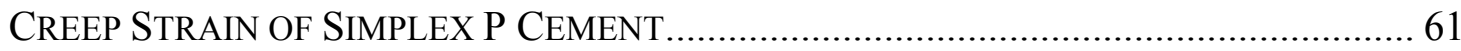

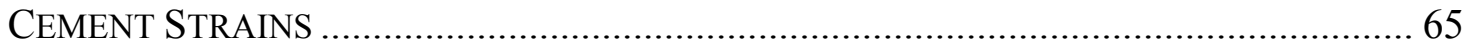

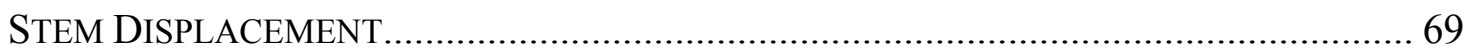

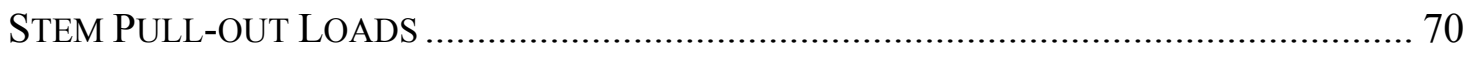

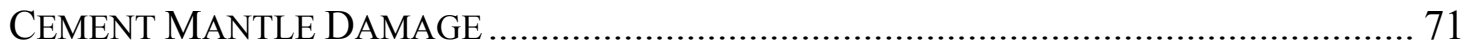

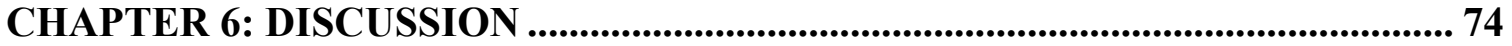

COMPARISON OF CEMENT CREEP BEHAVIOR ........................................................ 74

COMPARISON OF MEASURED CEMENT STRAINS TO FEM RESULTS ......................... 75

Stem GeOMETRy AfFeCts Subsidence, CEMENT StRAins AND TAPER LOCK ...... 77

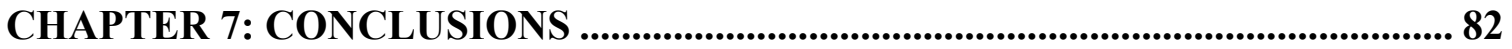

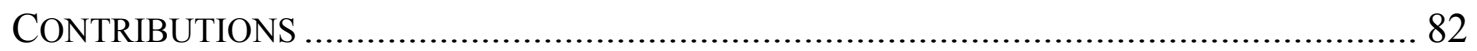

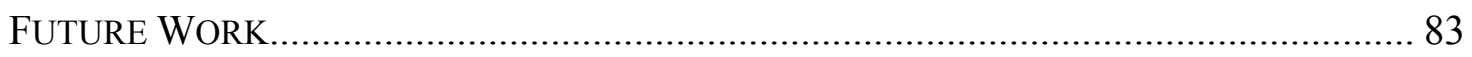

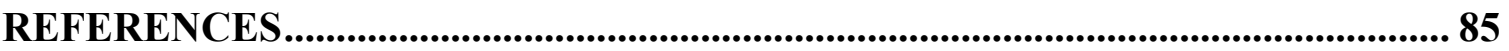

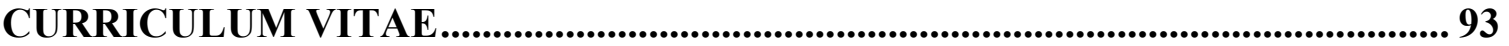




\section{LIST OF FIGURES}

Figure 2-1. The human skeleton. The human skeleton is divided into the axial skeleton and the appendicular skeleton.

Figure 2-2. Posterior view of the human femur. The head of the femur is connected to the shaft by the femoral neck. The greater and lesser trochanters are sites of muscle attachment.

Figure 3-1. Elastic material behavior. Under a constant load below the elastic limit $\left(\sigma_{\mathrm{el}}\right)$ the material experiences a constant strain that is relieved immedialtey upon removal of the load

Figure 3-2. Plastic material behavior. Under a constant load above the elastic limit $\left(\sigma_{\mathrm{el}}\right)$ the material experiences a constant strain. This strain may not be fully recovered upon unloading. The unrecovered strain is known as plastic strain $\left(\varepsilon_{\mathrm{p}}\right)$.

Figure 3-3. Generalized creep curve. A viscoelastic material can experience three stages of creep: the primary stage marked by an increasing strain rate, the secondary stage with a constant creep rate and the tertiary stage with an increasing creep rate culminating in material failure.

Figure 3-4. Creep recovery. A viscoelastic material experiences increasing strain under constant load. Upon removal of the load, the elastic strain is immediately removed. While the creep strain will gradually decrease over time, some permanent strain may remain.

Figure 3-5. Stress relaxation. As a result of internal creep, a viscoelastic material may experience a reduction is stress while subjected to a constant strain.

Figure 4-1. Creep load frame used in this study. A heated saline bath maintains the specimen at body temperature.

Figure 4-2. Typical strain data for creep speciemens. The creep strain is taken to be the portion of strain that occurs after the initial load application.

Figure 4-3. Front view of hip simulator load frame. The femur is shown oriented for single-legged stance................................................................................................................... 38

Figure 4-4. Relation between Cartesian and spherical coordinate systems....................... 41

Figure 4-5. Coordinate system defined by Davy et al., 1988.

Figure 4-6. graphical representation of applied joint and muscle forces for the a) singlelegged stance, b) cyclic and c) stair climb load conditions. 
Figure 4-7. The stems used in this study. These stems are identical except for surface finish. The stem on the left has the original polished finish. The stem on the right has been sandblasted to achieve a rough surface finish.

Figure 4-8. Positions of strain gage rosettes on femur.

Figure 4-9. Comparison of normalized axial strains on the plastic femur to strains measured by $\mathrm{Oh}$ and Harris (1978) ........................................................................................... 50

Figure 4-10. Axial bone strains from single-legged stance loading of intact femur. ....... 50

Figure 4-11. Strain gage carrier. .................................................................................. 53

Figure 4-12. Locations of cement strain gage carriers........................................................... 53

Figure 4-13. Beam calibration specimen. .............................................................................. 54

Figure 4-14. Results of gage carrier calibration test............................................................. 55

Figure 4-16. Stem displacement measurement using a DVRT.......................................58

Figure 4-17. Stem-pull out fixture. .............................................................................................5 59

Figure 4-18. Longitudinal section of cement mantle-bone damage specimen. ................. 60

Figure 4-19. Cement damage specimen....................................................................6 60

Figure 5-1. Total compressive strain for the Simplex P creep specimens loaded at

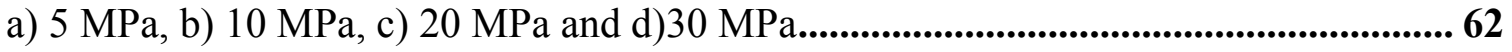

Figure 5-2. Comparison of measured creep strain of Simplex P bone cement to that predicted by a power law expression derived from experimental data for several load levels. Error bars indicate standard deviation of measured strains.

Figure 5-3. Regression line for predicted creep strain plotted against measured creep strain. Both the slope and coefficient of correlation are close to one. This indicates that the creep law accurately models creep strain.

Figure 5-4. Cement mantle hoop strain during single-legged stance loading for the a) proximal-lateral b) proximal-medial c) distal-lateral and d) distal-medial gage locations.

Figure 5-5. Cement mantle hoop strain during cyclic loading for the a) proximal-lateral b) proximal-medial c) distal-lateral and d) distal-medial gage locations.

Figure 5-6. Cement mantle hoop strain during stair climb loading for the a) proximalmedial b) proximal-lateral c) distal-medial and d) distal-lateral gage locations.

Figure 5-7. Axial creep displacement of the stem during single-legged stance loading. . 69 
Figure 5-8. Pull-out strengths of the polished stems after each load condition. The error bars indicate one standard deviation. ..................................................................... 70

Figure 5-9. Mean failure loads of the sandblasted stems compared to the initial pull-out load of the polished stems. The error bars indicate one standard deviation.

Figure 5-10. Photomicrographs of a) untested bulk specimen and b) tested cement mantle of Palacos $\mathrm{R}$ specimens. The cement cracks in the tested cement mantle are oriented in the hoop direction.

Figure 5-11. Schematic showing damage patterns in Palacos R cement mantle specimens.

Figure 5-12. Photomicrograph of cement damage in a loaded cement mantle of Osteobond cement. There is a network of cracks between PMMA beads. 73

Figure 6-1. Comparison of predicted creep strain after 24 hours of static compression for Surgical Simplex P, Osteobond (Saab, 1997) and Palacos R (Williams, 1995) bone cements.

Figure 6-2. Elements and nodes corresponding to gage locations.

Figure 6-3. Comparison of measured cement mantle creep strains to FEM results for the single-legged stance case. The bold lines with no markers represent FEM results. Shown are the strains at the a)proximal-lateral, b)proximal-medial, c)distal-lateral and d)distalmedial gage locations.

Figure 6-4. Schematic diagram showing the forces acting on idealized stems having a) no taper, b) constant taper and c) increasing taper. There is no cement below the tip of the

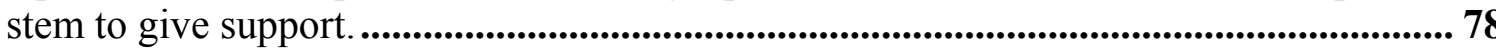

Figure 6-5. Schematic diagram showing stem geometry and forces acting on the stem used in this study. The stem has no taper laterally and distally while it has an increasing taper along the proximal-medial aspect. 


\section{LIST OF TABLES}

Table 4-1. The load parameters used in this study. All load magnitudes were calculated for a subject with a body weight of 667 N.................................................................................. 43

Table 4-2. Surface roughness values for the two stems used in this study......................... 45

Table 5-1. Average creep strain and standard deviation for each load level at hourly intervals............................................................................................................................... 63

Table 5-2. Crack density and length for Palacos R and Osteobond cement mantles. ..... 73 


\section{NOMENCLATURE}

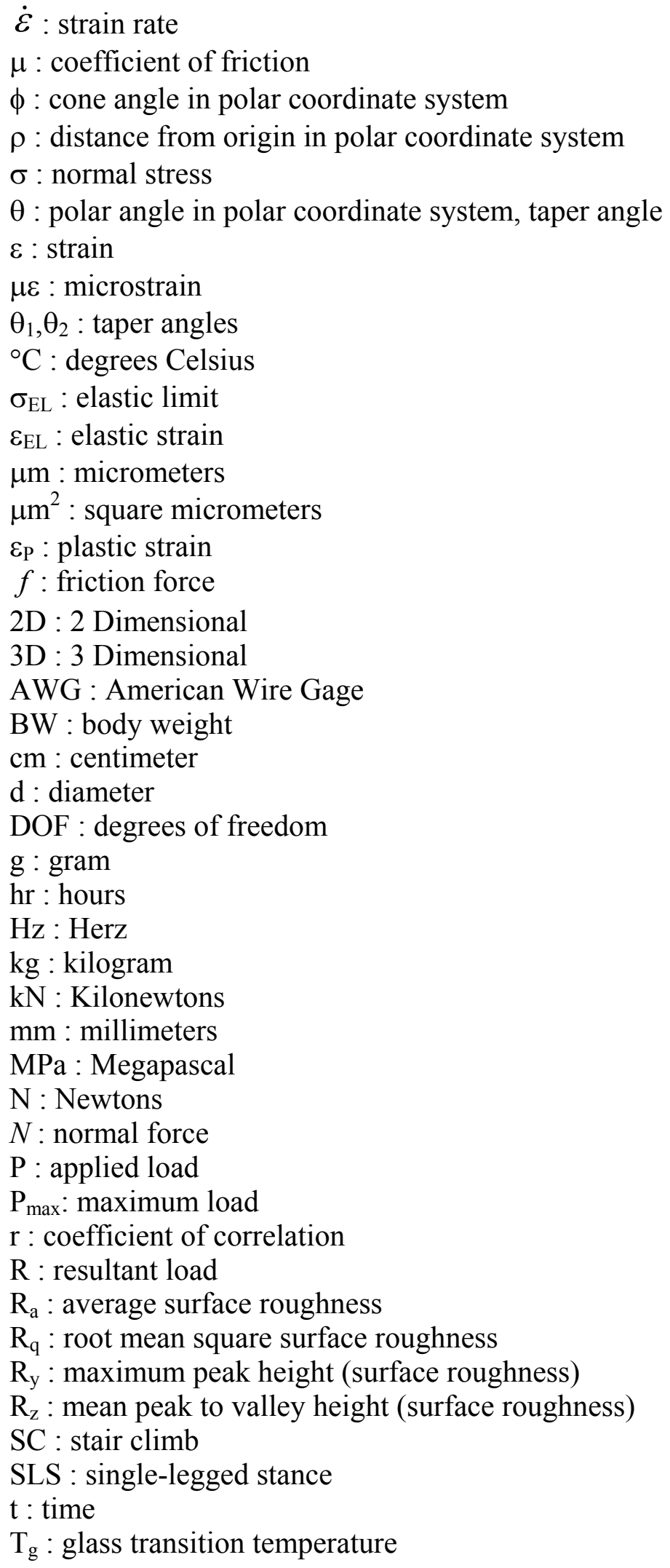




\section{CHAPTER 1 : Introduction}

Cemented total hip arthroplasty (THA) has enjoyed widespread success since its introduction over thirty years ago. Long-term follow-up studies have documented well functioning THA up to 28 years post-operatively (Dall et al., 1993; Schulte et al., 1993; Jasty et al., 1991; Fowler et al., 1988; Stauffer, 1982). Despite such examples of success, there are threats to the long term-stability of THA. Schulte et al. (1993) identified three modes of failure in THA: loosening with infection (septic loosening), loosening without infection (aseptic loosening) and gross mechanical failure of the stem (i.e. fracture or dislocation). Improvements in THA design have drastically reduced the frequency of gross mechanical failure of the stem, but loosening of the stem within the cement mantle still occurs. In 1982, a consensus report by the National Institutes of Health (NIH) concluded that loosening constitutes one of the most serious long-term complications of cemented THA.

\section{Radiographic Assessment}

Femoral component loosening is a significant problem because it prevents the efficient transfer of body forces through the cement to the proximal femur. This may cause pain in the patient severe enough to warrant surgery to replace the loose component. A prosthesis is classified as radiologically loose based on the progressive changes in the width or length of radiolucent zones, appearance of sclerotic bone reaction, widening of cement fracture gaps, the increase in cement fragmentation, gross movement of the femoral component or stem fracture (Gruen et al, 1979). A prosthesis is said to be clinically loose when the patient experiences excessive pain on weight bearing 
due to inefficient load transfer. Radiographic loosening is generally thought to be a sign of potential clinical failure.

Radiographic studies are used to assess the state of implants in patients. Weber and Charnley (1975) noted that transverse fracture of the cement mantle occurred in $1.5 \%$ of the Low Friction Arthroplasties (LFA) radiographs they observed. These cracks occurred most frequently in the distal $2 \mathrm{~cm}$ of the cement mantle. They attributed these cracks to prosthesis subsidence associated with component loosening within the cement mantle. A loosened prosthesis stem becomes end bearing on the distal portion of the cement mantle. Subsequently, the cement in this region is subjected to elevated tensile loads, which leads to cement fractures. They speculated that a prosthesis subsides to a new and final position of stability where the load will be more evenly transmitted over the whole surface of the cement. Loudin and Charnley (1980) determined that when cement tip fractures occur within 1 year after implantation measurable prosthesis subsidence had occurred. Continuing this study, Loudin (1986) discovered that after 5 years, subsidence of unflanged stems usually stabilized after approximately $5 \mathrm{~mm}$ of distal subsidence.

A radiographic study by Wroblewski (1986) observed cement fracture in 17 of $116(14.6 \%)$ LFA. In 16 of the 17 cases, fractures occurred at the tip of the prosthesis. Older (1986) detected transverse failure of the cement near the tip of the prosthesis stem in $21 \%$ of 128 LFA studied. Dall et al. (1986) detected cement fracture near the tip in 12 of 84 (14.2\%) unrevised LFA performed in South Africa between 1970 and 1974.

Numerous clinical studies have documented revision surgery due to aseptic loosening in THA. Stauffer (1982) reported that 14 of the first 300 patients to receive Charnley THA at the Mayo Clinic between 1960 and 1970 required revision surgery due 
to loosening of the femoral component or of both the femoral and acetabular component within 10 years. Sutherland et al. (1982), in a 10-year follow-up study documented revision surgery due to aseptic loosening of the femoral component in 13 of 66 hips (20\%). More recently, Dall et al. (1993) found that $11.4 \%$ of modern Charnley THA studied required revision surgery due to femoral component loosening at an average follow-up of 7.5 years. Schulte et al. (1993) in a 20 year follow-up study documented revision rate due to a loose stem or loose stem and acetabular cup at approximately $10 \%$.

\section{Proposed Failure Scenarios}

Many investigators have tried to define the mechanisms that lead to aseptic loosening of THA. Jasty et al. (1991) examined 16 cemented femoral stems retrieved post-mortem from patients who had well functioning THA. The stems had been implanted from 2 weeks to 17 years prior to retrieval. Although 15 of the 16 stems showed no physical, radiographic or clinical signs of loosening and all of the cementbone interfaces were intact, some stem-cement interface debonding was observed in each specimen. This debonding occurred most often at the proximal and distal ends of the prosthesis. Fatigue cracks associated with stem-cement debonding and cement mantle defects were common. The most extensive cracking appeared to have started at or near sharp corners of the prosthesis or where the cement mantle was thin or incomplete. Their observations indicate that progressive cement damage occurs long before apparent radiographic or clinical loosening. This led to the conclusion that long-term failure of the fixation of cemented femoral components is primarily mechanical, not biological, in nature. It starts with debonding at the stem-cement interface and continues as slowly developing cracks in the cement mantle. 
Histological studies of failed THA suggest that wear particles can have a destructive effect on implant stability. Lennox et al. (1987) concluded that stem micromotion generates bone cement wear particles which trigger a biological response leading to bone resorption. The loss of supporting bone tissue causes more micromotion. This cycle leads to failure of THA. Horowitz et al. (1993) propose that cement particles generated by mechanical failure (i.e. fatigue failure) of the cement mantle induce bone resorption at the cement-bone interface destroying the bond formed between the cement and bone at implantation leading to aseptic loosening.

Huiskes (1993) proposed two concurrent failure scenarios, the accumulated damage failure scenario and the particulate reaction failure scenario. According to the accumulated damage failure scenario repeated dynamic loads eventually lead to mechanical failure of the cement and the stem-cement and cement-bone interfaces. These failures bring about cement-bone interface loosening, micromotion and bone resorption. In the particulate reaction failure scenario, particles generated from wear of the cement or implant produce biological reactions that lead to bone resorption and loss of support. The combined effects of these processes lead to gross loosening of the implant. All of the observations concerning THA failure mechanisms indicate that while biologic processes play an important role, mechanical factors are the underlying cause of failure of THA.

\section{The Effects of Loosening}

The effect of stem loosening on cement mantle stresses has been experimentally investigated. Crowninshield and Tolbert (1983) measured strain in the cement mantles of loose and well-fixed femoral component stems. Femoral components implanted in fresh 
frozen cadaver femora were coated with a debonding agent to prevent stem-cement bonding. The distal cement plug was instrumented with vertically oriented strain gages on the medial and lateral surfaces. Additionally, encapsulated strain gages were inserted in the proximal cement mantle while the cement was still viscous. The gages situated in the proximal-medial region of the cement mantle were oriented vertically, mediallaterally and anterior-posteriorly. One gage oriented medial-laterally was placed in the proximal-anterior region of the cement mantle. The specimens were placed in a test fixture and subjected to a $3000 \mathrm{~N}$ load. First, the load was applied parallel to the shaft of the femur. Next, the load was applied inclined $15^{\circ}$ medially within the frontal plane. After loading, the stem was removed from the cement. The stem and cement were cleaned; the stem was replaced in the cement with either a complete or proximal onethird coating of epoxy. The epoxy served to create a strong bond between stem and cement. The specimens were then loaded as before.

The condition of the stem cement interface had a strong effect on measured cement strains. The strains were greatest in the case of a debonded stem. A fully bonded stem reduced cement strains in the proximal cement mantle by $42 \%$ in the anteriorposterior direction, $21 \%$ medial-laterally and $17 \%$ vertically but had little effect on distal cement strains. A proximal one-third bond decreased cement strains proximally by $30 \%$ in the anterior-posterior direction, $18 \%$ medial-laterally and $48 \%$ vertically compared to a debonded stem. Distally the strains decreased $30 \%$ medially and $25 \%$ laterally.

The issue of debonding has been the subject of a number of finite element studies. Huiskes (1990) used generalized 2D Finite Element Model (FEM) to study load transfer mechanisms in THA. The different models represented the mid-frontal plane of cemented, fully ingrown, proximally ingrown and smooth press-fitted stems. $\mathrm{He}$ 
determined that bonded stem systems relied on shear forces generated at the interfaces to equilibrate applied compressive axial loads. An unbonded stem does not generate high shear stresses. Instead, the stem subsides until interface compression forces become high enough for their axial components to balance the applied axial loads. Three factors influence the amount of subsidence needed for equilibrium: interface friction, stem geometry and constraint stiffness. Friction at the interface decreases the amount of subsidence necessary to balance external forces because it causes shear forces that contribute to equilibrium. The amount of compression generated for a given amount of subsidence increases with increasing stem taper angle and with increasing constraint stiffness. Thus the greater the stem taper angle or the stiffer the cortical bone shell, the less subsidence needed to generate the compressive forces necessary for equilibrium.

Lu et al. (1992) used a 3D FEM of a straight stem with a rectangular cross section cemented into a cortical bone shell to assess the effect of the stem-cement bond strength on cement stresses. The stem was subjected to a transverse load. In successive runs the bond strength was varied. The maximum value of the largest cement von Mises stress occurred with no stem-cement bonding and was $30 \%$ larger than in the presence of a perfect bond. The maximum value of the largest cement principal stress occurred in the presence of a perfect bond and was $54 \%$ greater than the minimum value that occurred in the presence of partial interface bonding. The results of this simplified model suggest that the longest cement fatigue life may be obtained with a less than perfect bond.

Mann et al. (1991) used a 3D FEM of a smooth, straight stem cemented into a femur to determine the effect of stem-cement debonding on cement stresses. The model was subjected to a joint load of $3408 \mathrm{~N}$ and a greater trochanter load of $2581 \mathrm{~N}$ corresponding to peak load during gait. Two cases were considered, a perfectly bonded 
stem and a debonded stem with a coefficient of friction 0.22 between the stem and cement. Debonding had a significant effect on cement stress distribution. A tensile hoop stress of $8.4 \mathrm{MPa}$ was present in the proximal-medial cement mantle of the debonded case that was not present in the case of a perfect bond. A radial compressive stress region was present in the medial cement mantle of the debonded case that was a region of small radial tensile stress in the bonded model. Compressive radial stresses doubled at the distal tip from $5 \mathrm{MPa}$ to $10 \mathrm{MPa}$ as a result of debonding. The tensile hoop stress approached the endurance limit of the cement suggesting the possibility of cement failure in the proximal-medial region.

Rabb et al. (1981) studied the strength the implant-bone interface for four commonly used implant materials (Co-Cr-Mo, Ti-6Al-4v, 316SSLVM and UHMWPE). The interface specimens were formed by joining bone cement to prepared surfaces of the implant materials. The surface roughness of the specimens was comparable to that of sandblasted stem surface. Static tests of tensile and shear specimens indicate that a combination of shear and tension causes interface failure. Fatigue tests showed that repeated low-level loads could also cause interface failure. Analysis of the specimens indicated that intimate interfacial contact between bone cement and the tested materials was impossible. They concluded that failure of the stem-cement interface probably occurs shortly after implantation and that interface failure may be a major contributor to implant loosening. 


\section{Rough vs. Smooth Stems}

In 1994, the NIH Consensus Panel on Total Hip Replacement concluded that the optimal stem surface finish has not yet been determined. The predominant method of preventing loosening of cemented THA femoral components focuses on improving the bond between the prosthesis stem and the acrylic bone cement. This is done by using a stem with a rough surface or by pre-coating the stem with bone cement. Miles (1990) developed an experimental model to investigate the effects of surface roughness on implant behavior. A steel stem cemented into an aluminum sleeve with a tapered bore represented the stem-cement-bone system. Stems with polished surfaces, sandblasted surfaces and sandblasted and grooved surfaces were cemented into aluminum sleeves with a uniform cement mantle thickness of $4 \mathrm{~mm}$. Strain gages were positioned within the cement mantle to measure axial and hoop stresses $2 \mathrm{~mm}$ from each interface. The stem was subjected to repeated static axial loads at increasing levels and strain values were recorded. After strain data had been collected, the stems were removed from the sleeves in reverse push-out tests. The smooth stem was removed with a load of $5.6 \mathrm{kN}$. The cement mantle was pristine and glassy in appearance. The sandblasted stem was removed with a load of $15.8 \mathrm{kN}$. The cement mantle was matte in appearance and cement particles had adhered to the stem surface. The grooved stem could not be removed from the cement mantle with a push-out load so these models were cut in half to remove the stem.

Analysis of the model showed that in the case of the polished stem there was very low interfacial shear stress between the stem and the cement and that the bulk of the load was transferred through radial compression of the cement. On the other hand, the rough 
stems created a high degree of mechanical interlock between the stem and cement resulting in greater interfacial shear stresses, lower radial compression and slightly lower hoop stress. They concluded that a smooth-polished stem would reduce destructive shear loading at the cement-bone interface and provide a fixation system capable of adapting to bone remodeling through cement creep.

Verdonschot and Huiskes (1995) used a similar model to measure the effects of surface roughness on dynamically loaded straight-tapered stems. The stems were $125 \mathrm{~mm}$ long with a taper angle of $8^{\circ}$. The cement mantle was $80 \mathrm{~mm}$ long with a uniform thickness of $10 \mathrm{~mm}$. After curing, the cement mantle with the taper was stored in a saline solution for one month at a temperature of $37^{\circ} \mathrm{C}$. Uni-directional strain gages were applied to the outer surface of the cement mantle to measure hoop strains at the proximal, middle and distal levels. The tapers were subjected to a purely axial compressive sinusoidal load ranging from 0 to $7 \mathrm{kN}$ at a frequency of $1 \mathrm{~Hz}$ for 1.7 million cycles. Cyclic micromotions and subsidence relative to the top of the cement mantle were measured using an extensometer. After loading, the specimens were sectioned and prepared for scanning electron microscope (SEM) analysis.

SEM analysis showed that the rough stems could subside only after local destruction of the cement mantle that created wear particles. The polished stem subsided substantially in the cement mantle without causing significant damage to the cement mantle. SEM analysis revealed very few cement cracks, indicating that subsidence was not the result of cement failure but rather due to cement creep. The subsidence occurred in a step-wise manner that was attributed to slip-stick processes at the interface interacting with creep processes in the cement mantle. They concluded that while a stem with a rough surface may have a stronger stem-cement interface, its fail-safe mechanism 
against the effects of debonding are inferior to that of a polished stem. A rough surface may reduce subsidence of a debonded straight-taper stem but it will also increase the amount of cement mantle damage.

While it has been shown that a rough stem improves the load carrying capability and fatigue strength of the stem-cement interface (Manley et al., 1985), there is clinical evidence to suggest that strengthening the stem-cement interface may significantly increase the chances of failure of the bone-cement interface (Gardiner and Hozack, 1994) and that it does not ensure the long term integrity of the stem-cement interface (Schmalzreid, 2000; Sporer et al., 1999; Collis and Mohler, 1998; Woolson and Haber, 1996; Mohler, Callaghan et al. 1995; Mohler, Kull et al. 1995; Oishi et al., 1994). A different approach to prevent loosening is to incorporate debonding of the stem-cement interface into prosthesis design. This requires the use of a stem with a highly polished, smooth surface (Norman, et al., 1996, Miles 1990). Lee (1990) asserts that the goal of any implant must be to preserve the bone stock of the joint. To do this, the cement-bone interface must be loaded in static compression and shear loading must be minimized to stimulate new bone growth. There is clinical evidence to suggest that in some stemdesigns a polished surface is preferable (Schmalzreid, 2000; Sporer et al., 1999; Fowler et al., 1988).

The overall goal of this study is to experimentally characterize the mechanical behavior of a polished, tapered stem with an unsupported distal tip. Finite element analysis of the proposed stem design has been done previously using idealized geometry and simplified loading (Norman et al., 1996, Hustosky, 1993) and with accurate 3-D geometry and phsyiologic loading (Norman et al., 2001). These models incorporated creep behavior of the bone cement and were used to investigate the effects of stem- 
cement interface debonding. According to these models, in the presence of stem-cement interface debonding the cement mantle will experience viscoelastic deformation. This leads to distal subsidence of the stem within the cement mantle. The stress state in the cement suggests that these polished, tapered stems will achieve a taper lock within the cement mantle. The 3D model shows that normal stresses in the cement are greatest in regions of greatest taper and are not diminished by cement creep.

\section{Objective of this Study}

This study has two components. First, bulk specimens of Simplex P bone cement were subjected to compressive creep tests. Second, polished, tapered, cemented stems were implanted in cadaveric femora. These specimens were subjected to three different physiologic load conditions. During loading, cement mantle strains were measured to verify that bone cement experiences creep under in vivo loading and boundary conditions. Axial displacement of the stem within the cement mantle was measured for comparison to finite element results. Stem pull-out tests were performed before the specimens were loaded and after each load case to determine if a mechanical taper lock is achieved between the stem and cement mantle. Finally, the cement mantles of the tested specimens were examined for damage to determine if failure of the cement mantle occurred. The following chapters describe the details of this study.

The results of these tests were used to accomplish the objectives of this study

which are a) to characterize the creep behavior of Simplex P bone cement, b) to determine if bone cement experiences creep under in vivo boundary conditions c) to determine if the stem subsides within the cement mantle, d) to determine if the stem 
achieves taper-lock fixation and e) to determine if damage occurs within the cement mantle.

Chapter 2 provides background information on the anatomical terms, anatomy of the skeletal system, joint classification and the adaptive behavior of bone.

The material in chapter 3 discusses the nature, role and behavior of polymethylmethacrylate (PMMA) bone cement. The viscoelastic behavior of PMMA bone cement and the role it plays in cemented THA is discussed.

Chapter 4 describes the experimental methods used in this study. It discusses the design and fabrication of the hip simulator load frame. The various load conditions used to evaluate the specimens, their derivation and their significance are explained. Measurement of in vitro cement mantle strains and stem displacement is discussed. It will be shown how these parameters can be used to evaluate prosthesis behavior, how these design criteria have been measured in previous studies and how they were measured in this study. The use of stem pull-out tests to measure taper-lock fixation will be described. Finally, the methods used to evaluate cement mantle damage will be described.

Chapter 5 reports the results of the experiments.

Chapter 6 discusses the differences in creep resistance of several commercially available bone cements, compares measured cement mantle strains to those found in a corresponding finite element model and discusses the effect of a stem geometry on its behavior in the presence of a debonded stem-cement interface.

Chapter 7 provides a summary of the significance of this work and makes suggestions about what future areas of investigation should follow this study. 


\section{CHAPTER 2: Anatomy}

The musculoskeletal system is made up of bones, muscles, tendons and ligaments. Collectively the bones of the body are called the skeleton. The muscles are tissues whose contractions cause the body to move. Tendons are the tissues that connect muscle to bone and ligaments are tissues that connect bone to bone.

\section{Anatomical Terms}

There are many terms in anatomy to describe relative position and motion. The following list provides definitions of the terms used in this paper (Mercier, 1995; April, 1990):

Position

Anterior - toward the front

Posterior - toward the back

Medial - closer to the center-line of the body

Lateral - further from the center-line of the body

Proximal - closer to a reference point, usually the center of the body Distal - further from a reference point, usually the center of the body

Superior - toward the head

Inferior - toward the feet

Dorsal - more toward the back surface

Ventral - more toward the belly surface

Motion

Adduction - motion toward the center-line of the body

Abduction - motion away from the center-line of the body

Flexion - bending of a joint

Extension - straightening of a joint

\section{Orientation}

Sagittal Plane - the longitudinal vertical plane that divides the mouth into two halves Coronal (frontal) Plane - A vertical plane at right angles to a sagittal plane, dividing the body into anterior and posterior portions 


\section{Bone Structure and Classification}

While bones act as reservoirs from which the body can retrieve inorganic materials such as calcium, phosphate and carbonate and are the sites of red blood cell, white blood cell and platelet production, their main function is to provide support for the body, protect internal organs and serve as levers on which muscles act to produce motion. The human skeleton consists of 206 bones. It is divided into the axial skeleton and the appendicular skeleton (Figure 2-1). The axial skeleton consists of the bones of the head, vertebral column, ribs and sternum. The appendicular skeleton consists of the bones of the extremities (the arms and legs) (April, 1990).

Two kinds of bone tissue contribute to the structural strength of bone. Cortical bone is the hard tissue on the surface or cortex of bones. It is a dense material with no marrow and only microscopic blood vessels. Cancellous bone is part of the interior of bones. It is made up of a network of hard, interconnected filaments called trabeculae interspersed with marrow and blood vessels. Cancellous bone is also known as trabecular or spongy bone (Cowin and Hegedus, 1976).

There are five types of bones: flat, long, short, sesamoid and irregular. Flat bones are sandwiches of spongy bone between two layers of cortical bone. Their main purpose is to provide protection. Bones of the cranium are flat bones. Long bones are the bones of the extremities. They consist of a tubular shaft called the diaphysis. The diaphysis consists of an outer ring of cortical bone. Inside this ring is a ring of trabecular bone. Within this ring is a hollow region containing marrow, which is responsible for blood cell production. At the ends of the bone are the metaphyses. This region of the bone is mainly trabecular bone surrounded by a thin layer of cortical bone. The outer surface of 


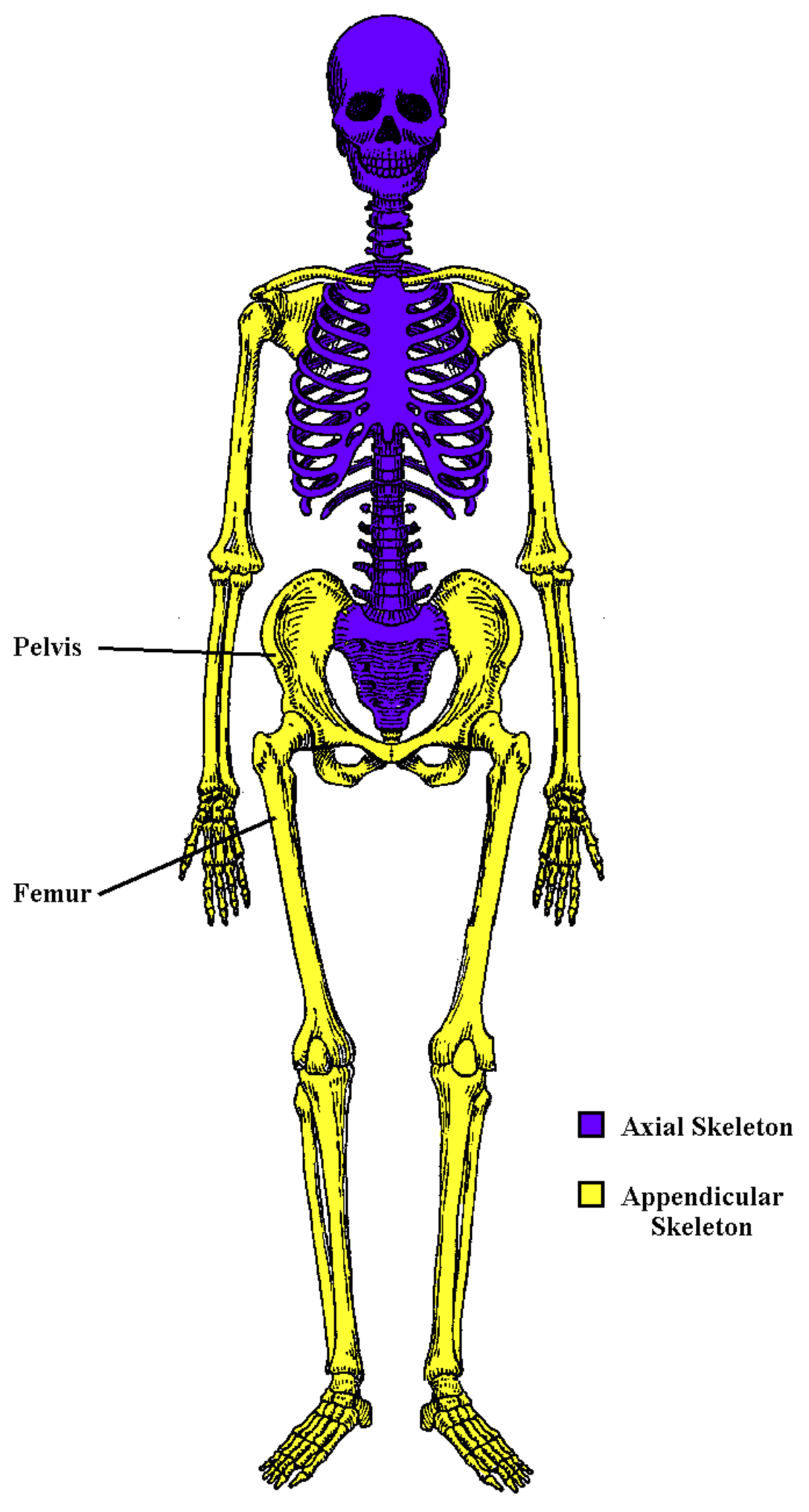

Figure 2-1. The human skeleton. The human skeleton is divided into the axial skeleton and the appendicular skeleton. 
the cortical bone is covered with articular cartilage. The femur is a long bone. Short bones are similar to long bones but smaller. The bones of the fingers are short bones. Sesamoid bones are bones that are found within a tendon. They increase the lever arm of a muscle by moving the tendon away from the fulcrum. The kneecap (patella) is a sesamoid bone. Irregular bones are bones that do not fit into any of the other categories. They are variable in size and shape. The vertebra are irregular bones. (April, 1990)

\section{Joint Classification}

Locations where two or more bones come together are called joints. Joints are categorized into three groups based upon the type of connective tissue at the articulating surfaces. Fibrous (synarthroses) joints are held together by a thin layer of connective tissue. There is no movement at these joints. The bones of the skull are joined with fibrous joints. In cartilaginous (amphiarthroses) joints bones are connected to each other by cartilaginous disks. They allow slight movement. The vertebral disks are cartilaginous joints. Synovial (diathroses) joints permit free motion. The articulating surfaces are covered with a thin layer of cartilage. The joint is surrounded by a synovial membrane which secretes lubricating synovial fluid. Around this membrane is a tough fibrous joint capsule which keeps the ends of the bones in proper orientation. Most joints of the body, including the hip joint, are synovial joints.

\section{Hip Joint Anatomy}

The hip joint is a ball and socket joint formed between the femur (thigh bone) (Figure 2-2) and the pelvis. The proximal femur consists of a spherical head that is connected to the shaft by the femoral neck. The head of the femur is the ball and the pelvic socket in which it articulates is called the acetabulum. The femoral neck is angled 
upward about $125^{\circ}$ and angled forward about $15^{\circ}$. On the lateral surface of the femur above the junction of the neck and the shaft is the greater trochanter. It is the attachment point of the gluteus medius, gluteus minimus and piriformis muscles. The gluteus medius and gluteus minimus muscles are hip abductors. The piriformis laterally rotates the hip. On the medial surface of the femur distal to the junction of the neck and shaft is the lesser trochanter. The iliopsoas muscle group attaches to the femur here. This group consists of the iliacus and psoas muscles and act to flex the hip.

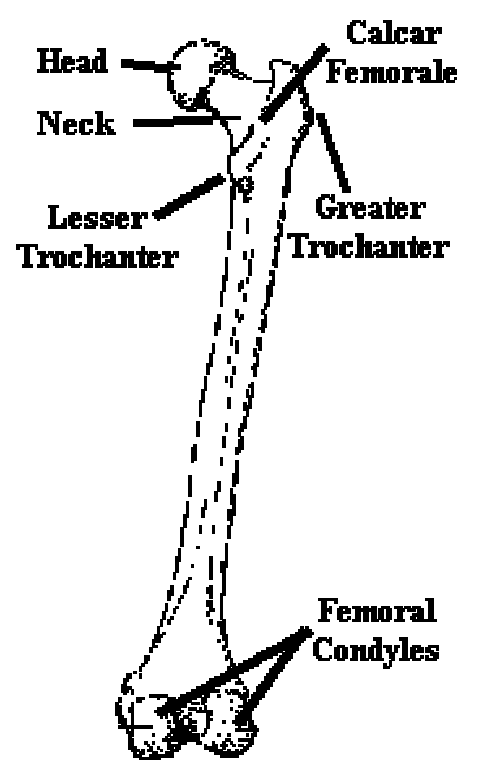

Figure 2-2. Posterior view of the human femur. The head of the femur is connected to the shaft by the femoral neck. The greater and lesser trochanters are sites of muscle attachment.

\section{Adaptive Behavior of Bone}

Bone is a living material that is constantly undergoing growth, reinforcement and resorption. These processes are collectively referred to as remodeling. Remodeling allows bone to adapt its histological structure in response to long term loading. Bone 
reacts to a prolonged increase in strain by increasing its mass and to a prolonged decrease in strain by decreasing its mass.

Early studies that describe the adaptive nature of bone were motivated by observations of German anatomist Julius Wolff and others on the coincidence of trabecular orientation and directions of principal stress (Jacobs et al., 1995). The idea that bone architecture is related to stress transfer and that bone is able to adapt its structure to variations in the stress state is known as Wolff's Law (Wolff, 1892). Bone will adapt or remodel because of altered stress distribution in one of two ways: it will change its architecture through external remodeling or change its tissue quality through internal remodeling (Currey, 1984). The primary unit of bone is the osteon. Osteons are typically $150 \mu \mathrm{m}$ in diameter with a length of 1-2 $\mathrm{cm}$. Cancellous bone osteons are trabeculae arranged along lines coinciding with principal stress directions. Cortical bone osteons are arranged parallel to the long axis of the bone. Each osteon has a fluid filled hollowing or lumen of $40 \mu \mathrm{m}$ at its center. Within the lumen, called the Haversion canal, is a blood vessel responsible for supplying nourishment to the bone cells in the vicinity of the osteon. External remodeling is the resorption or deposition of material on the external surface of bone through the addition of new osteons to the Haversian system or resorption of osteons without replacement. External remodeling is the only way by which bone can change its overall dimensions. Internal remodeling is the resorption or reinforcement of lamellar bone within a set of existing osteons by changing the osteonal lumen diameter. Internal remodeling modifies the density of bone and changes its Young's modulus (Cowin and Hegedus, 1976).

According to the adaptive elasticity theory of bone remodeling, cortical bone has site specific homeostatic equilibrium strain states. An abnormal strain state will 
stimulate bone to adapt its mass until the equilibrium strain state is regained (Huiskes et al., 1987). Most investigators agree that bone remodeling is regulated by mechanical stimuli detected by sensors in the bone although the exact nature of these sensors is a controversial issue. It has been postulated that bone remodeling is triggered by changes in hydrostatic pressure in the osteonal lumen, electrical impulses generated in the bone or chemical factors. Regardless of how the bone detects a change in strain, this process leads to bone apposition in areas of higher than normal strain and to bone resorption in areas of lower than normal strain (Weinans et al., 1992). Bone apposition results in increased cortical thickness. Bone resorption manifests itself as cortical osteoporosis or reduction of cortical thickness (Huiskes et al., 1987).

Bone remodeling is seen after THA because the stiff intermedullary stems significantly alter the strain patterns in bone. In the intact femur, forces generated at the hip joint are transferred from the femoral head to the cortical bone in the region of the femoral neck to the cortical bone tube. After cemented THA, the forces are transferred from the head of the prosthesis to femoral stem which transmits forces through the cement to the cortical bone (Harris, 1992).

The effect of this change in load transfer or "stress shielding" on bone strains has been investigated experimentally. Oh and Harris (1978) applied strain gages on five intact cadaveric femora to measure longitudinal strains at 4 levels. Gages were placed on the medial, lateral, anterior and posterior surfaces at each level except at the femoral neck level where no lateral gage was mounted and the distal most level where no posterior gage was mounted. Additionally, gages were placed on the anterior-medial and posterior-medial surfaces in the neck region. Each femur was potted in PMMA and loaded by a Instron Universal Testing Machine (Instron Corporation, Canton, MA). 
After loading, each femur was implanted with a cemented femoral stem and loaded as before. They found that the strain magnitudes diminished distally in an intact femur but increased distally after stem insertion. Strain in the calcar femorale decreased to nearly zero. It was found that good contact between a collared stem and the calcar femorale would diminish but not eliminate strain reduction in this region.

Crowninshield et al. (1980) performed similar tests to compare the strain in intact femora to that of femora implanted with either titanium alloy or stainless steel stems. The stems had identical geometries and surface roughness. In both cases there was a reduction in strain in the proximal-medial femur as a result of stress shielding. The titanium stem produced a $12 \%$ reduction in strain and the stainless steel stem produced a $17 \%$ reduction in strain in this region. There was no significant difference in strain in any other region. They concluded that clinical observed resorption of the proximalmedial cortex in the region of the neck-osteotomy was a result of stress shielding.

Maloney et al. (1989) applied strain gages to the surfaces of 11 whole femur specimens retrieved from patients who had satisfactory cemented THA. The specimens were placed in a load frame and subjected to loads that simulated single-legged stance and stair climbing. Marked stress shielding was observed in the proximal-medial cortex even in specimens that had THA for up to 17 years. They concluded that in order to prevent complete bone loss, resorption would stop when the bone had reached some minimum thickness or density.

Maloney et al. (1995) harvested 23 pair of whole cadaveric femora from patients with unilateral THA. Of the 23 patients, 13 had had cemented stems and 10 had had uncemented stems. The specimens were sectioned at $5 \mathrm{~mm}$ intervals and $\mathrm{x}$-rayed. Measurements were made of the mean cortical bone thickness, mean cortical bone area 
and bone mineral density at each level. The intact contra-lateral femora served as control specimens for the implanted femora. This allowed the investigators to quantify bone remodeling secondary to stress shielding. They found a pronounced difference between the implanted femora and their respective controls. There was a maximum mean decrease in cortical thickness of $58 \%$ with a maximum mean decrease in cortical bone area of $40 \%$ in the case of cementless stems which occurred at the mid-proximal level. The maximum decrease in cortical thickness of the femora with cemented stems was $46 \%$ at the proximal level and the maximum mean decrease in cortical area was $36 \%$ occurring at the middle level. The minimum mean decrease in cortical thickness and cortical bone area occurred at the distal level in both cases with decreases of $7 \%$ and $18 \%$ respectively in the case of cementless stems and $11 \%$ and $15 \%$ respectively in the case of cemented stems. In both cases there was a change in the bone mineral density only in the proximal region with a decrease of $29 \%$ with uncemented stems and a decrease of $24 \%$ with cemented stems. There is more remodeling in the case of a cementless stem because they are generally larger and stiffer than cemented stems and thus transmit less load to the femur. 


\section{CHAPTER 3: The Role of Bone Cement in THA}

Polymethylmethacrylate (PMMA) is a thermoplastic polymer that was first synthesized industrially in the early 1900's. During the Second World War it became an essential component in the making of dentures (Saha and Pal, 1984). It was introduced into orthopedic surgery over 40 years ago. John Charnley used it in THA as a grout material between the metallic prosthesis and the surrounding bone (Charnley, 1960). This allows the forces generated at the hip joint to be evenly transferred by the stem to the proximal femur through the cement mantle over a uniform interface between the stem and cement (Charnley, 1964).

\section{Mixing of Surgical PMMA}

Surgical grade PMMA, known as acrylic bone cement, is mixed in the operating room during surgery. Modern formulations of acrylic bone cement consist of a liquid and a powder component. The powder consists of pre-polymerized PMMA beads, a catalyst and granules of a radiopacifier. The liquid contains methylmethacrylate monomer, a catalyst and a stabilizing agent. These components are combined and mixed. When the components are combined, they begin an exothermic reaction that within minutes transforms the mixture from a viscous fluid to malleable dough. While the cement is in a "doughy" state, it is introduced into the prepared femoral canal either by hand packing or through injection. The femoral component is then inserted into the cement and held in place until the cement polymerizes to its final state of a brittle solid. 


\section{Viscoelastic Behavior of PMMA Bone Cement}

The behavior of most materials under low stresses can be approximated as linearly elastic (Findley et al., 1976). Loading of a linearly elastic material results in an instantaneous strain response. Elastic strain is proportional to the stress experienced by the material and remains constant under constant load. The strain is removed upon removal of the load (Figure 3-1).

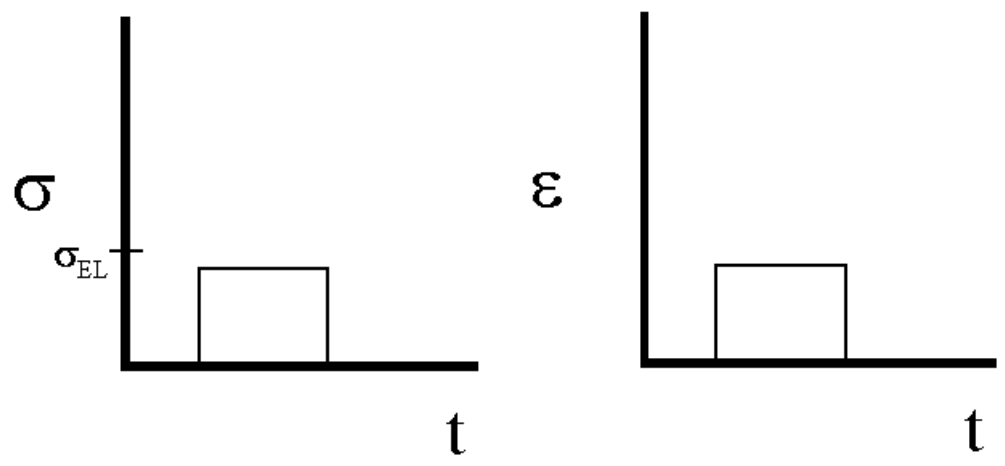

Figure 3-1. Elastic Material Behavior. Under a constant load below the elastic limit $\left(\sigma_{\mathrm{EL}}\right)$ the material experiences a constant strain that is relieved immedialtey upon removal of the load.

Once the strain exceeds a certain value known as the elastic limit of the material, strain is no longer directly proportional to stress. The material is said to behave plastically beyond this point. The strain may continue to increase for a short time after application of the load, but will remain constant under constant load. After the load is removed, some permanent strain remains. This permanent strain is called plastic strain (Figure 3-2). Plastic behavior can be time-dependent or time-independent.

Some materials experience an increase in strain when subjected to a constant stress below the elastic limit. These materials are called viscoelastic materials. Upon application of the load the material responds elastically. Slowly, strain continuously increases at a decreasing rate. The strain of a viscoelastic material is a function of 
applied stress, time and temperature (Byars et al, 1993). Some materials that exhibit viscoelastic behavior are wood, concrete, plastics and metals and ceramics at high temperatures (Findley et al., 1976).
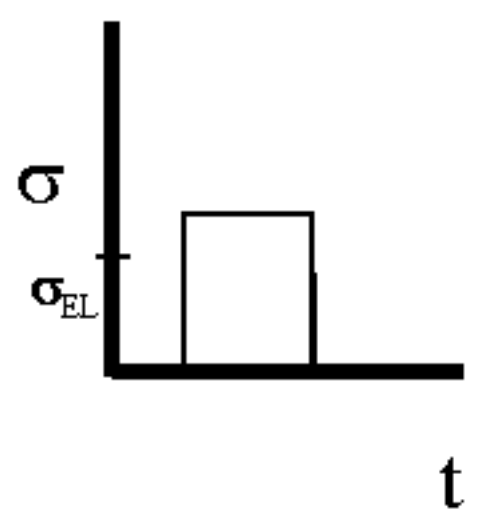
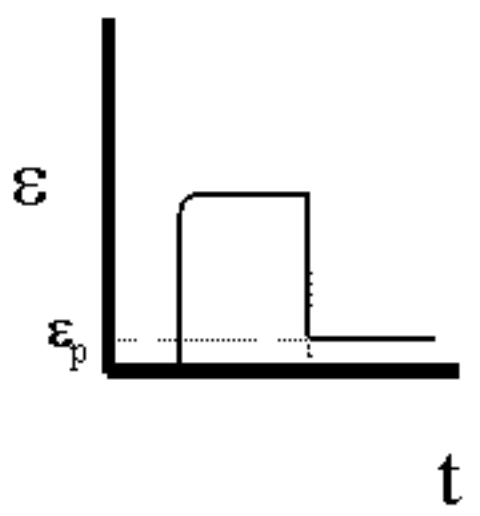

Figure 3-2. Plastic Material Behavior. Under a constant load above the elastic limit $\left(\sigma_{\mathrm{EL}}\right)$ the material experiences a constant strain. This strain may not be fully recovered upon unloading. The unrecovered strain is known as plastic strain $\left(\varepsilon_{\mathrm{p}}\right)$.

There are three modes of viscoelastic behavior: creep, recovery and relaxation. The time-dependent deformation of a viscoelastic material subjected to constant load is called creep. Creep behavior occurs in three distinct stages. After the instantaneous elastic response to loading, creep occurs at a decreasing rate. This is the primary or transient stage. During the secondary or steady state stage creep continues at a constant rate. In the tertiary stage the creep rate increases quickly until failure occurs (Figure 3-3). If the load is removed from a viscoelastic material prior to failure, the elastic strain will be removed instantaneously and the creep strain will be reduced at a decreasing rate (Figure 3-4). This reduction of creep strain is called recovery. The amount of strain recovered and the recovery rate are material dependent properties. The reduction of stress in a viscoelastic material subjected to a constant strain is called stress relaxation (Figure 3-5). A material that exhibits creep is likely to experience relaxation as well. Relaxation is a 
result of internal creep that causes a decrease in and redistribution of stress without significant deformation (Byars et al. 1983).

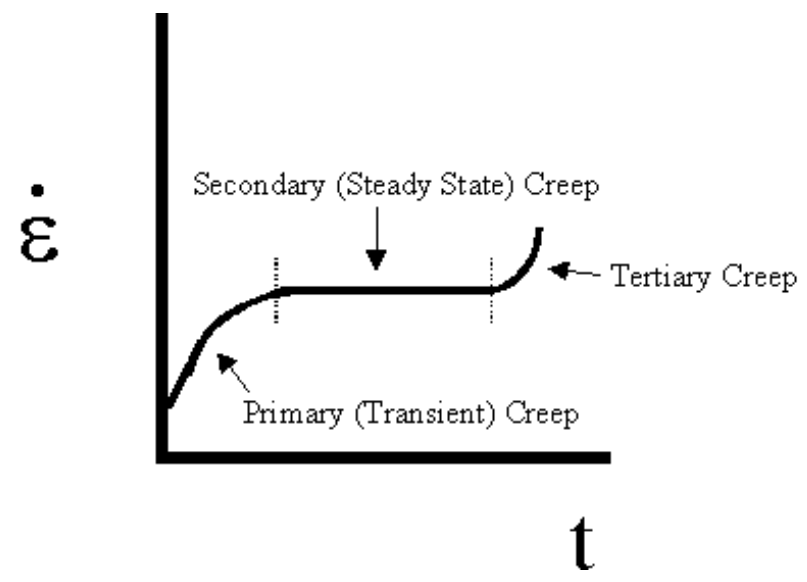

Figure 3-3. Generalized creep curve. A viscoelastic material can experience three stages of creep: the primary stage marked by an increasing strain rate, the secondary stage with a constant creep rate and the tertiary stage with an increasing creep rate culminating in material failure.

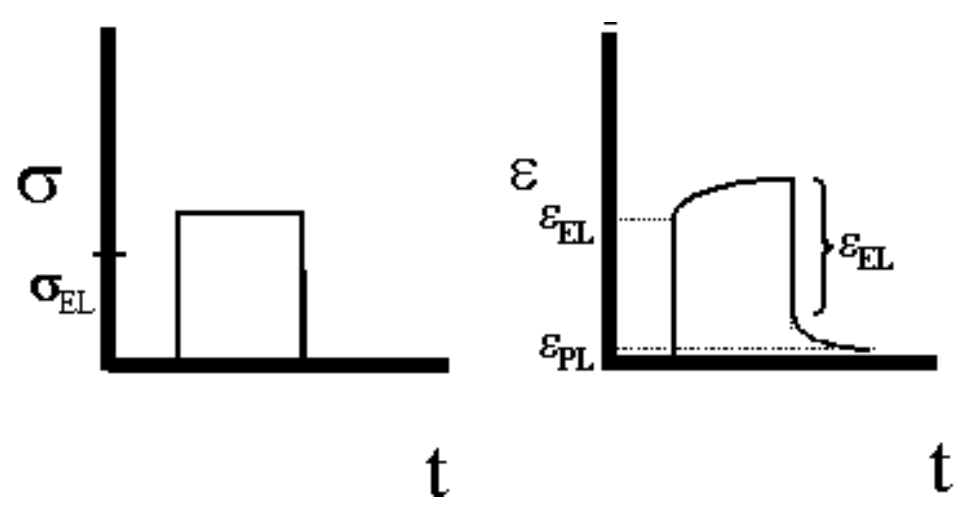

Figure 3-4. Creep recovery. A viscoelastic material experiences increasing strain under constant load. Upon removal of the load, the elastic strain is immediately removed. While the creep strain will gradually decrease over time, some permanent strain may remain.

PMMA is thermoplastic polymer. The primary creep stage of polymers is governed by the entanglement and stretching of the long polymer molecules. The constant creep rate observed during secondary creep stage is a result of friction forces 
between the entangled molecules sliding along each other (Verdonschot and Huiskes, 1994a). Many factors influence the viscoelastic behavior of thermoplastics. Creep of thermoplastics is primarily dependent on applied stress, time and temperature although humidity, preparation methods and storing conditions can also have a significant effect (Darlington and Turner, 1978). Treharne and Brown (1975) performed room temperature compressive creep and recovery tests on pure PMMA (Plexiglas) and several types of PMMA cements. They concluded that density was the most important variable influencing creep resistance. Slight variations in mixing temperature and stirring time did not affect the creep behavior provided that the final density was not changed. It was found that storing the specimens in water or Ringer's solution or the presence of residual monomer in the specimens decreased creep resistance. It was determined that water, Ringer's solution and residual monomer act as plasticizers. Differences in creep strengths of specimens made from different cement types were attributed to differences in particle size. Apparently, the larger the particle size the greater the creep resistance. Norman et al. (1995) determined that vacuum mixing, which reduced porosity, increased specimen compressive creep resistance at room temperature.

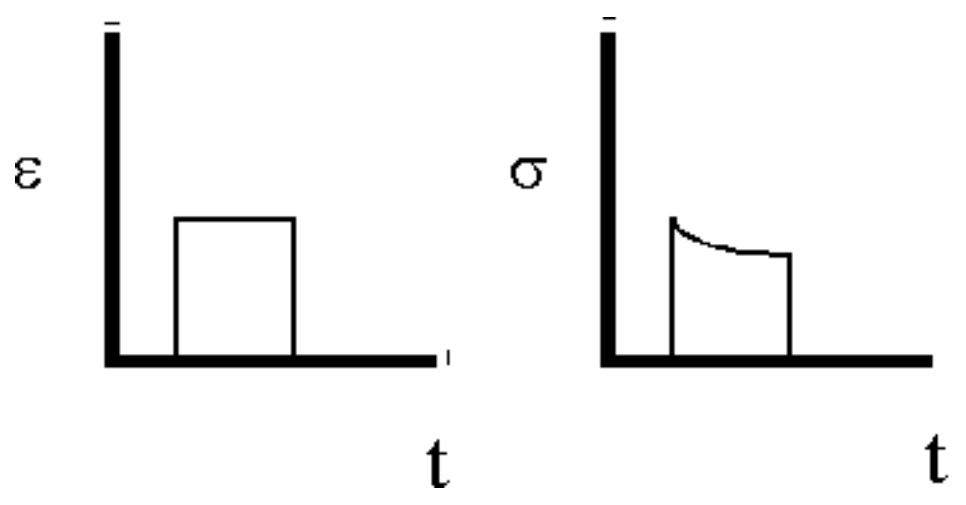

Figure 3-5. Stress relaxation. As a result of internal creep, a viscoelastic material may experience a reduction is stress while subjected to a constant strain. 
For polymers there exists a material property called the glass transition temperature $\left(\mathrm{T}_{\mathrm{g}}\right)$. Well below this temperature the polymer is glass and acts as a brittle solid. Well above this temperature the polymer is a viscous liquid. At temperatures close to $\mathrm{T}_{\mathrm{g}}$ plastics behave as viscoelastic solids (Lee et al., 1990). Generally, plastics do not exhibit a significant secondary stage and may recover a large amount of creep strain up to full recovery. $\mathrm{Tg}$ for PMMA is $100{ }^{\circ} \mathrm{C}$. This is close enough to normal body temperature $\left(37^{\circ} \mathrm{C}\right)$ that the viscoelastic behavior of PMMA must be considered in the design of cemented prosthesis.

Many investigators have attempted to quantify the viscoelastic behavior of PMMA cements. Holm (1980) molded rectangular specimens of CMW, Surgical Simplex and Palacos R bone cements across the open end of a U-shaped spring. The cements were hand mixed at room temperature and placed in the mold. Shrinkage of the cement during curing compressed the spring. The spring and specimen were placed in distilled water bath and kept at $38{ }^{\circ} \mathrm{C}$. Relaxation of the specimens occurred under a slowly decreasing load as the spring regained its shape. After 500 hours the Palacos R experienced 68\% relaxation, the CMW 30\% and the Surgical Simplex 20\%.

Chwirut (1984) performed compressive creep test on five commercially available acrylic bone cements under conditions more closely simulating in vivo usage. After mixing, the cement was poured into test tubes. At least four days after casting the specimens were machined to a length of $30-40 \mathrm{~mm}$ and a diameter of $18-20 \mathrm{~mm}$. The specimens were statically loaded for 1000 hours on a deadweight testing machine while immersed in normal saline solution at a temperature of $37{ }^{\circ} \mathrm{C}$. The applied load ranged from 6.9 MPa to 4.1 MPa for various specimens. By 200 hours the creep strain was 
greater than the elastic strain in every case. An empirical exponential model derived form experimental data predicted creep strain within $10 \%$. Interpore cracks were found to occur as a result of creep at stresses at which no cracks would appear as a result of short-term loading. It was suggested that this cracking could be a factor leading to THA failure.

Norman et al. (1995) conducted room temperature compressive creep tests on cylindrical specimens of doughtype and radiopaque cements at stress levels higher than previously investigated. The cements were hand mixed according to manufacturer's directions and placed into $16 \mathrm{~mm}$ diameter syringes for curing. After 24 hours the cement was removed from the syringes and machined to a length of $2.54 \mathrm{~cm}$ and immediately immersed in physiological saline. The specimens were tested moist at room temperature in a compression fixture on a servohydraulic testing machine. Specimens were not tested until at least four days after curing. Radiopaque specimens were tested at stress levels of 10.5 MPa and $14 \mathrm{MPa}$. Doughtype specimens were tested at stress levels of $10.5 \mathrm{MPa}, 14 \mathrm{MPa}$ and $30 \mathrm{MPa}$. After 24 hours the creep strain of the radiopaque specimens tested at $10.5 \mathrm{MPa}$ and $14 \mathrm{MPa}$ was approximately $50 \%$ of the elastic strain and the creep strain of the $30 \mathrm{MPa}$ specimens was $200 \%$ of the elastic strain. Creep strain of the doughtype specimens at the same time was approximately $110 \%$ of the elastic strain at both the $10.5 \mathrm{MPa}$ and $14 \mathrm{MPa}$ stress levels. It was shown that increasing the applied stress level from $14 \mathrm{MPa}$ to $30 \mathrm{MPa}$ for the radiopaque specimens increased the creep strain by more than $1000 \%$. This indicates that creep of a cement mantle subjected to high stresses resulting from debonding or imperfections in the cement might play a significant role in prosthesis behavior. 
Verdonschot and Huiskes investigated the tensile (1994b) and compressive (1995) dynamic creep behavior of PMMA cement. Simplex P with barium sulfate was hand mixed and molded to $5 \mathrm{~mm}$ thick slices that were machined to dumbbell shaped specimens. The tensile and compressive specimens were stored in saline for $60-100$ days. Each specimen was subjected to either a tensile or compressive sinusoidal dynamic load with a frequency of $1 \mathrm{~Hz}$. The tensile load varied from 0 to either $3 \mathrm{MPa}, 7 \mathrm{MPa}$ or $11 \mathrm{MPa}$ and the compressive load varied from 0 to $7 \mathrm{MPa}, 11 \mathrm{MPa}, 15 \mathrm{MPa}$ or $20 \mathrm{MPa}$. The specimens were tested while immersed in a saline bath at a temperature of $38.5^{\circ} \mathrm{C}$. A phase shift in the recorded load and strain signals indicated viscoelasticity of the cement. The $3 \mathrm{MPa}$ tensile specimens were loaded for 250,000 cycles at which point the creep strain was $50 \%$ of the elastic strain. The $7 \mathrm{MPa}$ and $11 \mathrm{MPa}$ tensile specimens failed before 250,000 cycles with an average fatigue life of 228,000 and 25,000 cycles respectively. The test duration was 250,000 cycles for all compressive load cases.

For small creep strains, the viscoelastic behavior of PMMA cement is very sensitive to polymer chain orientations, molecular weight, internal stress and porosity. It was found that the initial creep strain rate of the higher stressed specimens was much higher than for the lower stressed specimens, but the strain rate decreased more rapidly for the higher stressed specimens. This suggests that even very high cement mantle stresses may be reduced due to creep. A two-parameter creep model was selected to linearly interpolate the log-log relationship between primary and secondary creep microstrain and the number of load cycles. Separate models were used to model tensile and compressive creep behavior, which was found to be much different. In the 5-15 MPa load range the bone cement tensile creep rate is 5-10 times greater than the compressive creep rate. Comparison to Chwirut's (1984) compressive creep law indicates that there is 
a difference between static and dynamic creep. A statically loaded specimen will experience more creep strain than a specimen loaded dynamically to the same maximum load. This may be because the cyclically loaded specimen has the possibility to relax between load cycles.

Several investigators have examined PMMA cement creep behavior in constrained conditions. Lee et al. (1990) inserted a polished, conical metal stem into cement constrained by a conical metal cylinder. A constant axial load of $10 \mathrm{kN}$ was applied to the proximal end of the stem. The temperature was maintained at $37^{\circ} \mathrm{C}$. After 48 hours some cement had extruded from the distal end of the constraint. Inspection of the cement mantle revealed that a small longitudinal crack had developed in the extruded cement while no cracks were present in the constrained portion of the cement. In a second series of tests, grooves were cut into the outer metal constraint. A plain smooth conical shell of cement was placed inside of it and the metal taper was forced down into the middle of the cement as before. As the stem moved downward, the cement crept radially outward into the grooves and extruded out of the bottom. These tests show that PMMA cement can grossly deform by creep in a way that may change the shape of the cement mantle and the contact conditions between the stem and cement and between the cement and the constraining bone.

Several investigators have included PMMA bone cement viscoelastic properties in FEM to determine their effect on THA behavior. McKellop et al.(1994) used a 3D conical stem model to assess the effect of on bone cement mantle stresses. A resultant load of $2100 \mathrm{~N}$ was applied to the proximal end of the stem at an angle of $16^{\circ}$ to its axis. The analysis was run with three different stem-cement interface conditions: fully bonded $(\mu=\infty)$, debonded with friction $(\mu=0.22)$ and debonded without friction $(\mu=0.0)$. The 
bone cement was assigned the viscoelastic properties of Zimmer Regular cement at $37^{\circ} \mathrm{C}$. A load path that simulated cyclic loading was selected. In the case of the fully bonded stem-cement interface and the case of debonding with friction the maximum tensile cement stress decreased by $8 \%$ and $22 \%$ respectively. The maximum compressive cement stress decreased by $18 \%$ and $11 \%$ respectively. The maximum cement von Mises stress decreased by $14 \%$ and $15 \%$ respectively. In the case of the debonded stem-cement interface without friction the maximum tensile cement stress increased by $16 \%$ and the maximum compressive cement stress increased by $11 \%$ but the maximum cement von Mises stress decreased by $4 \%$. Stress concentrations within the cement were found just below the distal tip of stem. They concluded that the distal portion of the cement mantle acted as a constraint against axial movement of the stem and may have been the dominant factor controlling the degree of stress variation during creep.

Lu and McKellop (1995) used a similar FEM to determine the effects of cement creep on a cyclically loaded cemented hip stem. The same three bonding conditions used by McKellop et al. (1994) were used in this study. A cyclic transverse load of $600 \mathrm{~N}$ and a cyclic axial load of $2000 \mathrm{~N}$ were applied to the stem. Each load cycle represented one day of patient activity followed by rest at night. The results of one cycle demonstrated the short-term creep effects and the cumulative effect of many cycles demonstrated long term creep effects. Over one day, creep reduced stress levels for all bonding conditions. The creep was completely recovered during the unloaded rest period for the fully bonded and the debonded without friction cases, indicating that there was no long-term accumulation of creep. In the case of debonding with friction creep recovery was not complete with a residual stress of as much as $29 \%$ of the maximum stress. Stress relaxation over successive days did decrease the maximum stress. After the sixth day the 
creep effects had stabilized with no further relaxation. The maximum tensile stress had decreased by $9 \%$; the maximum compressive stress had decreased by $2 \%$ and the maximum von Mises stress had decreased by $13 \%$. The stem had subsided a total of $0.45 \mathrm{~mm}$ distally and the total creep strain was $22 \%$ of the elastic strain.

Norman et al. (1996) examined the effects of cement creep in an axisymmetric FEM of a tapered cone stem without distal cement mantle support. The stem had a proximal diameter of $14 \mathrm{~mm}$, a distal diameter of $6 \mathrm{~mm}$ and was $80 \mathrm{~mm}$ in length. The cylindrical cortical bone constraint had an inner diameter of $20 \mathrm{~mm}$ and was $10 \mathrm{~mm}$ thick. PMMA cement filled the space between the stem and bone except for the distal most $10 \mathrm{~mm}$ of the stem, which was free of cement. Three stem-cement bond conditions were modeled: fully bonded $(\mu=\infty)$, debonded with friction $(\mu=0.22)$ and debonded without friction $(\mu=0.0)$. A constant axial load was applied to the proximal end of the stem for a simulated period of 24 hours. Creep had little effect in the case of perfect bonding. In the debonded with friction case under a $3000 \mathrm{~N}$ load the peak cement von Mises stress decreased by $13 \%$ from $9.5 \mathrm{MPa}$ to $8.3 \mathrm{MPa}$ and the hoop stress decreased by $13 \%$ from $6.0 \mathrm{MPa}$ to $5.2 \mathrm{MPa}$. The frictionless debonded case decreased by $46 \%$ from $51 \mathrm{MPa}$ to $26.7 \mathrm{MPa}$ and the hoop stress decreased by $71 \%$ from $28.4 \mathrm{MPa}$ to 8.3 MPa. In all cases creep had very little effect on cement radial stress. There was no creep-induced subsidence of the stem in the presence of perfect stem-cement bonding. Under the $3000 \mathrm{~N}$ load creep induced subsidence accounted for 6.9\% $(18 \mu \mathrm{m})$ and $34.3 \%$ $(614 \mu \mathrm{m})$ of the total distal motion of the stem for the debonded with and without friction cases respectively. They concluded that creep induced subsidence caused compressive radial stresses which lead to a mechanical taper lock between the stem and cement that could promote long term stability of the prosthesis. 
This chapter provided evidence to show that acrylic bone cement experiences creep. The next chapter discusses the methods that will be used to experimentally evaluate this stem design. 


\section{CHAPTER 4: Experimental Methods}

The goal of this project is to experimentally evaluate the mechanical behavior of the proposed femoral stem. This chapter will discuss the application of approximate physiologic loads and measurement of bone cement creep, bone strains, cement mantle strains and stem displacement. It will give a brief overview of how these loads and measurements have been obtained by other investigators and describe the methods used in this study.

\section{Creep of Simplex P Cement}

In order to further our understanding of cement creep and its clinical significance, creep tests were performed on specimens of Surgical Simplex P (Stryker Howmedica Osteonics, Rutherford, NJ) bone cement using methods employed in earlier studies of Palacos R (Merk, Darmstadt, Germany)(Williams, 1995) and Osteobond (Zimmer, Inc., Warsaw, IN)(Saab, 1997). Cement was hand mixed in an open air container according to manufacturer's specifications. Once the cement had reached a doughy consistency, it was hand packed into syringes with a diameter of $12.5 \mathrm{~mm}$. After curing the cement was removed from the syringes and machined into specimens approximately $22.38 \pm 0.20 \mathrm{~mm}$ in length. A total of 21 specimens was produced. After the length of each specimen was measured they were randomly assigned to one of four test groups. The test groups corresponded to load levels of 5, 10, 20 or $30 \mathrm{MPa}$. A creep load frame (Figure 4-1) was used to apply a static compressive load to the specimen. The heavy steel frame consisted of a loading platform that was submerged in physiologic saline maintained at $99^{\circ} \mathrm{C}$. A loading rod rested atop the specimen. Load was transmitted to the rod from the cantilever arm which suspended dead weight. An LVDT (Linear Variable Differential 
Transformer) measured displacement of the rod as the specimen experienced compressive deformation. The specimens were placed in the heated saline bath 24 hours before loading. Each specimen was then loaded for 24 hours. Time, load, bath temperature and displacement of the loading rod were measured using a PC based data acquisition system. This data was used to determine creep strain of the specimens. Strain is calculated by dividing the change in length of the specimen (displacement) by its original length. Creep strain is taken to be the strain that occurs after the initial load application (Figure 4-2).

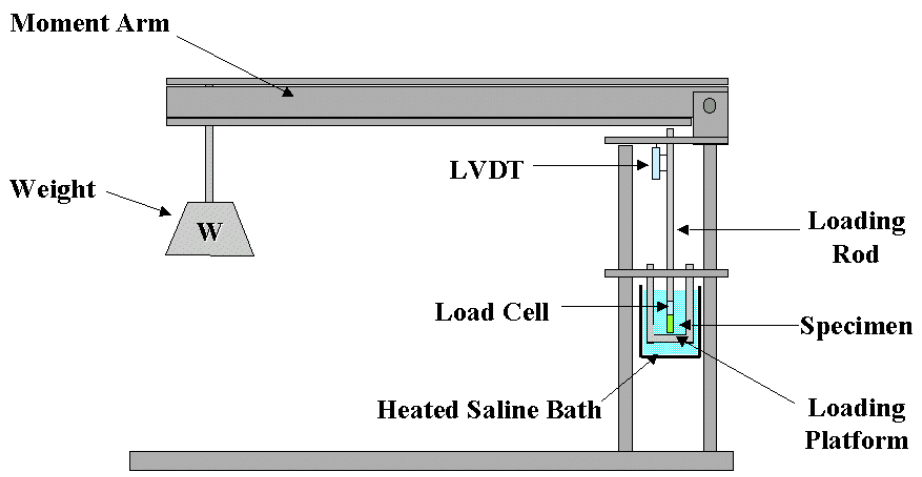

Figure 4-1. Creep load frame used in this study. A heated saline bath maintains the specimen at body temperature.

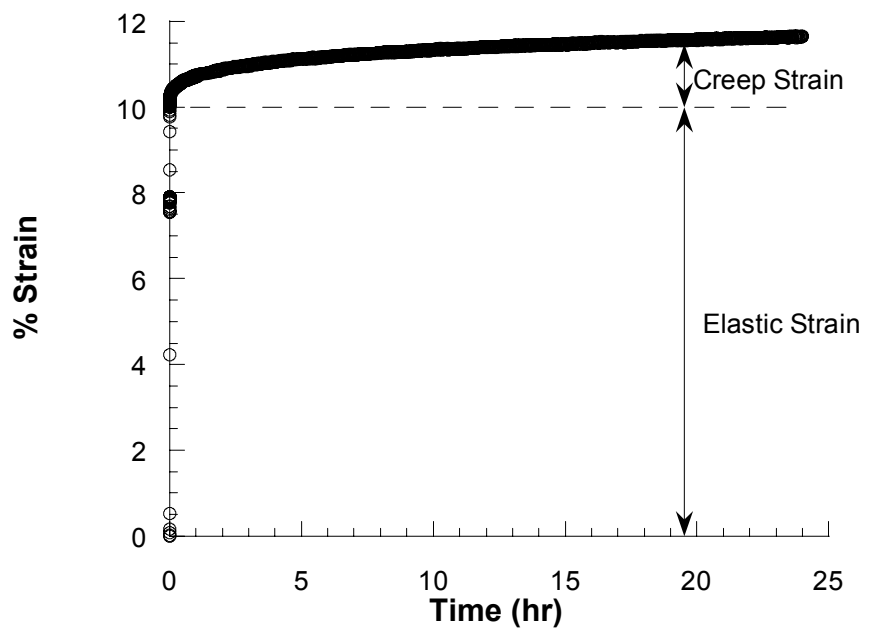

Figure 4-2. Typical strain data for creep speciemens. The creep strain is taken to be the portion of strain that occurs after the initial load application. 


\section{Experimental Application of Physiologic Hip Loads}

Many previous investigators have applied loads to cadaveric femora with (Crowninshield et al. 1980; Burke et al., 1985; Maloney et al., 1989; Sugiyama et al., 1989; Jasty et al., 1994) or without (Oh and Harris, 1978; Rohlmann et al., 1982, 1983; Crowninshield and Tolbert, 1983) implanted femoral stems with varying degrees of complexity. Oh and Harris (1978) applied loads that were to simulate femoral head forces during normal single-legged stance of an $80 \mathrm{~kg}$ man. Static frontal plane loads of $671 \mathrm{~N}, 1342 \mathrm{~N}, 2012 \mathrm{~N}$ and $2683 \mathrm{~N}$ were applied to the head of an intact femur. The femur was placed in adduction ranging from $5^{\circ}$ to $20^{\circ}$ in $5^{\circ}$ increments. Crowninshield et al. (1980) loaded intact femora with a $1000 \mathrm{~N}$ static frontal plane load. The load angle varied form $0^{\circ}$ to $30^{\circ}$ medially in $10^{\circ}$ increments. Crowninshield and Tolbert (1983) applied a $3000 \mathrm{~N}$ load to heads of a prostheses implanted in cadaveric femora. The load was applied either parallel to the long axis of the femur or inclined $15^{\circ}$ within the frontal plane. These three studies neglected muscle forces that act across the hip and out of plane (torsional) loads acting on the femoral or prosthesis head.

The abductor forces generate a moment about the hip joint that balances the moment generated by body weight and contributes to the net force acting on the femoral head. McLeish and Charnley (1970) calculated the forces acting in the abductor muscles and on the femoral head during single-legged stance. They determined that muscle forces range from 1.0 to 1.8 times body weight and that joint forces range from 1.8 to 2.7 times body weight. In an experimental and finite element study, Rohlmann et al. (1982) showed that neglecting muscle forces significantly altered the stress state of a loaded femur. They concluded that neglecting the muscle forces may be justifiable in qualitative 
studies of the femoral shaft, but the effect this would have on the measured response to loading might severely affect the accuracy of any quantitative studies.

Simplifying the experimental setup by considering only forces acting within the frontal plane makes it impossible to measure the effects of the broad range of loads encountered during normal activity. Several investigators have used telemetrized implants to measure the magnitude and direction of joint forces generated during various activities. Davy et al. (1988) determined that even during single-legged stance there was a measurable out of plane component of load directed posteriorly. The out of plane component of the peak resultant force during stair climb was much higher than during single-legged stance. Bergmann et al. (1993) measured hip joint resultant loads and their directions in patients during walking and running. They determined that small out of plane forces act on the hip from the medial or medial and dorsal side during slow walking and from the ventral side during fast walking or running. Later, Bergmann et al. (1995) measured the joint force and its direction, the bending moment in the frontal plane and the torque in two patients during stair ascent, stair descent and level walking. They determined that the torsional loads experienced by the femoral prosthesis in vivo are close to or exceed the torsional strength of implant fixations reported in the literature. Sugiyama et al. (1989) measured the mean failure torque and rotational subsidence of cemented and cementless femoral stems. They detected signs of microfailure of the cement mantle at torsional loads experienced in everyday activities such as walking up and down stairs or rising from a chair.

In order to evaluate the behavior of femoral components they must be subjected to a range of loads representing those that will be experienced in vivo. The studies previously cited indicate that these loads should include joint forces acting within the 
frontal plane and out of the frontal plane. The specimens in this study were loaded by a uniaxial servohydraulic materials testing machine (MTS, Eden Prairie, MN). This machine can apply only a vertical tensile or compressive force. Forces cannot be arbitrarily directed. If a load other than vertical tension or compression is desired some type of load fixture must be used. To apply physiologic joint loads to the head of a femur or prosthesis the femur must be oriented with respect to the applied vertical load. A load frame was constructed that will transmit the vertical load generated by the actuator to the femur in a more physiologic manner (Figure 4-3).

The femur is placed in the fixture. The head of the femur articulates with the cupped end of an aluminum cylinder. The head of the prosthesis articulates with a polyethylene cup inserted into the cupped end of the cylinder. This aluminum cylinder is bolted to a load cell that measures the magnitude of the joint force. The load cell is bolted to a thick steel bar that is mounted to the upper load frame of the testing machine. The distal portion of the femur is potted in a section of threaded pipe using PMMA dental

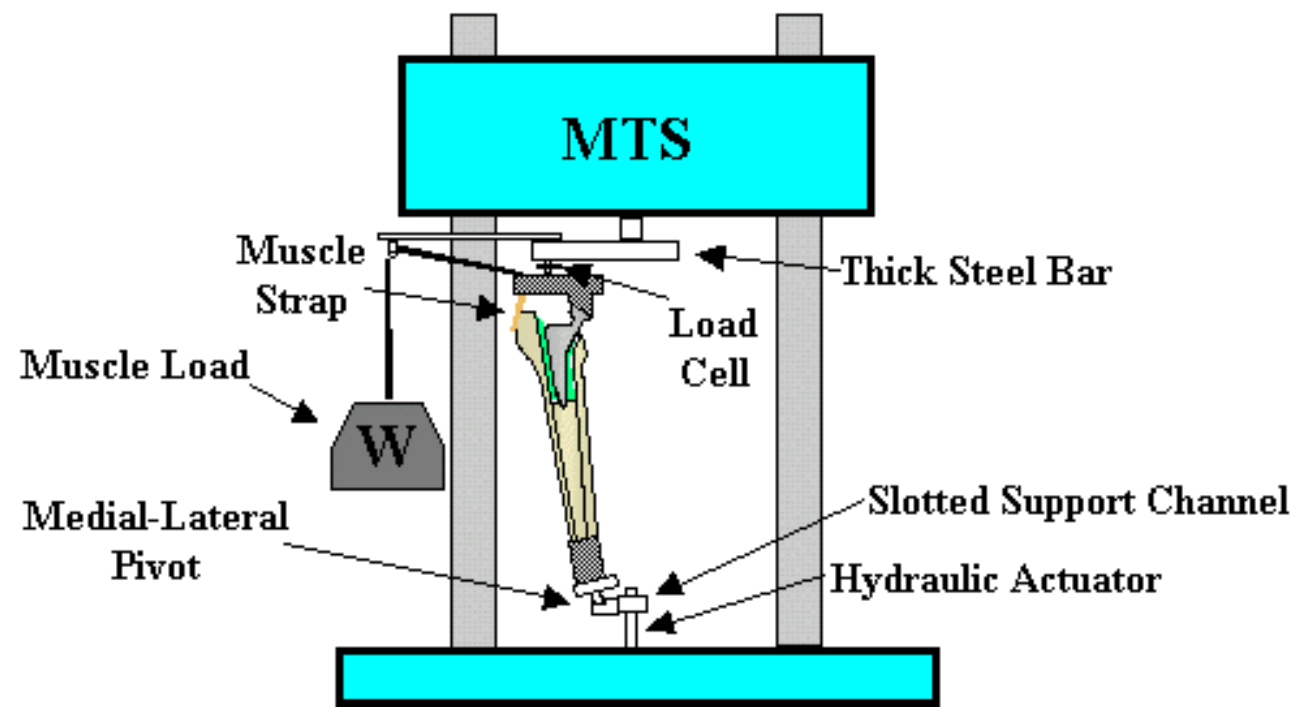

Figure 4-3. Front view of hip simulator load frame. The femur is shown oriented for single-legged stance. 
cement. This pipe is screwed into a fixture that is bolted to a slotted support channel. The support channel is mounted to the load actuator of the testing machine. This fixture has two pivot points. The bolt connecting the fixture to the support channel serves as an anterior-posterior pivot that is used to adjust the flexion angle of the femur (its orientation in the sagittal plane). A medial-lateral pivot on the fixture is used to adjust the adduction angle of the femur (its orientation in the frontal plane). These two pivots make it possible to orient the femur with respect to the vertical force to simulate any resultant joint load.

The abductor muscle forces are applied through a brass strap attached to the femur in the region of the greater trochanter. Pilot holes are drilled into the femur just below the greater trochanter. These holes are flushed with saline and then filled with PMMA dental cement. After the cement cures the brass strap is attached to the femur with screws through the holes. Dead weight is suspended from a synthetic fiber cord that runs through a series of pulleys and is attached to a hook at the end of the brass strap. The orientation of the strap relative to the femur determines the line of action of the muscle forces. This can be varied by changing the attachment points of the strap or the position of the pulleys. The magnitude of the muscle force is determined by the amount of weight suspended from the cord.

Three load cases are used in this study. A static, long-term load corresponding to single-legged stance was chosen so that the effects of static cement creep on prosthesis behavior could be measured. A cyclic load simulating slow gait was chosen so that the effects of dynamic loading and cement creep on prosthesis behavior could be measured. The joint load will be cycled sinusoidially between minimum and maximum values corresponding to the stance phase of gait. The muscle load will be held constant because 
of the limitations of the load frame. A short-term static load corresponding to stair climbing was chosen to evaluate the durability of the fixation under conditions where a relatively large torsional component to the load is present.

A literature search was conducted to determine the loads that would be applied to the specimens in this study. Many sources report resultant loads in terms of $\mathrm{x}, \mathrm{y}, \mathrm{z}$ components in a Cartesian coordinate system. It is necessary to express these loads in terms of magnitude and orientation with respect to the femur. In a Cartesian coordinate system one must define three mutually orthogonal lines as the $\mathrm{x}, \mathrm{y}$ and $\mathrm{z}$-axes. In this study the $\mathrm{x}$-axis was chosen as the femoral condyle axis defined by a line drawn through the condyles directed medially-laterally with the medial direction being positive. The positive y-axis was taken to be directed posteriorly. The positive z-axis was defined as the line directed proximally along the femoral axis. Cited values for the components of joint and muscle load were converted to this system. In order to determine the orientation of the femur relative to these loads, they were converted to a spherical coordinate system. In spherical coordinates (Figure 4-4) a point is defined by three parameters: its distance from the origin $(\rho)$, a cone angle $(\phi)$ and a polar angle $(\theta)$. A load vector is defined by a point in spherical space and the origin of the system located at the center of the femoral head. The spherical cone angle $(\phi)$ is the angle between the load vector and the positive z-axis. The polar angle $(\theta)$ is the angle between the positive $\mathrm{x}$ axis and the projection of the load vector into the $\mathrm{x}-\mathrm{y}$ plane. The $\mathrm{x}, \mathrm{y}$ and $\mathrm{z}$ components of the joint load were used to determine the cone and polar angles of the load vector. Physically the cone angle represents the amount of adduction or abduction of the femur and the polar angle represents the torsion angle of the femur. The torsion angle is the angle between a line drawn through the femoral condyles (the $\mathrm{x}$-axis) and the femoral 
neck. Flexion of the femur can be interpreted as a rotation of the anterior-posterior plane about the x-axis. This formulation made it possible to translate published load data into a usable format.

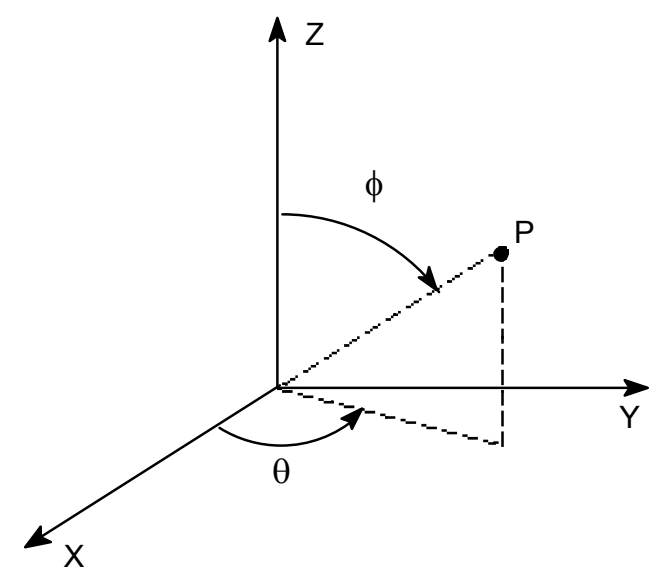

Figure 4-4. Relation between Cartesian and spherical coordinate systems.

Davy et al. (1988) reported their telemetrically measured joint loads in polar coordinates. In their coordinate system, the cone angle defined load orientation with respect to the axis of the neck of the prosthesis and the polar angle defined the orientation of the load with respect to the plane of the prosthesis (Figure 4-5).

The prosthesis was implanted in a 67 year old woman who had a weight of $556 \mathrm{~N}$. The joint force during single-legged stance was $1160 \mathrm{~N}$ with a polar angle of $32^{\circ}$ and a cone angle of $-15^{\circ}$. The measured joint force during stair climb was $1450 \mathrm{~N}$ with a polar angle of $22^{\circ}$ and a cone angle of $-42^{\circ}$. Assuming a neck angle of $135^{\circ}$ and a torsion angle of $15^{\circ}$ the reported loads can be converted to the current coordinate system through rotation of $45^{\circ}$ about the $y$-axis and $15^{\circ}$ about the z-axis. Muscle load data for singlelegged stance and stair climb was obtained from Harrigan et al. (1992). They used joint load directions that corresponded to those found by Davy et al. (1988) but the magnitude 
corresponded to a subject with a body weight of $641 \mathrm{~N}$. They applied an abductor muscle force of $880 \mathrm{~N}$ for single-legged stance and $608 \mathrm{~N}$ for stair climb.

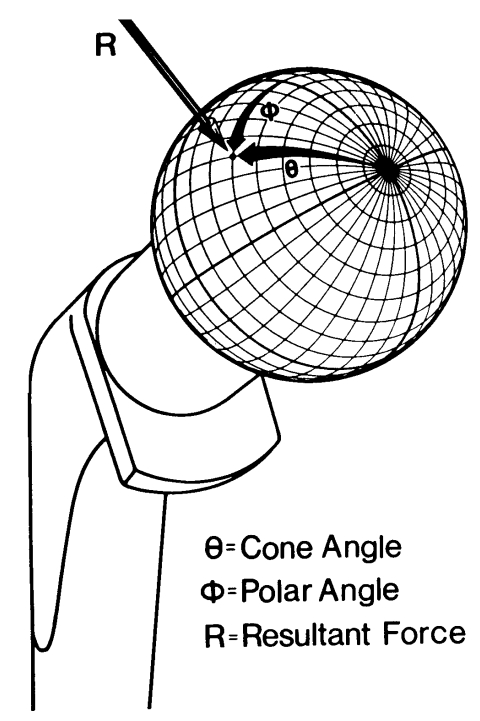

Figure 4-5. Coordinate system defined by Davy et al., 1988.

Load data for the stance phase of gait were taken from Cheal et al. (1992). They reported the magnitude of applied forces in terms of body weight and the direction of load in terms of Cartesian unit vectors. Their $\mathrm{x}, \mathrm{y}$ and z-axes were aligned with the medial-lateral, anterior-posterior and proximal-distal directions. The muscle loading was broken into components attributed to various muscle groups acting across the hip. The abduction forces were taken to be equal to the vector sum of the forces applied by the gluteus minimus and the gluteus medius muscles.

The load magnitudes for the stair climb load had to be modified. When specimens were loaded to the initially selected load levels the test fixture failed. Improvements to the test fixture resulted in specimen fracture in the distal femur near the threaded pipe. It was determined that the non-physiological constraints at the distal extent of the femur resulted in very high bending loads near the constraint. Further 
review of the literature revealed that other investigators (Burke et al., 1985) experienced similar problems. They scaled the loads to a level where the specimen would not be in danger of fracture. They chose to examine the effects of high torsional loads relative to the applied axial loads. A similar approach was used in this study. Applied stair climb loads were scaled to $25 \%$ of the original calculated values. This ensured that the specimen survived the test intact but allowed the effect high relative torsional loading to be observed. The load parameters used in this study are shown in Table 4-1 and graphically in Figure 4-6.

\begin{tabular}{|c|c|c|c|c|}
\hline \multirow[b]{2}{*}{ Load Case } & \multicolumn{2}{|c|}{ Loads } & \multicolumn{2}{|c|}{ Orientation } \\
\hline & Joint & Muscle & ${ }^{\circ}$ Adduction & ${ }^{\circ}$ Flexion \\
\hline $\begin{array}{l}\text { Single-Legged } \\
\text { Stance }\end{array}$ & $\begin{array}{c}1400 \mathrm{~N} \\
(\sim 2.2 \mathrm{BW})\end{array}$ & $\begin{array}{c}880 \mathrm{~N} \\
(\sim 1.3 \mathrm{BW})\end{array}$ & 12 & 0 \\
\hline $\begin{array}{c}\text { Cyclic } \\
(0.5 \mathrm{~Hz}) \\
\end{array}$ & $300-1700 \mathrm{~N}$ & $\begin{array}{c}667 \mathrm{~N} \\
(\sim 1 \mathrm{BW}) \\
\end{array}$ & 12 & 0 \\
\hline $\begin{array}{c}\text { Stair } \\
\text { Climb }\end{array}$ & $\begin{array}{c}413 \mathrm{~N} \\
(\sim 0.6 \mathrm{BW}) \\
\end{array}$ & $\begin{array}{c}152 \mathrm{~N} \\
(\sim 0.24 \mathrm{BW})\end{array}$ & 12 & 35 \\
\hline
\end{tabular}

Table 4-1. The load parameters used in this study. All load magnitudes were calculated for a subject with a body weight of $667 \mathrm{~N}$.

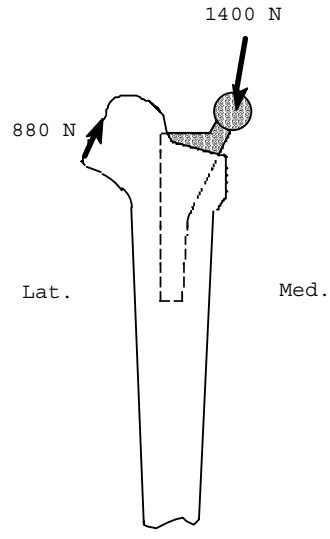

Frontal View

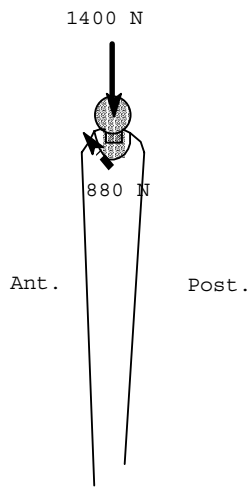

Saggital View

a) Single-legged Stance Load Case 


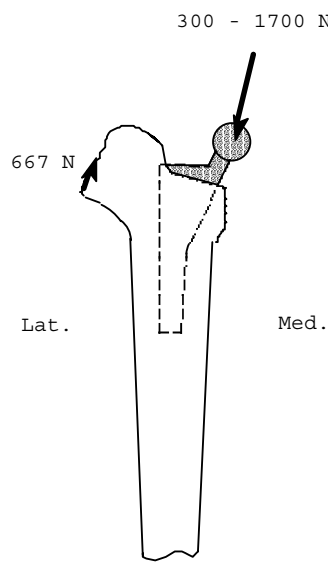

Frontal View

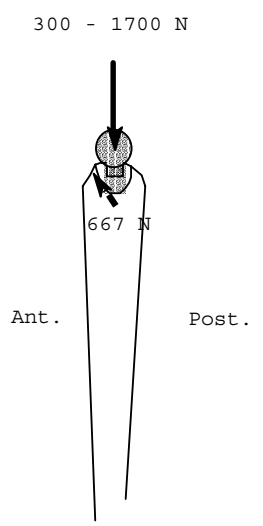

Saggital View

b) Cyclic Load Case

$$
413 \mathrm{~N}
$$

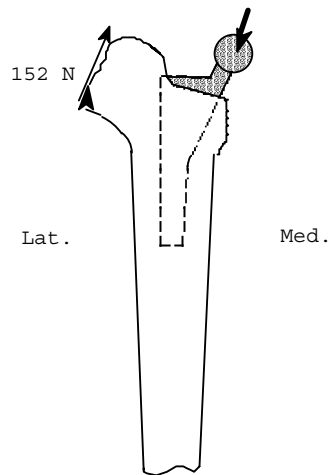

Frontal View
$413 \mathrm{~N}$

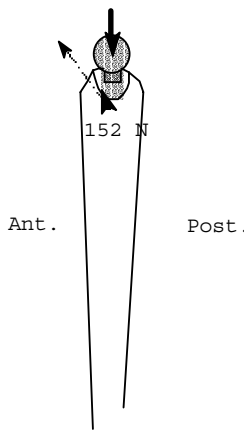

Saggital View

c) Stair Climb Load Case

Figure 4-6. Graphical representation of applied joint and muscle forces for the a) singlelegged stance, b) cyclic and c) stair climb load conditions.

\section{Stem Type}

The stem used in this study is a custom stem (Figure 4-7). The collarless stem is $140 \mathrm{~mm}$ in length and has no taper along the lateral aspect or for the distal most $20 \mathrm{~mm}$ of the medial aspect. It has an increasing taper in the proximal medial region with the greatest taper in the proximal third of the length. It is tapered slightly in the anteriorposterior dimension. The neck anteversion angle is $0^{\circ}$. It is made of cobalt-chrome and 
has a highly polished surface. Two stems were used in the study. One stem was sandblasted to achieve a rough surface finish in order to examine the effect of surface finish on stem behavior. Surface roughness measurements of the two stems were made using a Mitutoyo SJ-201 roughness tester (Mitutoyo America Corporation, Aurora, IL). The roughness values are shown in Table 4-2.

\begin{tabular}{|c|c|c|c|c|}
\cline { 2 - 5 } \multicolumn{1}{c|}{} & $\begin{array}{c}\mathrm{R}_{\mathrm{a}} \\
(\mu \mathrm{m})\end{array}$ & $\begin{array}{c}\mathrm{R}_{\mathrm{y}} \\
(\mu \mathrm{m})\end{array}$ & $\begin{array}{c}\mathrm{R}_{\mathrm{z}} \\
(\mu \mathrm{m})\end{array}$ & $\begin{array}{c}\mathrm{R}_{\mathrm{q}} \\
(\mu \mathrm{m})\end{array}$ \\
\hline Polished Stem & 0.26 & 2.03 & 1.24 & 0.35 \\
\hline Sandblasted Stem & 3.47 & 26.29 & 22.93 & 4.34 \\
\hline
\end{tabular}

Table 4-2. Surface roughness values for the two stems used in this study.

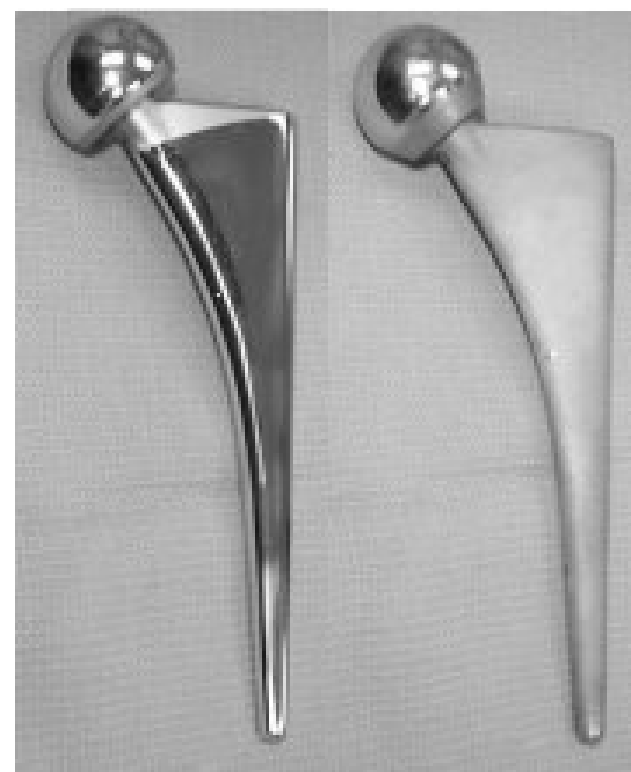

Figure 4-7. The stems used in this study. These stems are identical except for surface finish. The stem on the left has the original polished finish. The stem on the right has been sandblasted to achieve a rough surface finish.

\section{Bone Strain Measurement}

The state of strain in a femur is important because it will give an indication of the validity of the experimentally applied loads. Several investigators (Evans and Lissner, 
1948; Maloney et al., 1989) have used birefringent coatings to measure bone strain. This method is based on the principal that most transparent materials exhibit birefringence when stressed. A thin coating of the photostress plastic is applied to the surface of the specimen with special adhesive. The reflection of light shined on the specimen is viewed through a polarized lens. Fringe patterns visible through the lens indicate directions of principal strains on the surface of the specimen. Strain analysis using birefringent coatings is useful in determining patterns of strain over the entire surface of the specimen but requires tedious calculations to determine strain magnitudes.

In cases where strain magnitudes are of interest electrical resistance strain gages are often used. These strain measurement devices are based on the observation that the resistance of a thin metal wire changes as it is stressed. Incorporating the strain gage into a Wheatstone bridge circuit makes it possible to measure resistance change in terms of output voltage. These gages are bonded to the surface of the specimen with a thin layer of adhesive. Individual strain gages measure the average strain over their length in one direction. In order to characterize strain in the measurement area strain measurements must be made in at least three different directions. This requires at least three strain gages mounted in the same area. Rosettes are sets of gages with different orientations mounted to the same backing. They allow the gages to be precisely aligned with respect to each other so that the strains in several directions can be accurately measured. The three independent strain measurements are sufficient to fully characterize the state of stress in the specimen under the strain gage. Strain gages measure only average strains at particular areas of the specimen not full field strain patterns as birefringent coatings do. However, strain gages are inexpensive, easy to mount to a specimen and strain magnitudes can be easily determined. 
A number of investigators have used resistive strain gages to measure bone strains in the loaded femur (Oh and Harris, 1978; Crowninshield et al., 1980; Rolhmann et al., 1982, 1983; Maloney et al., 1989; Jasty et al., 1994). In order to apply gages to the femoral cortex the application site is cleaned of all soft tissue and cleaned, defatted and dried with ether, methanol or acetone. It may be necessary to sand the site with finegrained sandpaper to remove slight surface imperfections (Oh and Harris, 1978; Jasty et al., 1994). Oh and Harris (1978) applied a thin film of lacquer to the surface before sanding to clog the cortical bone pores, preventing moisture to accumulate under the gage. The gages are bonded to surface of the femur and lead wires are soldered to them. Oh and Harris (1978) then applied a waterproof coating to the gages to protect them in moist freezing conditions and during testing.

Because strain gages measure strain over a very small region, great care must be taken to select sites of interest. Oh and Harris (1978) applied longitudinally oriented unidirectional strain gages to the femoral cortex at levels corresponding to the femoral neck, the subtrochanteric region, the distal tip of the prosthesis and $5 \mathrm{~cm}$ distal to the prosthesis tip. Gages were bonded to the anterior, posterior, lateral and medial aspects of the femur at all levels except the distal level where no posterior gage was mounted and the neck level where no lateral gage was mounted. Additional gages were mounted to the anteriomedial and posteriomedial surfaces in the calcar region. Crowninshield et al. (1980) applied pairs of gages oriented longitudinally and circumferentially to the medial surface of the femur at levels $5 \mathrm{~cm}, 60 \mathrm{~cm}$ and $120 \mathrm{~cm}$ distal to the planned neck osteotomy. In related studies Rohlmann et al. (1982) and Rohlmann et al. (1983) applied 3-element strain gage rosettes to the anterior, medial-posterior and lateral-posterior surface of the femur at each of ten levels and 4 rosettes in the intertrochanteric or greater 
trochanteric region. Maloney et al. (1989) applied 12 biaxial or triaxial rosettes to the anterior, posterior, medial and lateral surfaces of the femur at proximal, mid-stem and distal tip levels. Jasty et al. (1994) applied strain gages to the medial and lateral surfaces of a femur at the same levels.

Several factors determined the gage type used in this study. It was decided that gages with a very small area should be used because the irregular surface of the femur would make it difficult to mount large gages without distorting them. Additionally, small gages give a very accurate indication of strain at the measurement site because the strain is averaged over a smaller area. Three element rosettes were chosen over single element gages so that a more complete measurement of the strain state could be made. Longitudinal strains generated by bending of the femur and torsional strains generated by twisting of the femur are of interest. The three strain readings obtained from the elements of the rosettes would make it possible to calculate these strains. Based on these factors micromeasurements EA-06-015RJ-120 (Vishay Measurements Group, Raleigh, NC) were selected. They are 3 element rectangular rosettes with a total area of $4.8 \mathrm{~mm} \mathrm{x}$ $5.8 \mathrm{~mm}$. Each gage has a gage length of $0.38 \mathrm{~mm}$.

As in the case of gage type selection, several factors determined the gage positioning used in this study. The data acquisition system used in this study has 4 Keithly Data EXP-GP 8 (Keithly Instruments, Inc., Cleveland, OH) channel strain conditioning boards. This limits the possible number of simultaneous strain readings to 32. Bone strain was measured to verify the physiologic loading of the load frame. It was decided that rosettes should be mounted at levels corresponding to the greater trochanter, mid-stem, the distal extent of the cement mantle and $5 \mathrm{~cm}$ below the distal tip of the prosthesis (Figure 4-8). This would provide strain measurements in regions studied by 
previous investigators. Because the posterior aspect of the cortex does not have suitable locations for mounting gages at the selected levels gages were mounted to the lateral, medial and anterior surfaces of the femur. No rosette was mounted to the lateral surface at the greater trochanter level because this is where the muscle strap is attached and the strain there would be unduly influenced by the local effects of the muscle strap.

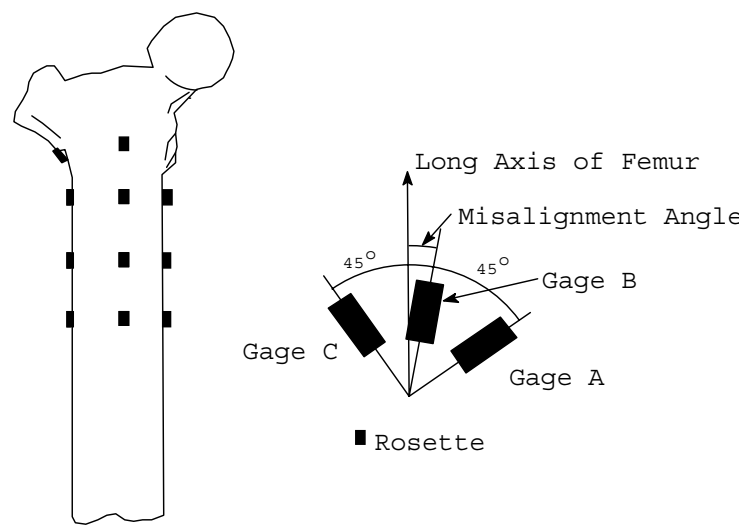

Figure 4-8. Positions of strain gage rosettes on femur.

\section{Validation of Load Frame}

An instrumented plastic femur was loaded to validate the effectiveness of the load frame. The femur was oriented as the intact femur in the study by Oh and Harris (1978) was $\left(15^{\circ}\right.$ adduction, $0^{\circ}$ flexion). After adjusting for the difference in specimen stiffness and applied load the measured axial bone strain compares favorably with that reported by Oh and Harris (1978) (Figure 4-9).

Next a fresh, frozen intact human femur was instrumented and loaded in singlelegged stance. Strain measurements were recorded and analyzed. Some gages were damaged or strained during application and could not be balanced. Adjustable potentiometers were added to the data acquisition board to increase the balance range of the gages. The axial strain was calculated at positions where valid measurements were made. Single-legged stance primarily causes bending of the femur in the frontal plane. 
Axial strains should be compressive on the medial surface, tensile on the proximal surface and nearly zero on the anterior surface. The measured axial strains (Figure 4-10) follow this trend. The fact that the measure strain values follow expected trends and compare well with the results of previous investigators provided validation of the load frame

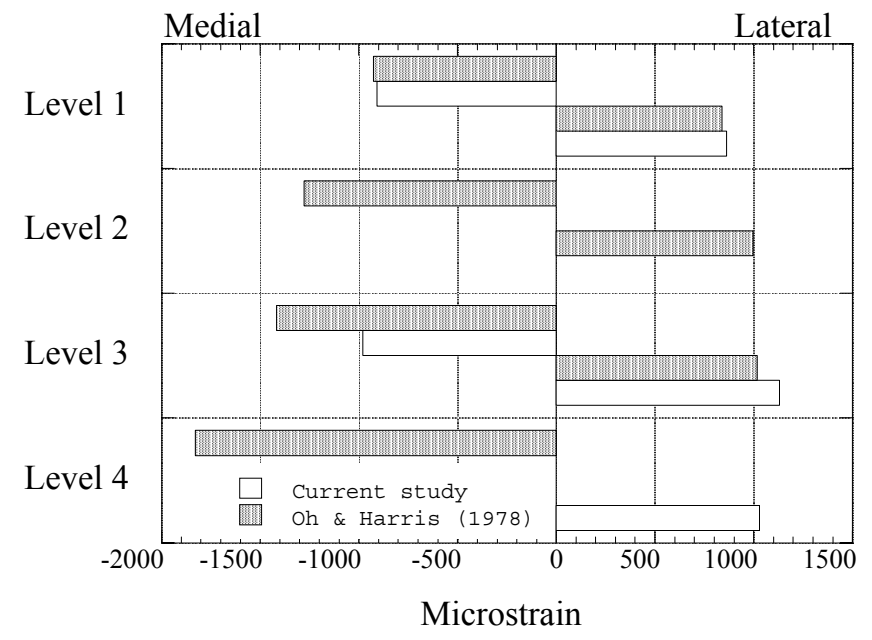

Figure 4-9. Comparison of normalized axial strains on the plastic femur to strains measured by Oh and Harris (1978)

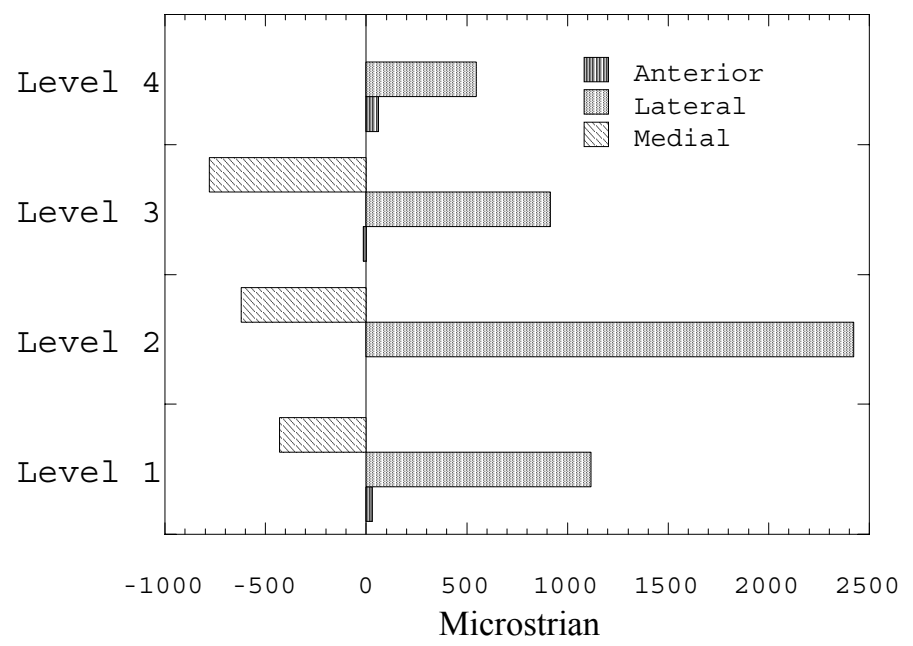

Figure 4-10. Axial bone strains from single-legged stance loading of intact femur. 


\section{Cement Mantle Strain Measurement}

One of the key points of this research is to determine the effects of PMMA bone cement viscoelasticity on prosthesis stem behavior. To accomplish this, one must first prove that the bone cement does indeed experience creep and relaxation in the cement mantle. Measurement of cement mantle strains during extended periods of constant loading of the prosthesis will determine if this is the case. A change in cement mantle strain is an indication of PMMA viscoelastic behavior.

There are examples of in vitro cement mantle strain measurement in the literature. Crowninshield and Tolbert (1983) encapsulated strain gages within PMMA bone cement by applying a very low viscosity mixture of cement to both surfaces to the gage. For calibration purposes encapsulated strain gages were incorporated into a cantilever beam specimen made from bone cement. Predicted and measured strain agreed to within $3 \%$. Just after a stem was inserted into a cement filled femoral canal, while the cement mantle was still relatively low in viscosity, encapsulated strain gages were inserted into the proximal cement oriented in various directions. This method is limited because gage can be placed only in the proximal cement mantle without severely disturbing the cement mantle, it is difficult to place the gages in precisely the same point in each specimen and a low viscosity cement must be used.

Burke (1985) fabricated a strain gage carrier from PMMA bone cement. This carrier conformed to the medial and lateral shape of the prosthesis stem and had a rectangular cross section of $3.175 \mathrm{~mm}$ x $6.35 \mathrm{~mm}$. Three mutually orthogonal strain gages were attached at six points along the lateral and medial aspects of the carrier. The gages would be positioned in the proximal, middle and distal aspects of the medial and lateral cement mantle. Calibration of the gage carrier using PMMA beams loaded in 
tension and bending indicated that the actual strain diverged an average of $18 \%$ from the measured strain. This effect was attributed to reinforcement of the cement by the gage and was corrected for in the strain measurement data. After the femur was rasped to accept the implant, the gage carrier was carefully inserted into and aligned in the canal. Strain gage lead wires left the canal through small holes drilled in the bone adjacent to the carrier. The canal was filled with cement and after pressurization, the stem was inserted into the cement.

This method is an improvement over that used by Crowninshield et al. (1983). The gages can be reproducibly placed within the medial or lateral cement mantle at almost any point. However, the large carrier and number and size of the lead wires may have a strong influence on the shape and thickness of cement mantle. Additionally, the holes drilled in the femur may have a strong effect on measured cement mantle strains.

For this study, much smaller strain gage carriers were used. Instead of having one large gage carrier that would carry all of the strain gages it was decided that each gage would have its own gage carrier large enough to carry one gage. Cubes of PMMA bone cement were cast in an aluminum mold. The cubes measured $7 \mathrm{~mm}$ long x $3 \mathrm{~mm}$ wide $\mathrm{x}$ $0.7 \mathrm{~mm}$ thick. Either a Micromeasurements EA-06-015LA-120 or EA-060915EH-120 strain gage (Vishay Measurements Group, Raleigh, NC) was mounted to the cube. These gages are unidirectional strain gages with a total area of $4.6 \mathrm{~mm} \times 2.5 \mathrm{~mm}$ and a gage length of $0.38 \mathrm{~mm}$ (Figure 4-11). They differ only in grid orientation. The gages were mounted so that they would measure strain in the circumferential direction. Very thin (36 AWG, $d=0.127 \mathrm{~mm}$ ) Teflon coated copper lead wires were soldered to the gage. 


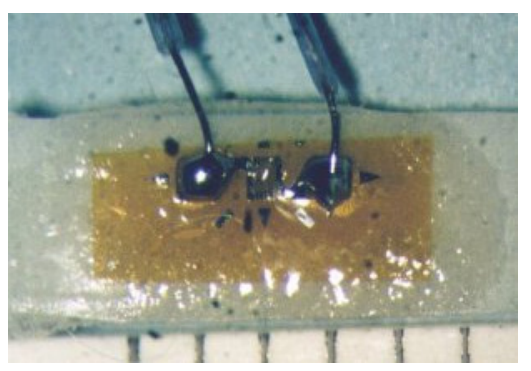

Figure 4-11. Strain gage carrier.

A small amount of PMMA is brushed over the gage to form a coating that protects the gages during stem insertion. These carriers are attached to the surface of the prosthesis stem (Figure 4-12). The prosthesis is inserted into the cement filled femoral canal as it would normally. The thin lead wires exit the cement mantle at its proximal extent.

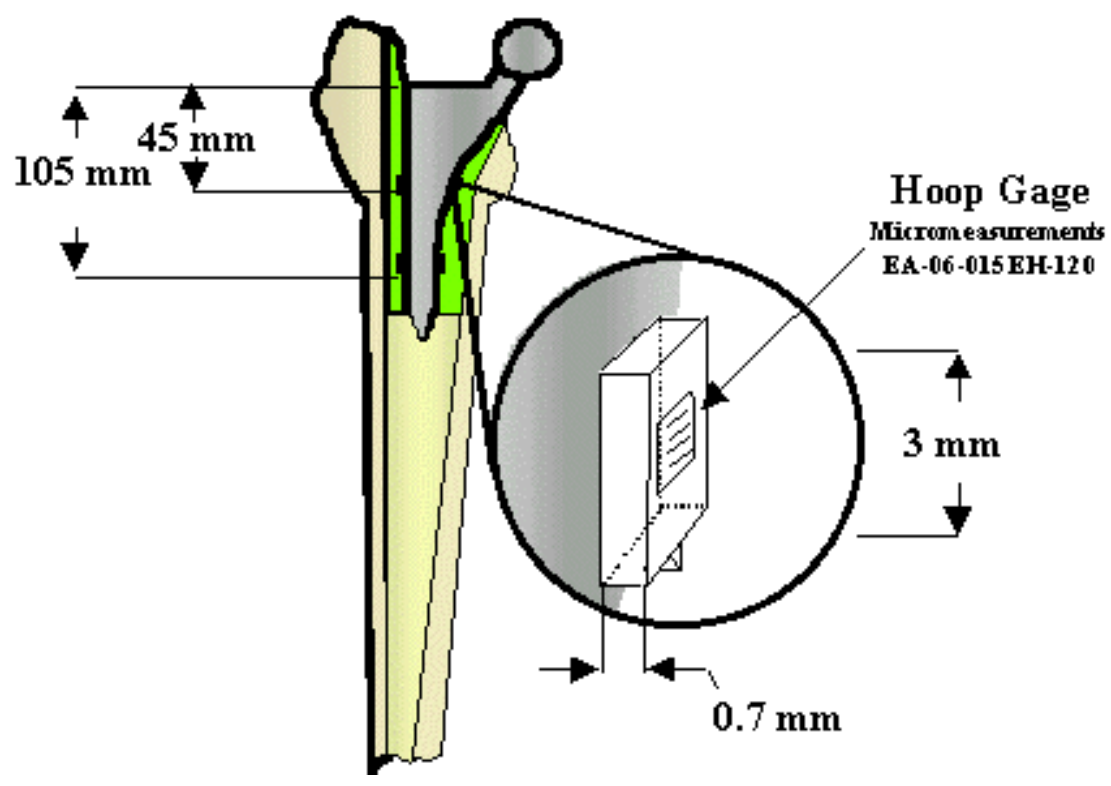

Figure 4-12. Locations of cement strain gage carriers.

The gage carriers have been calibrated using a PMMA cantilever beam (Figure 413). A beam $10 \mathrm{~mm}$ wide, $7.5 \mathrm{~mm}$ thick and $150 \mathrm{~mm}$ long was cast using PMMA cement. A uniaxial strain gage (Micromeasurements EA-06-062AK-120)(Vishay 
Measurements Group, Raleigh, NC) was mounted to the surface of the beam $75 \mathrm{~mm}$ from the end. Lead wires were soldered to the gage. The beam was then placed in another mold and an additional $2.5 \mathrm{~mm}$ of PMMA was added to the thickness of the beam. An strain gage identical to the internal gage was mounted to the new surface directly above the original gage. One end of the beam was clamped while increasing values of weight were hung from the other. Strains measured from the two gages were monitored. Using elastic beam theory, the elastic modulus of the beam was calculated from the surface gage. This value was used to calculate the internal bending stress from the strain measured by the internal gage. This value was compared to that calculated from beam theory. Measured stress values agreed within $1 \%$ of the expected value (Figure 4-14) so no calibration factor was necessary. Tests done as part of this study show that preformed PMMA coating on a stem will be fully incorporated into a cement mantle when the stem is implanted. The bond strength between the two sections of cement is much stronger than the bone of the PMMA coating to the stem surface.

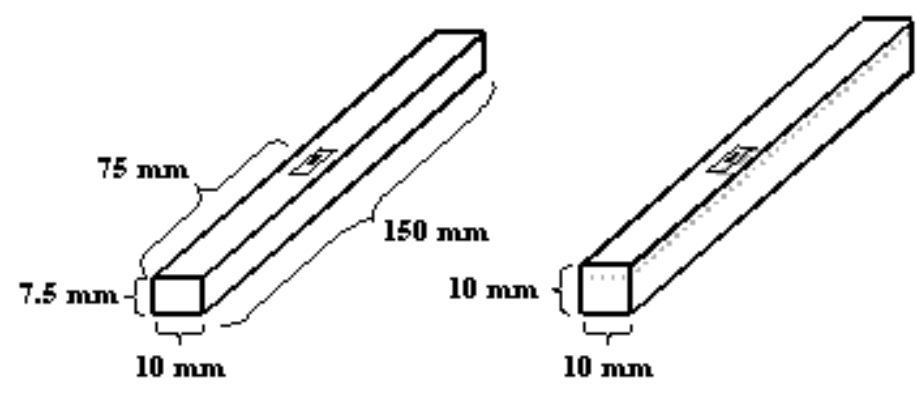

Figure 4-13. Beam calibration specimen. 


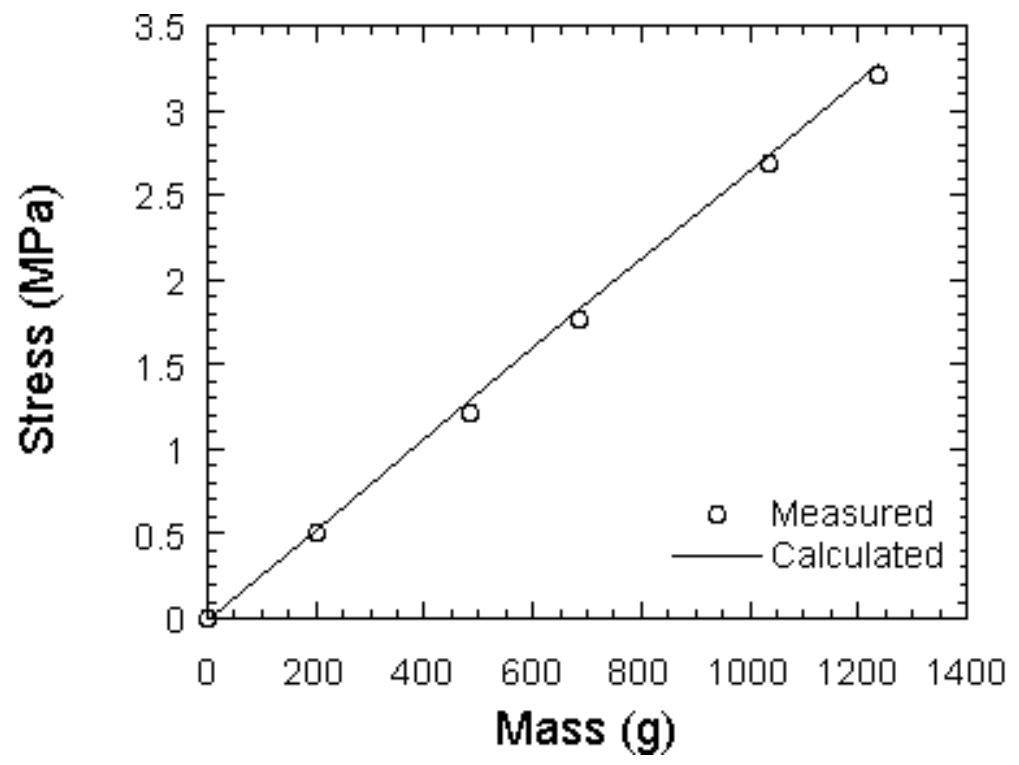

Figure 4-14. Results of gage carrier calibration test.

\section{Stem Displacement Measurements}

Clinical observations by Fowler et al. (1989) indicate that a smooth, tapered collarless femoral stem will displace within the cement mantle without disrupting the bone-cement interface. Other investigators (Weber and Charnley, 1975; Loudin and Charnley, 1980; Loudin, 1986) have noticed distal stem displacement in Charnley LFA's in the presence of cracks in the distal extent of the cement mantle. Roentgen stereophotogrammetric analysis (RSA) is a standard method of measuring prosthesis displacement in vivo (Baldursson, 1979; Kärrholm, Borssén, et al., 1994; Kärrholm, Malchau, et al., 1994), but there is no standard method for measuring prosthesis motion in vitro. Maloney et al. (1989) drove a metal pin through a hole in the femoral cortex into a hole in the prosthesis. A metal cylinder fit over the pin and was attached to the bone. An extensometer was used to measure the movement between the pin and cylinder. Changing the location and orientation of the extensometer allowed them to 
measure axial, transverse and rotational motion of the stem. Barich et al. $(1994,1995)$ used groups of three liquid metal strain gages out-rigger mounted to the stem surface to measure stem micromotion. Doehring et al. (1995) mounted pins with marker ball triads attached to them to the surface of the prosthesis through window holes drilled in the femoral cortex. A group of six LVDTs mounted to brackets attached to the bone provided 6 DOF measurement of the stem motion. Bühler et al. (1995) used an optoelectronic-mechanical sensor to measure stem motion. The sensor units were anchored to $9 \mathrm{~mm}$ diameter holes drilled in the cortex. The spherical measuring tip was placed on the surface of the prosthesis. A laser diode was connected to the measurement via precision ball bearing mechanisms. A silicon position sensitive detector registered the photons emitted by the LED. Measurement of the position of emitted light and its intensity were used to calculate $3 \mathrm{D}$ stem motion.

These techniques all involve bringing the measurement device into intimate contact with the prosthesis surface, often through a hole drilled in the bone. Because the magnitude of motion can be quite small (on the order of $100 \mu \mathrm{m}$ ) this contact may influence prosthesis motion. One goal of this research is to utilize a non-invasive motion measurement technique that will minimize instrument contact with stem to provide a more accurate measurement of stem motion.

The servohydraulic test machine used in this study has an internal LVDT that measures axial displacement of the loading ram. This provides a measurement of displacement due to elastic deformation of the load frame, bone, cement and stem. It is preferable to measure only stem displacement relative to the cement mantle. Two systems capable of doing this have been evaluated. One method uses a laser extensometer. A laser extensometer shines a laser beam on a specimen (Figure 4-15). 
Pieces of reflective marker tape placed on the specimen reflect the beam back to the laser extensometer. This device can determine the distance between the pieces of tape from the pattern of reflected light with a resolution of $0.001 \mathrm{~mm}$ (Electronic Instrument Research).

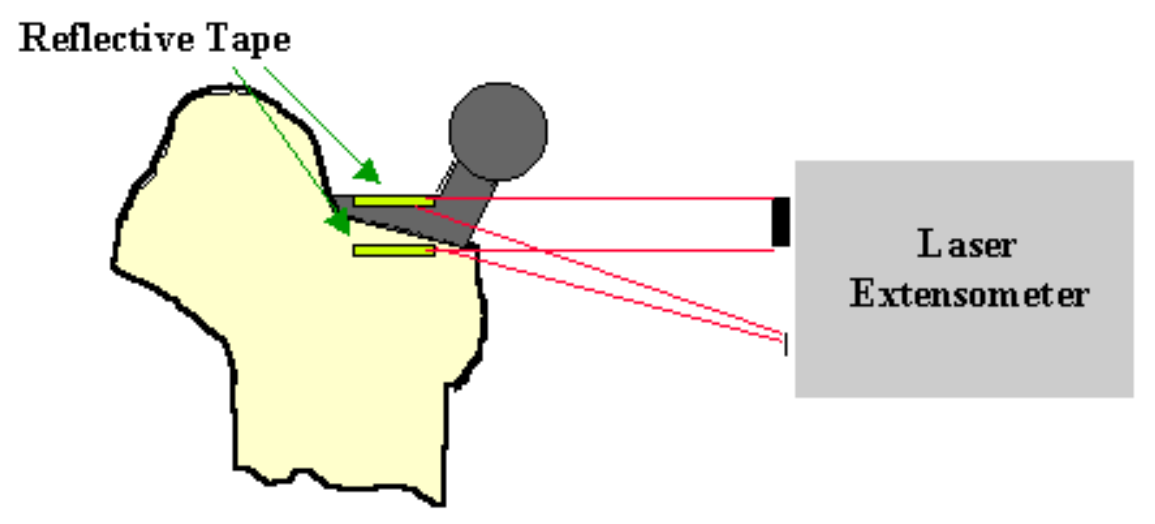

Figure 4-15. Laser extensometer setup. A model LE-01 laser extensometer (Electronic Instrument Research, Ltd., Irwin, PA) was used in this study.

Placing one piece of tape on the proximal femoral stem and one piece of tape on the proximal femur and orienting the beam along the femoral axis makes it possible to measure distal subsidence of the stem relative to the bone. The advantage of this method is that the measuring instrument is not in contact with the specimen. This method is limited in that the specimen must remain perpendicular to the light beam throughout the duration of the test. Also, because the laser extensometer is mounted away from the specimen and load frame, the measurement of stem displacement can be influenced by displacement of the test fixture and bone upon loading.

These limitations forced us to consider another measurement device. We chose to use miniature half-bridge LVDT called a DVRT (Differential Voltage Reluctance Transducer)(Microstrain, Inc, Burlington, VT). An LVDT consists of a series of inductors in a hollow cylindrical shaft and a solid cylindrical core. The LVDT produces an electrical output proportional to the position of the core. The hollow cylinder is 
mounted to the exposed proximal extent of the cement mantle. The core is mounted on the stem so that as the stem displaces distally within the cement mantle, the core moves into the hollow cylinder (Figure 4-16). The DVRT has a resolution of $1.5 \mu \mathrm{m}$ (MicroStrain, Inc.).

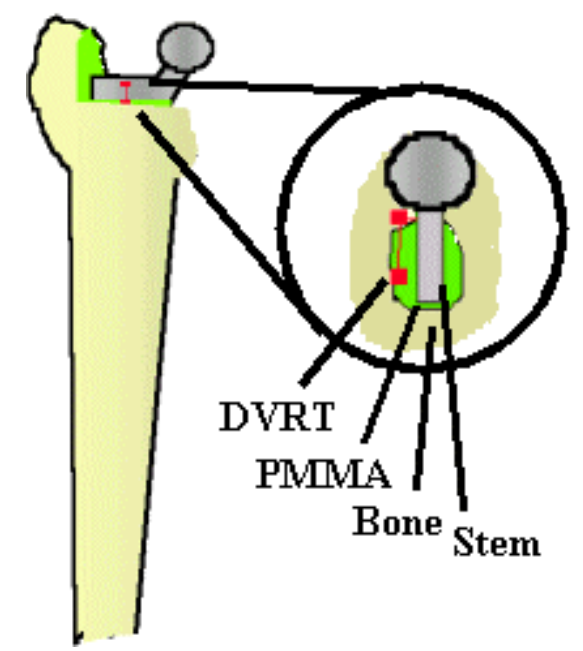

Figure 4-16. Stem displacement measurement using a DVRT.

\section{Pull-out Loads}

Huiskes (1990) has shown that in the presence of stem subsidence the load placed on the prosthesis is transferred to the bone as radial compression and tensile hoop stress. Lee (1990) argues that this will lead to a mechanical taper-lock of the stem within the cement mantle. In order to determine if a taper-lock occurred the stems were placed in a pull-out fixture (Figure 4-17) that applies tensile axial forces to the prosthesis. The fixture consists of a centering screw that is threaded into a load cell that is attached to the load frame. Axial load applied to that screw is transmitted to the stem through a set screw that rests in a dimple on the inferior surface of the prosthesis neck. The load necessary to extract the stems from the cement mantle can be used as a measure of taperlock fixation. 


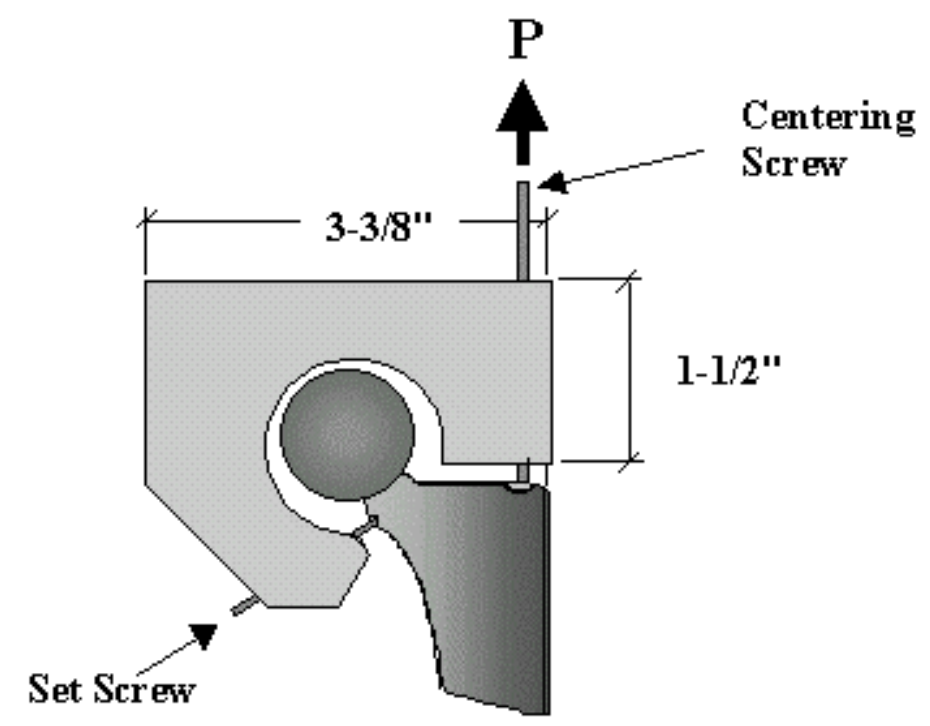

Figure 4-17. Stem-pull out fixture.

\section{Cement Mantle Damage Assessment}

After the final pull-out test, the femur was cut at mid-diaphysis. The proximal portion of the femur containing the cement mantle was stained under vacuum in a bath of $100 \%$ basic fuschin for 48 hours. Upon removal from the stain, the femur was sectioned longitudinally (Figure 4-18) by cutting through the anterior and posterior surface or through the lateral and medial surfaces with a diamond blade. Serial sections (Figure 419) of the cement mantle-bone construct were made using a diamond blade. These sections were approximately $1 \mathrm{~cm}$ thick. Hand mixed cylindrical specimens Palacos R bone cement were made to serve as control specimens. After the specimens were cured, they were stained, sectioned and polished in the same manner as the cement-bone specimens. After polishing, these specimens were examined under an upright microscope (Olympus BH2, Melville, NY) using transmitted fluorescent light. Cement mantle cracks were counted and the lengths were measured using image analysis software (Optimas, Media Cybernetics, Silver Spring, MD). 


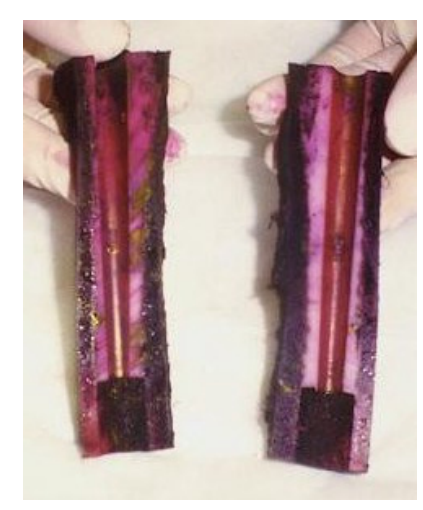

Figure 4-18. Longitudinal section of cement mantle-bone damage specimen.

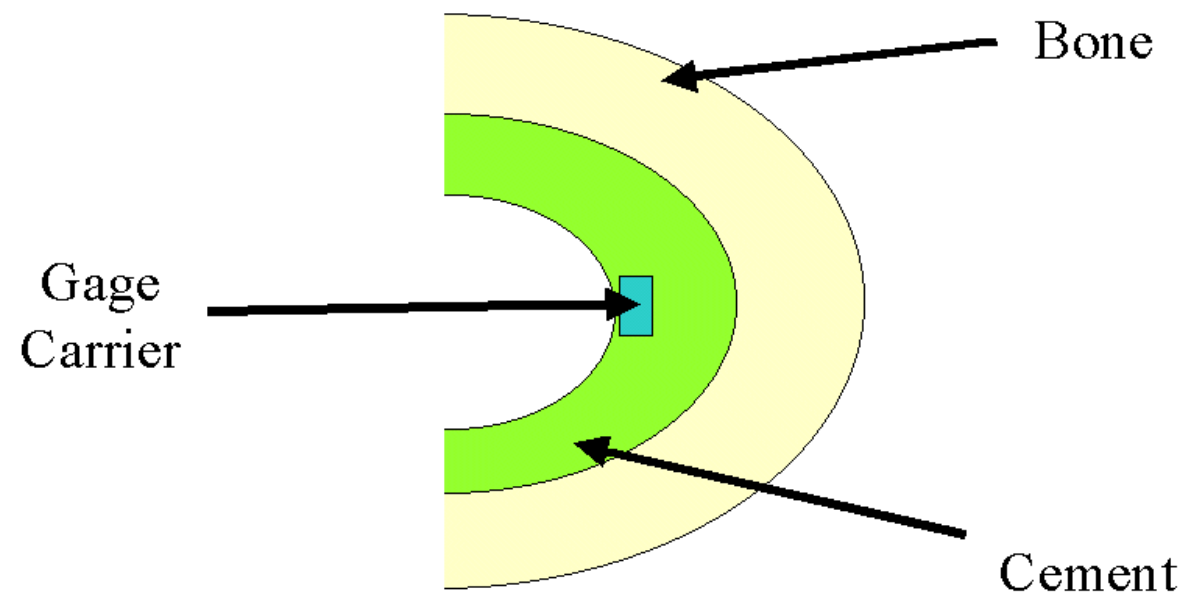

Figure 4-19. Cement damage specimen.

This chapter has discussed the experimental methods used in this study. Discussion of the work of previous investigators has provided background material to better understand the development of the techniques used in this study. 


\section{CHAPTER 5: Results}

Data from several tests have been obtained using the methods described in the previous chapter. This chapter describes those results and comments on the effectiveness of the methods in obtaining data useful in the evaluation of the proposed hip stem.

\section{Creep Strain of Simplex P Cement}

A total of 21 cylindrical specimens of hand mixed Surgical Simplex P bone cement was tested. For each specimen, measured displacement was divided by original length to obtain total strain. Elastic strain was subtracted from total strain to obtain creep strain (Figure 5-1). Average hourly creep strain values and their standard deviations for each load level are shown in Table 5-1. A non-linear least squares fit of the creep strain data was performed using JMP statistical software (SAS Institute, Inc., Cary, NC) to derive a power law relationship for strain as a function of time and applied stress level. The resulting creep law is:

$$
\varepsilon=7.642 \times 10^{-3} \sigma^{1.314} t^{0.252}
$$

which can be differentiated with respect to time to get a relationship for strain rate:

$$
\dot{\varepsilon}=1.962 \times 10^{-3} \sigma^{1.314} t^{-0.748}
$$

where $\varepsilon$ is strain expressed as $\%$ strain, $\sigma$ is stress in MPa and $t$ is time in seconds. The average creep strain predicted for each load level has been plotted (Figure 5-2) along with the average experimentally measured creep strain to demonstrate the agreement between the measured and predicted values. In order to assess the accuracy of the creep law, the predicted creep strain was plotted against the experimentally measured creep 
strain. A linear regression of the data was performed (Figure 5-3). If the creep law perfectly predicts observed creep the slope of the regression line and the coefficient of correlation (r) both would be equal to 1.0. The results of the regression are a slope of 0.948 and an coefficient of correlation of 0.966 . This indicates that the creep law models the creep strain with a high level of accuracy.

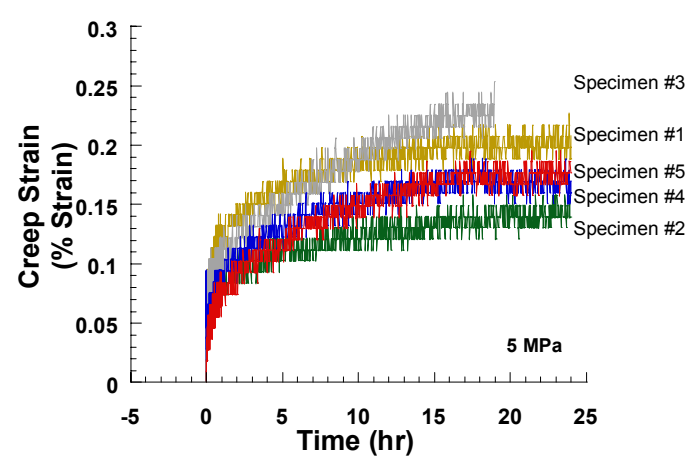

a)

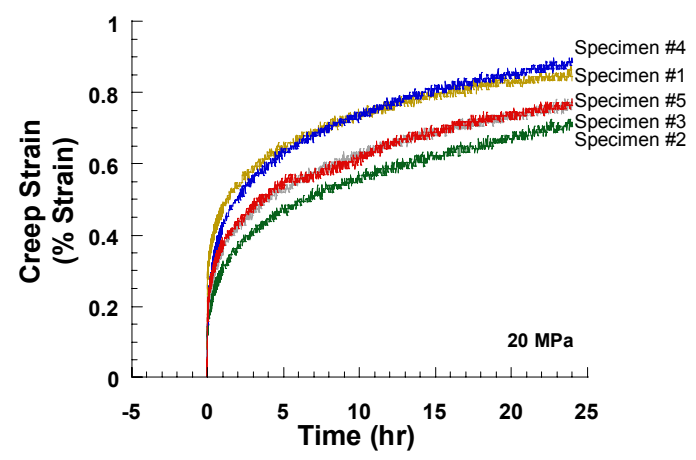

c)

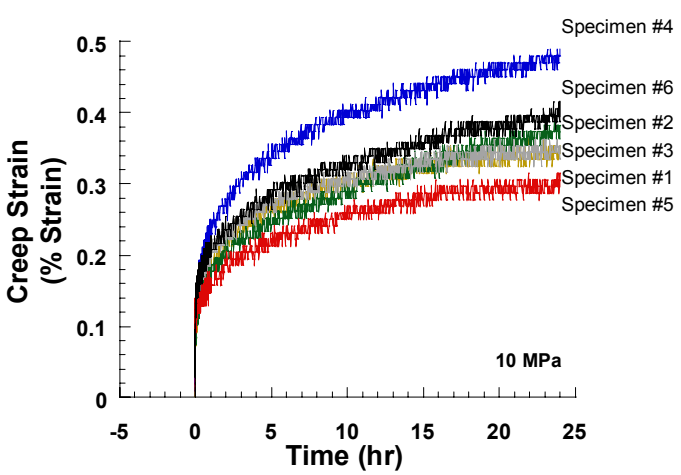

b)

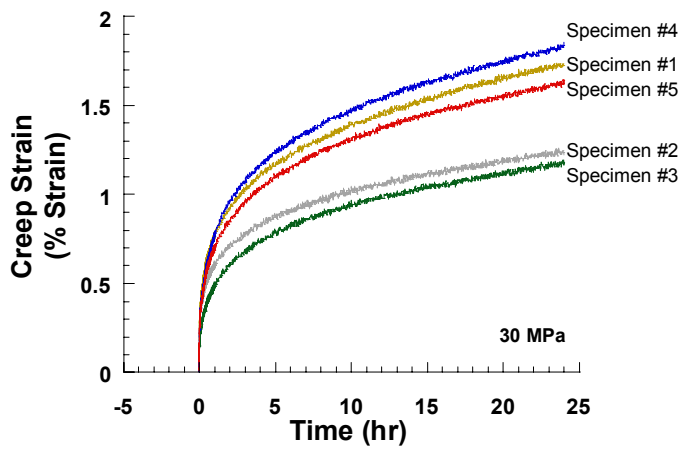

d)

Figure 5-1. Compressive creepstrain for the Simplex P creep specimens loaded at a) $5 \mathrm{MPa}, \mathrm{b}) 10 \mathrm{MPa}$, c) $20 \mathrm{MPa}$ and d) $30 \mathrm{MPa}$

The creep law underestimates the amount of strain at $5 \mathrm{MPa}$ and $10 \mathrm{MPa}$; overestimates strain at $20 \mathrm{MPa}$ and very closely models strain at $30 \mathrm{MPa}$. The differences between measured and predicted creep strain are within the standard deviation of the measured values for all stress levels. This is noteworthy because often models are more accurate at 
either low or high stress levels and have limited use outside the given range. This model appears to describe behavior over a wide range of load levels that may be experienced in the cement mantle of a debonded stem.

\begin{tabular}{|c|c|c|c|c|c|c|c|c|}
\hline \multirow{2}{*}{\begin{tabular}{l|} 
Load \\
Time (hr)
\end{tabular}} & \multicolumn{2}{|c|}{$5 \mathrm{MPa}$} & \multicolumn{2}{|c|}{$10 \mathrm{MPa}$} & \multicolumn{2}{|c|}{$20 \mathrm{MPa}$} & \multicolumn{2}{|c|}{$30 \mathrm{MPa}$} \\
\hline & $\begin{array}{c}\text { Average } \\
\text { Strain } \\
(\% \text { strain }) \\
\end{array}$ & S.D. & $\begin{array}{c}\text { Average } \\
\text { Strain } \\
(\% \text { strain }) \\
\end{array}$ & S.D. & $\begin{array}{c}\text { Average } \\
\text { Strain } \\
(\% \text { strain }) \\
\end{array}$ & S.D. & $\begin{array}{c}\text { Average } \\
\text { Strain } \\
(\% \text { strain }) \\
\end{array}$ & S.D. \\
\hline 1 & -0.09179 & 0.02382 & -0.19237 & 0.036435 & -0.39372 & 0.071325 & -0.67026 & 0.1182 \\
\hline 2 & -0.10117 & 0.026518 & -0.2234 & 0.032613 & -0.4569 & 0.067632 & -0.8094 & \\
\hline 3 & -0.11994 & 0.018625 & -0.24067 & 0.041033 & -0.4999 & 0.0678 & -0.90116 & 0.170929 \\
\hline 4 & -0.12737 & 0.023178 & -0.26094 & 0.038019 & -0.5317 & 0.070876 & -0.97244 & 0.189666 \\
\hline 5 & -0.1311 & 0.02613 & -0.26878 & 0.04419 & -0.56357 & 0.074969 & -1.03454 & 0.199507 \\
\hline 6 & -0.14614 & 0.026788 & -0.28291 & 0.050416 & -0.58401 & 0.074065 & -1.08154 & 0.211477 \\
\hline 7 & -0.14616 & 0.033362 & -0.29226 & 0.045707 & -0.60828 & 0.082988 & -1.12264 & $0.21 \mathrm{C}$ \\
\hline 8 & -0.15549 & 0.030485 & -0.30007 & 0.0451 & -0.61573 & 0.078912 & -1.16406 & 0.213361 \\
\hline 9 & -0.15743 & 0.029843 & -0.30787 & 0.043856 & -0.63799 & 0.076981 & -1.19783 & 0.228124 \\
\hline 10 & -0.15554 & 0.0276 & -0.31418 & 0.047751 & -0.65479 & 0.081438 & -1.23545 & 0.222619 \\
\hline 11 & & 0.032046 & & & & & & \\
\hline 12 & -0.16869 & 0.041905 & -0.32978 & 0.044121 & -0.68655 & 0.079483 & -1.27863 & 0.24408 \\
\hline 13 & -0.1649 & 0.033305 & -0.32827 & 0.051106 & -0.70714 & 0.081928 & -1.30491 & 0.251963 \\
\hline 14 & -0.1 & 0.03 & -0.34081 & 0.05 & -0.7 & 0.06 & 292 & 0.25 \\
\hline 15 & & & & & -0.7 & 0.0 & & \\
\hline 16 & -0.17617 & 0.036381 & -0.35026 & 0.057004 & -0.7296 & 0.073929 & -1.3705 & 0.269701 \\
\hline 17 & -0.1837 & 0.033538 & -0.35791 & 0.049362 & -0.74271 & 0.078548 & -1.3912 & 0.274957 \\
\hline 18 & -0.18366 & 0.03 & & 0.05 & 822 & 0.08 & -1 . & 0.27 \\
\hline 19 & & 0.0382 & & & & & & 0.275931 \\
\hline 20 & -0.17238 & 0.020008 & -0.35489 & 0.056579 & -0.76121 & 0.074779 & -1.44553 & 0.280021 \\
\hline 21 & -0.17428 & 0.02761 & -0.36429 & 0.058556 & -0.7687 & 0.073498 & -1.47004 & 0.284961 \\
\hline 22 & -0.17617 & 0.024088 & -0.36594 & 0.066165 & -0.77991 & 0.070083 & -1.48889 & 0.289881 \\
\hline 23 & -0.17615 & 0.02385 & -0.36904 & 0.063202 & -0.78367 & 0.076978 & -1.50016 & 0.290885 \\
\hline 24 & -0.17991 & 0.028208 & -0.37375 & 0.064973 & -0.7948 & 0.069142 & -1.5264 & 0.302039 \\
\hline
\end{tabular}

Table 5-1. Average creep strain and standard deviation for each load level at hourly intervals. 


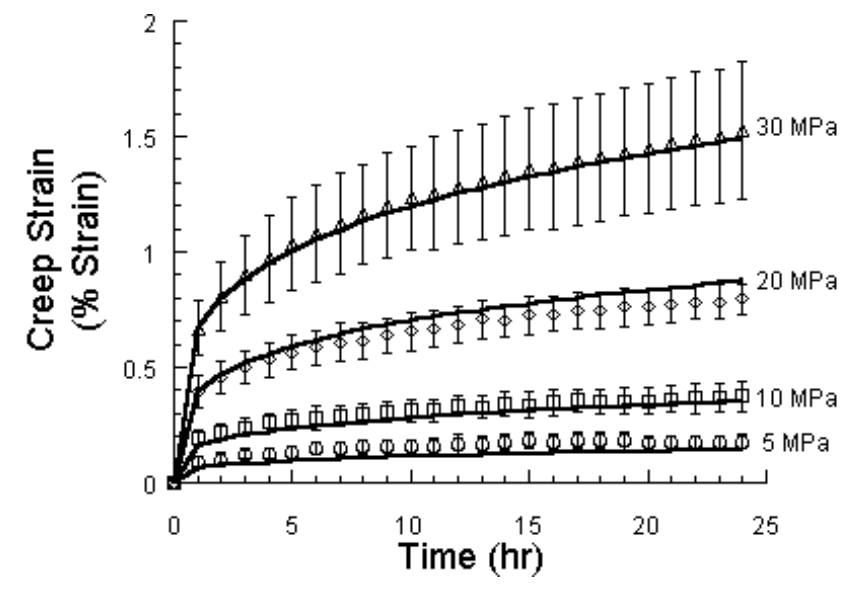

Figure 5-2. Comparison of measured creep strain of Simplex P bone cement to that predicted by a power law expression derived from experimental data for several load levels. Error bars indicate standard deviation of measured strains.

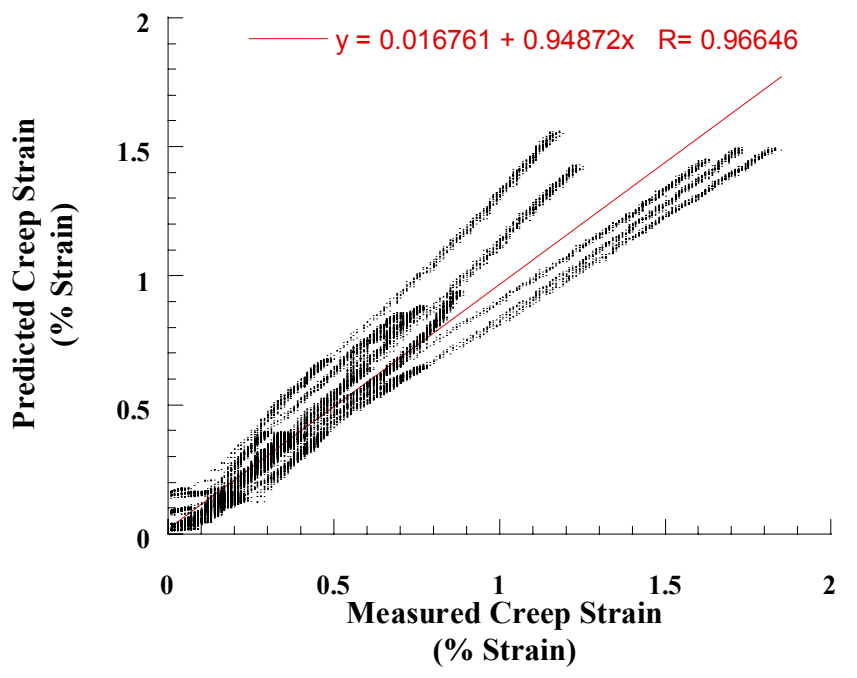

Figure 5-3. Regression line for predicted creep strain plotted against measured creep strain. Both the slope and coefficient of correlation are close to one. This indicates that the creep law accurately models creep strain. 


\section{Cement Strains}

Strain gage carriers were mounted to the medial and lateral surfaces of the prosthesis stem. Each carrier contained one gage oriented to measure cement hoop strain. Cement hoop strains were measure during each load case. The single-legged stance and cyclic load cases had the same load orientation. Only the magnitude and nature (static or sinusoidal) of the load differed. Therefore, the measured hoop strains should show similar trends.

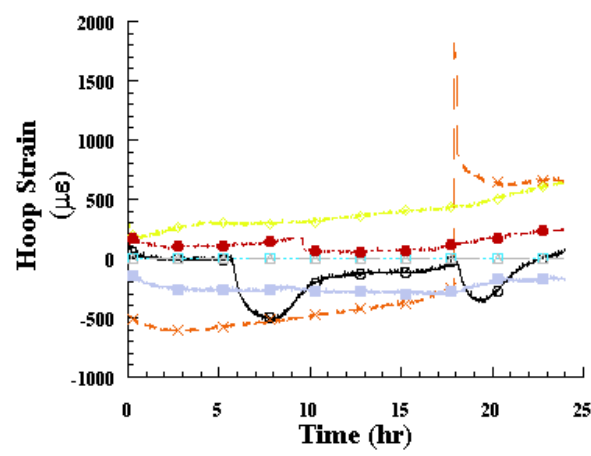

a)

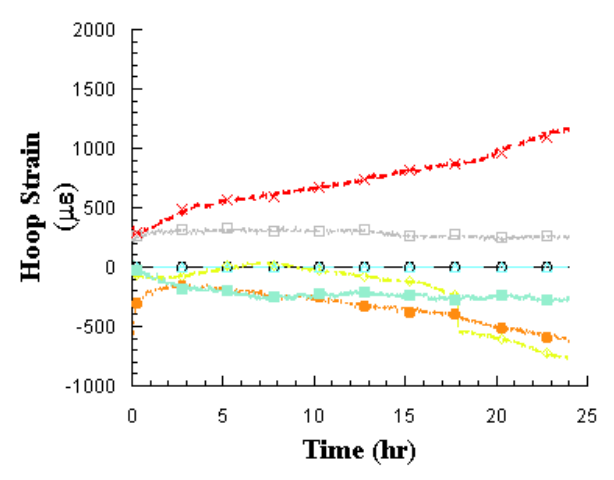

c)

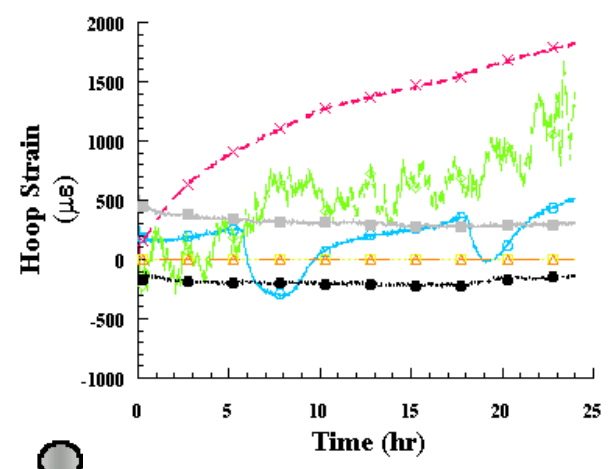

b)

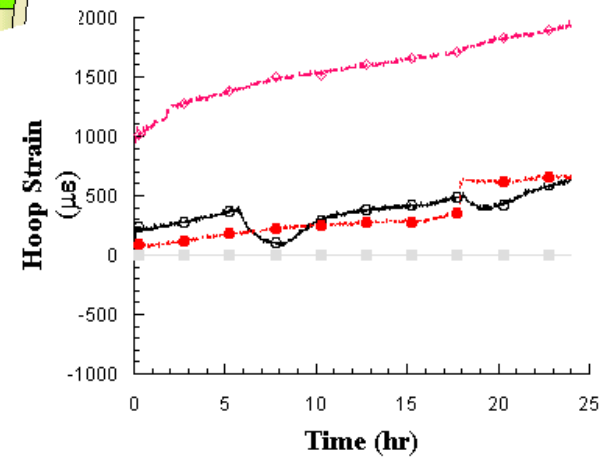

d)

Figure 5-4. Cement mantle hoop strain during single-legged stance loading for the a) Proximal-Lateral b) Proximal-Medial c) Distal-Lateral and d) Distal-Medial gage locations. 
The cement strains for the single-legged stance load case are not constant despite the fact that the applied load does not change throughout the test. Some strains measured at the proximal-lateral gage location (Figure 5-4a) were tensile and some were compressive. The tensile strains increase in magnitude during the test while the compressive strains decrease in magnitude. The same can be said for the strains measured at the proximal-medial gage location (Figure 5-4b). This indicates that as the test progresses, the tendency is for the hoop strains to become more tensile proximally. As observed in the proximal-lateral stains the gages at the distal-lateral location (Figure 5-4c) measured tensile strains for some specimens and compressive strains for others. The compressive strains tend to become more compressive while for the tensile strains there is no clear trend. The distal-medial strains (Figure 5-4d) are all tensile with a clear trend of increasing throughout the test.

The strains for the cyclic loading case follow the same trends as those in the single-legged stance load case. The strains in the proximal-lateral (Figure 5-5a) location were either tensile or compressive and tend to increase in tension throughout the test. Strains at the proximal-medial (Figure 5-5b) were lower than in all the same location for single-legged stance loading and for the other gage locations during cyclic loading. They tend to increase in tension throughout the test. As in the single-legged stance load case, strains at the distal-lateral (Figure 5-5c) show a mixed trend. Most of the measured strains were initially tensile. In some cases the tensile strains increased while others the strains decreased in tension and even became compressive. The case of initial compressive strain decreased in magnitude slightly throughout the test. The strains in the 
distal-medial location (Figure 5-5d) were tensile and increased steadily throughout the test.

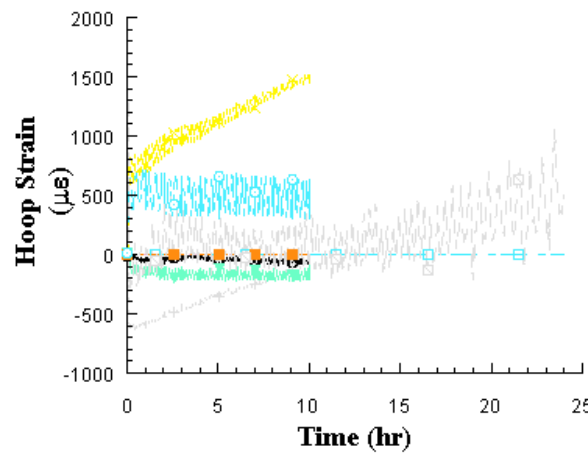

a)

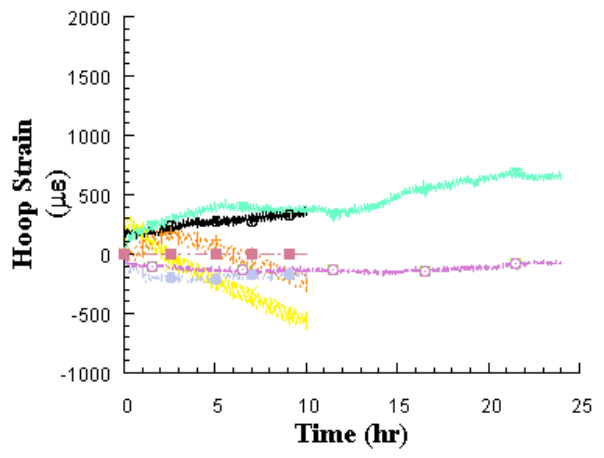

c)

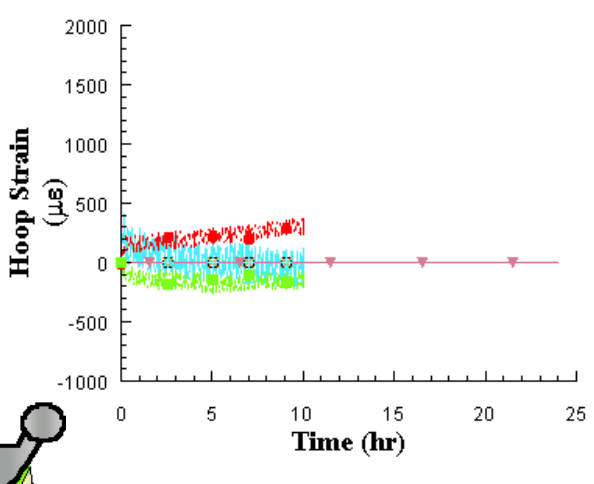

b)

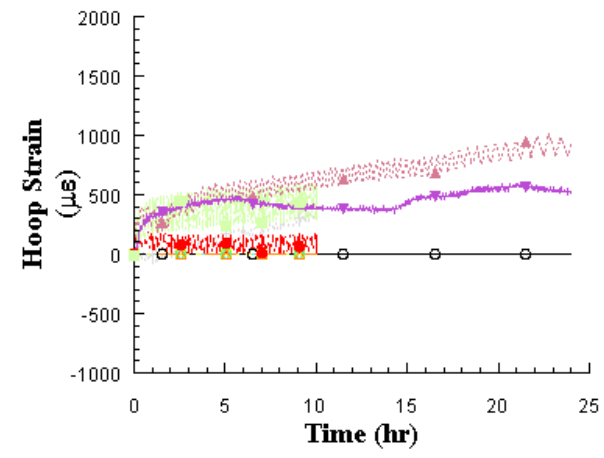

d)

Figure 5-5. Cement mantle hoop strain during cyclic loading for the a) Proximal-Lateral b) Proximal-Medial c) Distal-Lateral and d) Distal-Medial gage locations.

The load condition corresponding to stair climb load is much different than the two other load cases in this study. The femur is loaded in flexion so bending occurs in the A-P plane instead of the frontal plane. This load is maintained for 20 minutes instead of 24 hours. Generally, there is little change in measured strain during the short term test. Strains at the proximal-medial location (Figure 5-6a) were low compressive strains. Except for one specimen, the strains in the proximal-lateral location (Figure 5-6b) were 
low tensile strains. The highest strains were recorded at the distal-medial location (Figure 5-6c). Some specimens experienced tensile strains while others experienced compressive strains. All strains measured at the distal-medial location (Figure 5-6d) were initially compressive. In one specimen, which experienced very low strains, the near zero compressive strain changed to a near zero tensile strain. The other specimens experienced compressive strains that remained constant in magnitude for the duration of loading.
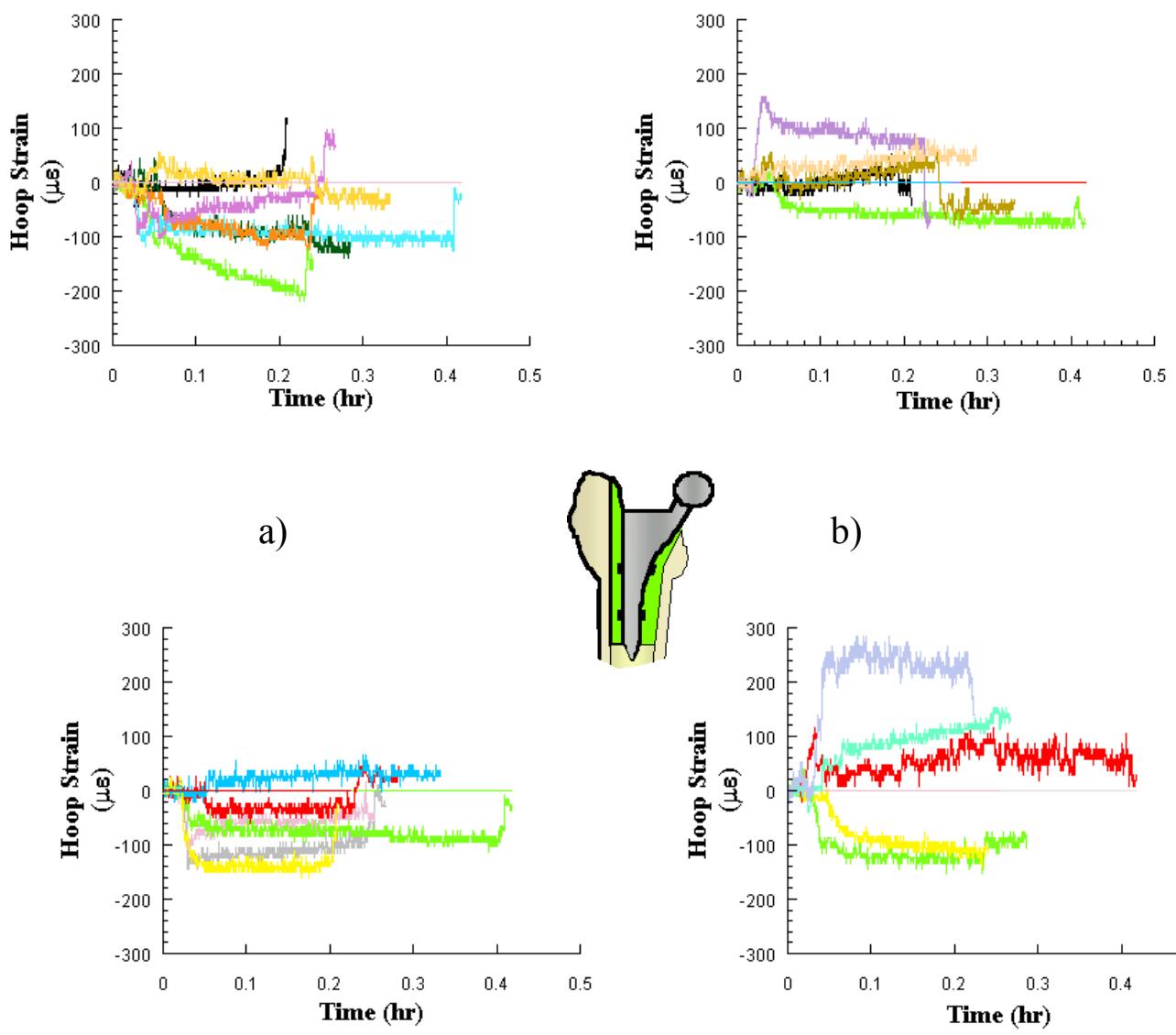

b)

c)

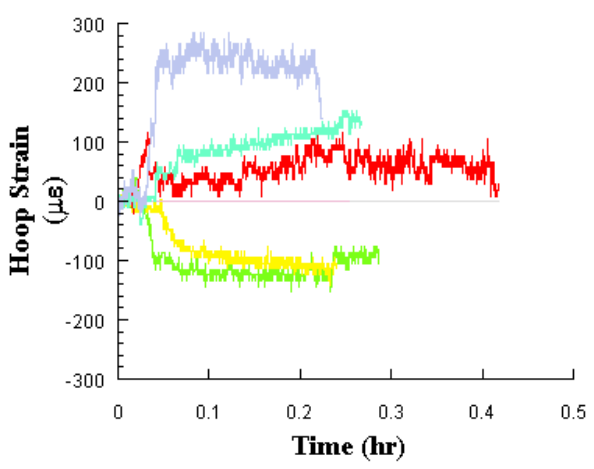

d)

Figure 5-6. Cement mantle hoop strain during stair climb loading for the a) ProximalMedial b) Proximal-Lateral c) Distal-Medial and d) Distal-Lateral gage locations. 


\section{Stem Displacement}

During single-legged stance loading, the axial displacement of the stem within the cement mantle was measured using a DVRT. Crosshead displacement of the loading ram was also recorded. The creep displacement was taken to be the difference between the last displacement measurement recorded and the displacement measurement recorded 30 minutes into the test. The crosshead displacement $(0.1512 \mathrm{~mm} \pm 0.046)$ is much greater than the DVRT displacement $(0.027 \mathrm{~mm} \pm 0.0028)$ (Figure 5-7). This is expected because crosshead displacement includes displacement due deformation of the load frame, bone, bone cement and stem, while the DVRT measures only displacement of the stem within the cement mantle. The DVRT displacement compares favorably with displacement data obtained from a finite element model of the specimen (Norman et al., 2001), suggesting that the stem was debonded and had an interface friction coefficient slightly less that 0.22 .

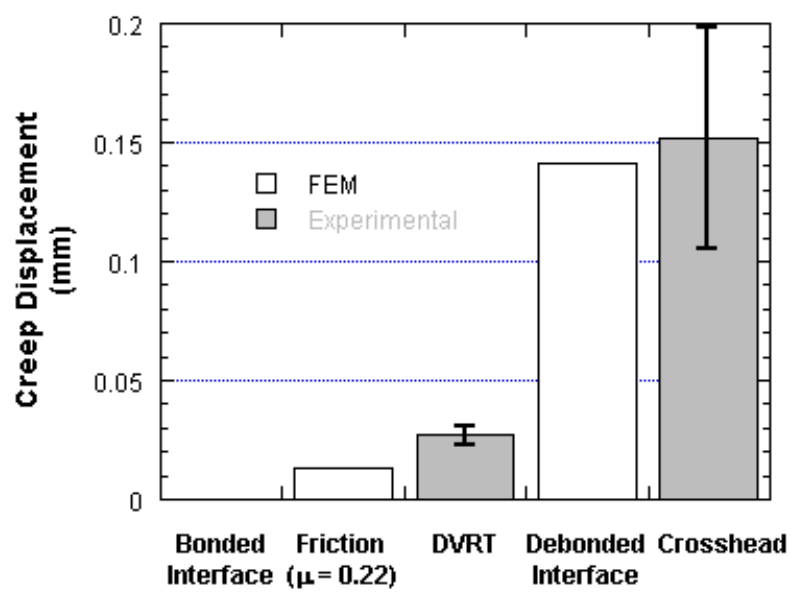

Figure 5-7. Axial creep displacement of the stem during single-legged stance loading. 


\section{Stem Pull-out Loads}

The polished stems pulled free of the cement mantle without damaging the cement, bone or fixture. The stems pulled free leaving the cement mantle intact. There was no cement debris on the stem and visual inspection of the cement mantle revealed a smooth, glassy surface. The average initial pull-out strength of the stems is $1170 \mathrm{~N}( \pm$ $357 \mathrm{~N}$ ) (Figure 5-8). The average pull-out strength of the stems after the 24 hour static load, 24 hour cyclic load and 20 minute stair climb load are $975 \mathrm{~N}( \pm 346 \mathrm{~N}), 1257 \mathrm{~N}( \pm$ $329 \mathrm{~N}), 939 \mathrm{~N}( \pm 428 \mathrm{~N})$ respectively. A student's t-test of the means indicate that there is no statistically significant difference between the means of each group.

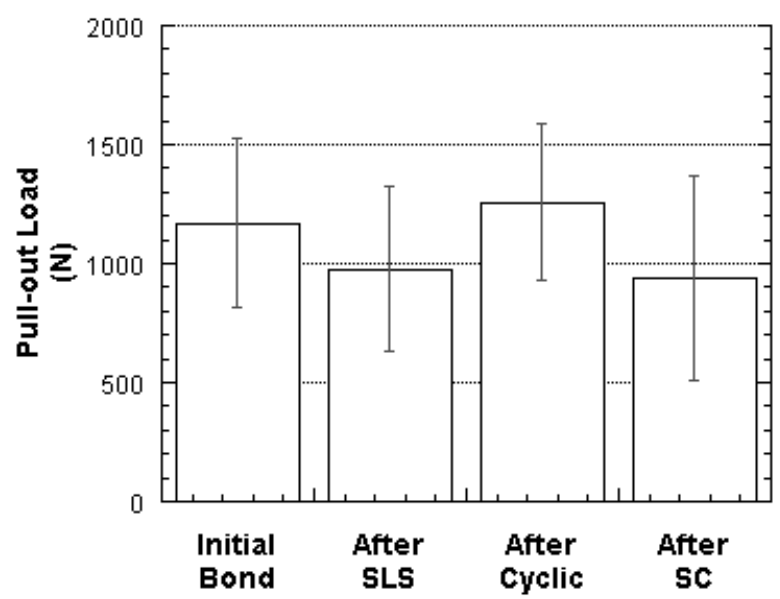

Figure 5-8. Pull-out strengths of the polished stems after each load condition. The error bars indicate one standard deviation.

The sandblasted stems did not pull free of the cement. In both cases, the femur fractured at mid-shaft. The mean failure load of the bones was $6743 \mathrm{~N}( \pm 327$ S.D.)(Figure 5-9). After the bone was sectioned longitudinally, the stem could only be removed by fracturing the cement mantle and prying it away with a chisel. 


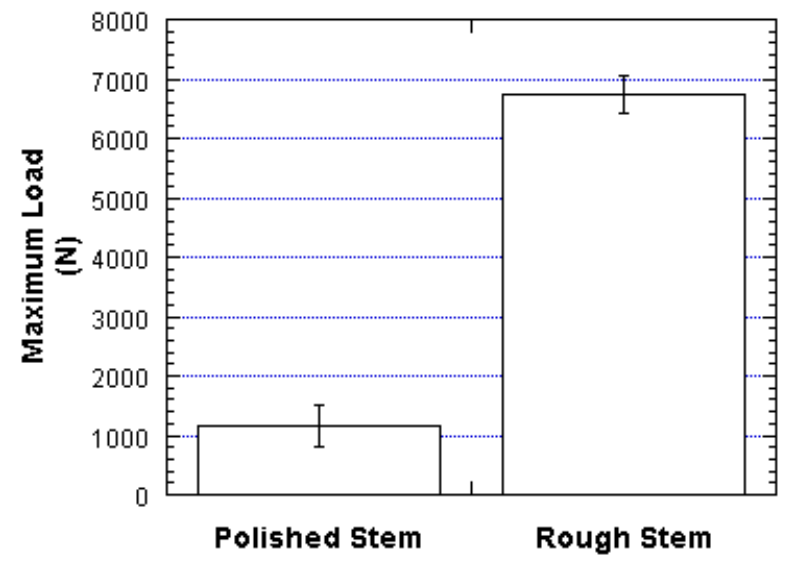

Figure 5-9. Mean failure loads of the sandblasted stems compared to the initial pull-out load of the polished stems. The error bars indicate one standard deviation.

\section{Cement Mantle Damage}

The damage to the cement mantle subject to the load protocol was assessed by counting the cracks in the cement mantle and measuring their length. Comparisons were made between untested bulk specimens of Palacos $\mathrm{R}$ to specimens from the cement mantles of stems loaded in this study. No cracks were visible in the untested bulk specimens (Figure 5-10a). In specimens of Palacos R cement mantles cracks were found to develop in the cement mantle away from the stem-cement and cement-bone interfaces (Figure 5-10b). Except for around strain gage lead wired embedded in the cement where cracks sometimes formed radially outward from the wire, the cracks were aligned in the hoop direction. The circumferential cracks averaged $36.2 \mu \mathrm{m}$ in length and did not branch into other cracks or around PMMA beads. The general crack pattern for a specimen taken from the area between the two strain gage levels (approximately $75 \mathrm{~mm}$ distal to the top of the stem) is shown in Figure 5-11. Areas of highest crack density were found in the middle of the cement mantle approximately $500 \mu \mathrm{m}$ from the cement- 
bone interface in the lateral and medial areas. The average crack density in these areas was $103.4 \mathrm{cracks} / \mu \mathrm{m}^{2}$. There were few cracks in the anterior and posterior regions of the specimens.

For comparison, one test specimen that had a cement mantle of Ostebond cement was examined. Cracks were found throughout the cement mantle from the stem-cement interface to the bone cement interface in all regions. The cracks grew around PMMA beads and branched into one another in many directions (Figure 5-12). The crack density for Osteobond cement is $203 \mathrm{cracks} / \mu \mathrm{m}^{2}$ and the average crack length is $131 \mu \mathrm{m}$. Both of these numbers are higher for Osteobond than Palacos R (Table 5-2).

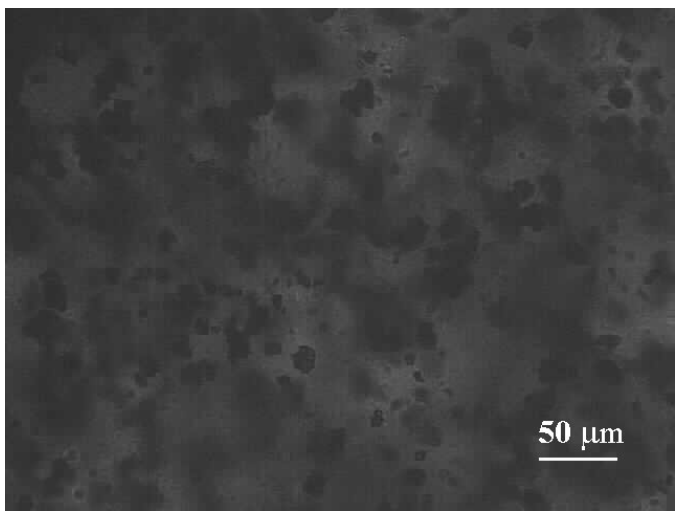

a)

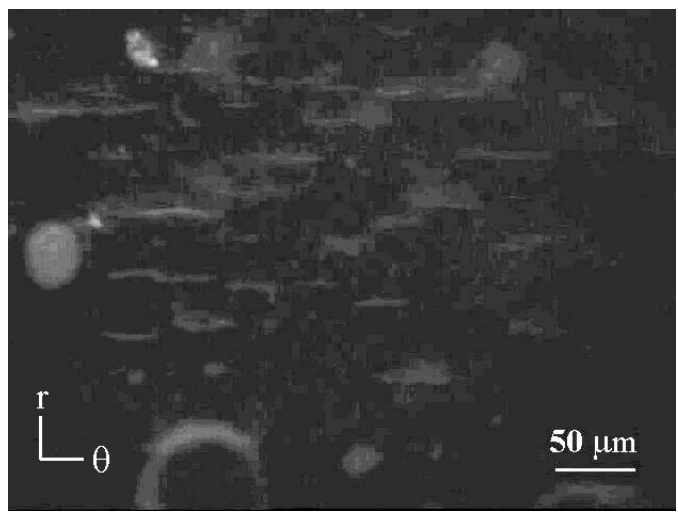

b)

Figure 5-10. Photomicrographs of a) untested bulk specimen and b) tested cement mantle of Palacos R specimens. The cement cracks in the tested cement mantle are oriented in the hoop direction.

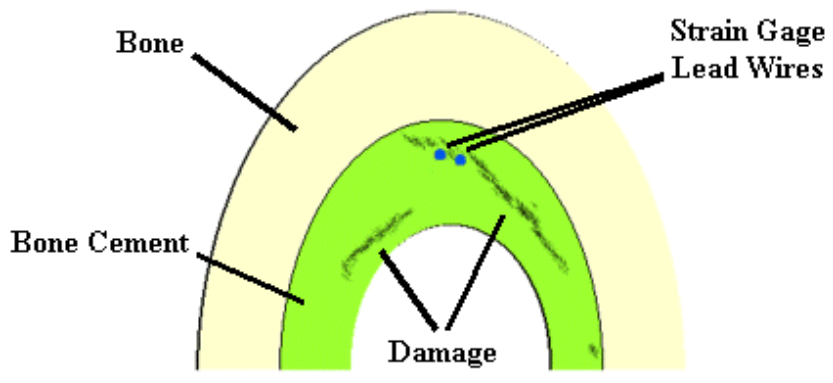

Figure 5-11. Schematic showing damage patterns in Palacos R cement mantle specimens. 


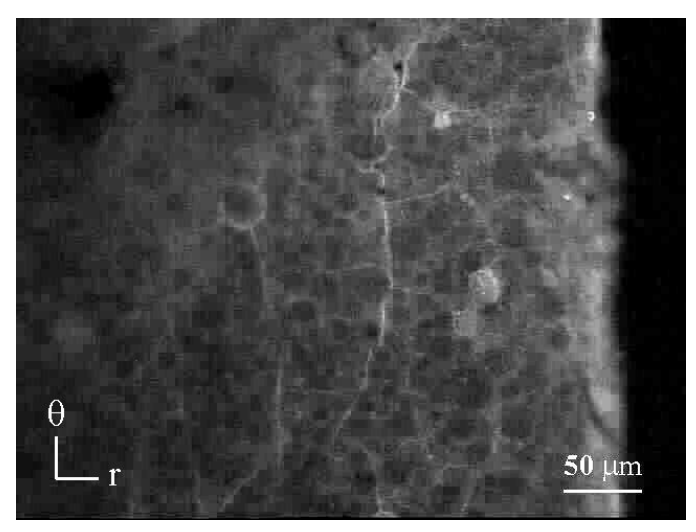

Figure 5-12. Photomicrograph of cement damage in a loaded cement mantle of Osteobond cement. There is a network of cracks between PMMA beads.

\begin{tabular}{|c|c|c|}
\cline { 2 - 3 } \multicolumn{1}{c|}{} & $\begin{array}{c}\text { Crack density } \\
\left(\# / \mu \mathrm{m}^{2}\right)\end{array}$ & $\begin{array}{c}\text { Average length } \\
(\mu \mathrm{m})\end{array}$ \\
\hline Palacos R & 103.4 & 36.2 \\
\hline Osteobond & 203 & 131 \\
\hline
\end{tabular}

Table 5-2. Crack density and length for Palacos R and Osteobond cement mantles. 


\section{CHAPTER 6: Discussion}

\section{Comparison of Cement Creep Behavior}

Surgical Simplex P experiences much less creep during 24 hour static load than Palacos R (Williams, 1995) at all stress levels considered. This difference increases disproportionally to applied load level. The amount of strain it experiences is comparable to that experienced by Osteobond (Saab, 1997) cement at the $5 \mathrm{MPa}$ and 10 MPa load levels but is higher at $20 \mathrm{MPa}$ and $30 \mathrm{MPa}$ load level (Figure 6-1).

Both Surgical Simplex P and Ostebond cements use a co-styrene co-polymer and barium sulfate as a radiopacifier. Palacos $\mathrm{R}$ uses a methylmethacrylate co-polymer and zirconium oxide as a radiopacifier. This may account for greater creep strain of Palacos R compared to Osteobond and Surgical Simplex P but does not explain the differences between Simplex and Osteobond. To explain the difference in creep resistance of Simplex and Osteobond, we must consider differences in cement formulation such as the size and regularity of the pre-polymerized PMMA beads and grains of radiopacifer in the powder component and differences in mixing technique.

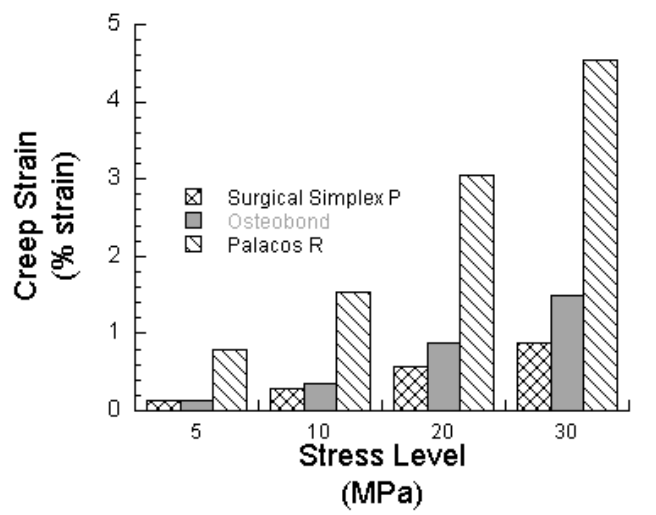

Figure 6-1. Comparison of predicted creep strain after 24 hours of static compression for Surgical Simplex P, Osteobond (Saab, 1997) and Palacos R (Williams, 1995) bone cements. 


\section{Comparison of Measured Cement Strains to FEM Results}

A 3D finite element model (FEM) of the specimen was constructed (Norman et al., 2001) This model incorporated cement creep laws and modeled the stem-cement interface as debonded. Nodal strain data was obtained for elements closest to the strain gage carrier locations (Figure 6-2)(Shultz, 2001). The FEM strains at the ProximalLateral position (Figure 6-3a) are all tensile and show little change over the 24 hour loading period. The measured strains are compressive but decrease in magnitude. At the Proximal-Medial location (Figure 6-3b) the FEM data envelopes the data. This is the location with the greatest change in cross section and the greatest difference in nodal strains occurs. The FEM data suggests that there is a large strain gradient in the radial direction in this area. The Distal-Lateral (Figure 6-3c) FEM data straddles 0, as does the experimental data, although the magnitudes differ. The FEM and experimental data for the Distal-Lateral location (Figure 6-3d) are similar but the FEM decreases slightly while the experimental increases greatly.

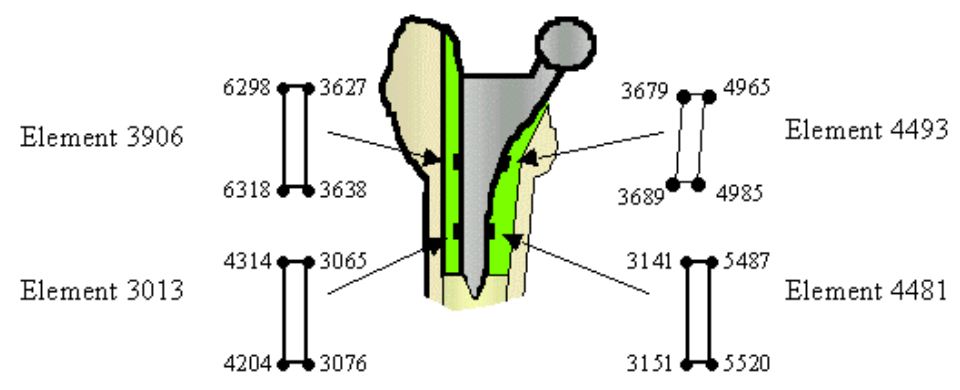

Figure 6-2. Elements and nodes corresponding to gage locations. 

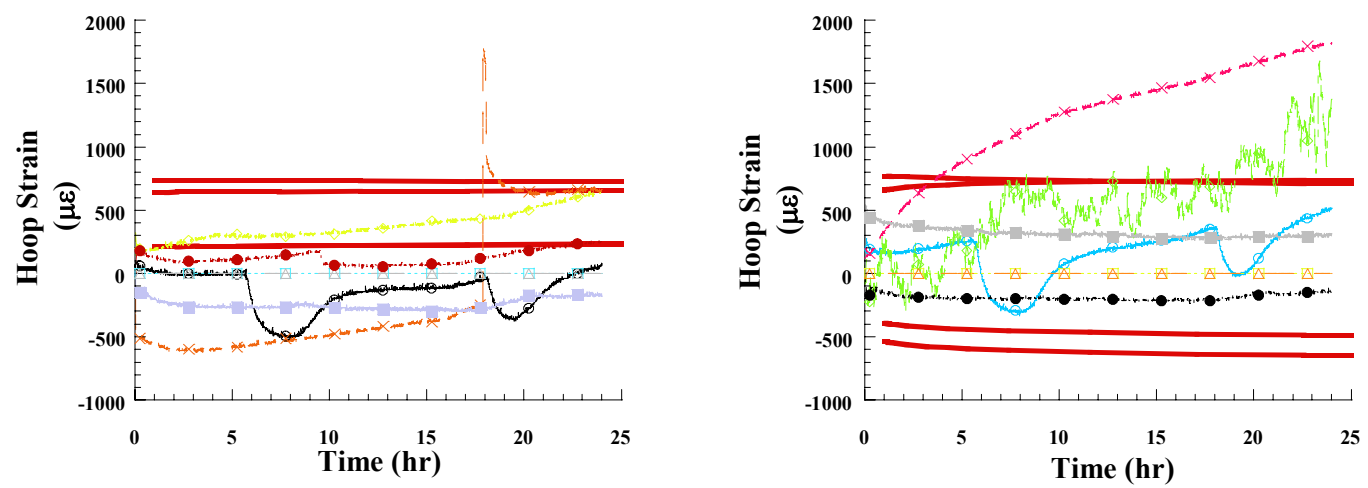

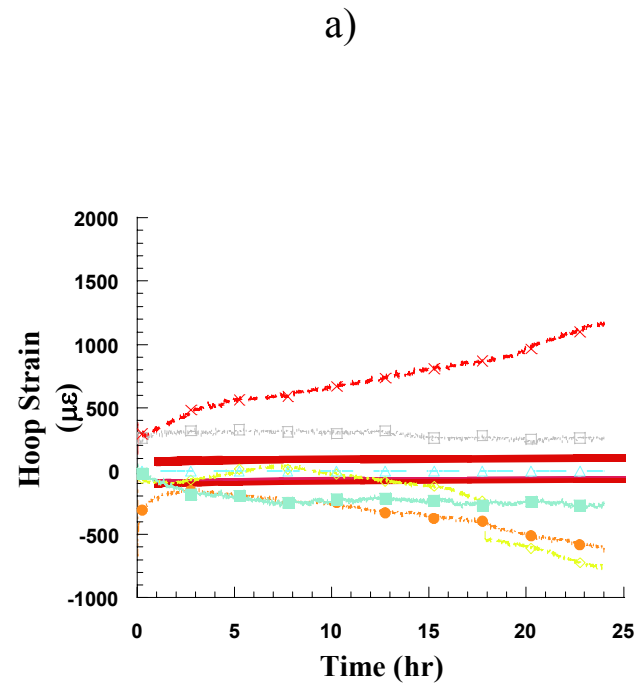

c)

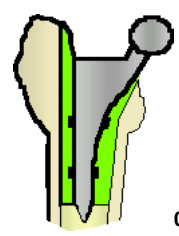

b)

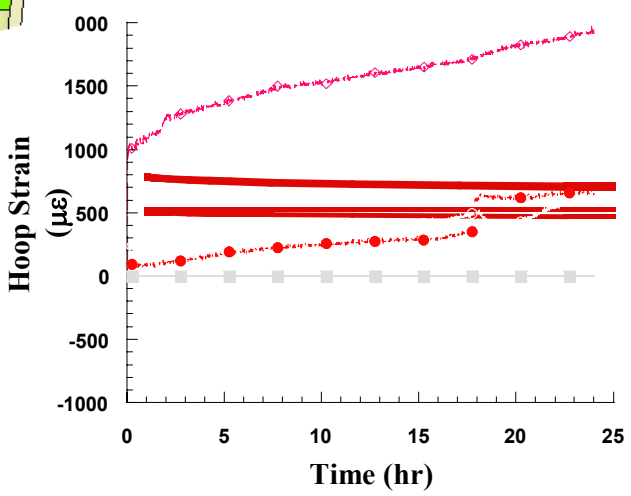

d)

Figure 6-3. Comparison of measured cement mantle creep strains to FEM results for the single-legged stance case. The bold lines with no markers represent FEM results. Shown are the strains at the a)Proximal-Lateral, b)Proximal-Medial, c)Distal-Lateral and d)Distal-Medial gage locations.

Several factors should be considered when making comparisons between experimental and FEM cement strains. There can be large variations in the geometry of the femur and in the stiffness of the bone from person to person. These variations are not accounted for in the finite element model. The debonded case modeled assumes a friction coefficient of 0.22 . This assumption may overestimate the amount of stemcement interface friction for the polished stems used in this study. It is also likely that this value varies from specimen to specimen and may not even be constant or uniform for 
a particular specimen. The data examined suggests that there are areas with a high strain gradient in the radial direction. Even a slight error in the measurement of the position of the gage carrier can account for a large difference between the experimental and FEM strain values. Because of these factors, comparison of experimental and FEM cement strains should be qualitative and not quantitative in nature.

\section{Stem Geometry Affects Subsidence, Cement Strains and Taper Lock}

There is a relationship between cement mantle creep and stem displacement. As the cement experiences creep displacement, the stem subsides within the cement mantle. The amount of subsidence that occurs and whether the stem will continue to subside are dependant on stem geometry and surface finish.

If there is no cement below the tip to give support, an axial load applied to a debonded stem is resisted by the axial component of the normal and friction forces. Force balance gives:

$$
\begin{aligned}
\Sigma F_{z} & =-P+f \cos (\theta)+N \sin (\theta) \\
& =-P+\mu N \cos (\theta)+N \sin (\theta)
\end{aligned}
$$

at equilibrium:

$$
P_{\max }=[\mu \cos (\theta)+\sin (\theta)] N
$$

where $P$ is the applied load, $N$ is the normal force at the stem-cement interface, $\mu$ is the coefficient of friction, $f$ is the friction force and $\theta$ is the stem taper angle. Thus, the maximum load that can be applied to the stem before the stem subsides within the cement mantle is a function of friction, the normal force and taper angle. The initial normal force is a result of cement shrinkage that creates an interference fit. If the applied load is greater than the maximum load for equilibrium or if the normal force is reduced due to the viscoelastic response of the bone cement the stem will subside. 
In the case of the stem with no taper (Figure 6-4a) there is no axial component of normal force so only friction forces resist subsidence. Once equilibrium is upset, there is nothing to limit subsidence. The stem will no longer be able to sustain any axial load and it will push out of the cement mantle.

This is not true for the stem with a constant taper (Figure 6-4b). As the stem subsides, the expanding stem radius creates interference between the stem and cement, increasing the normal force acting across the stem-cement interface that opposes the axial load. This process eventually restores equilibrium and brings subsidence to a halt. If equilibrium is again disturbed, the stem will subside at the same rate to restore stability.

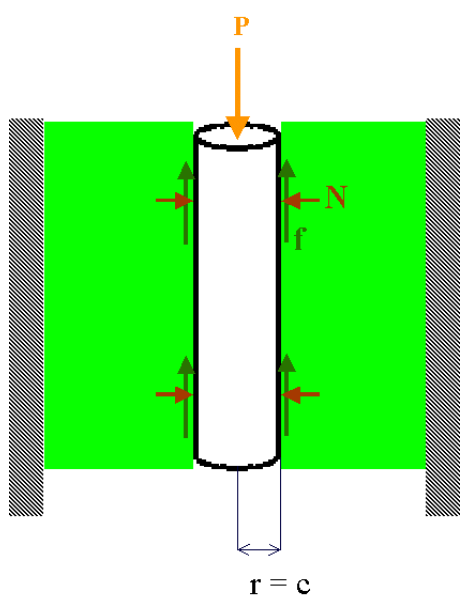

a)

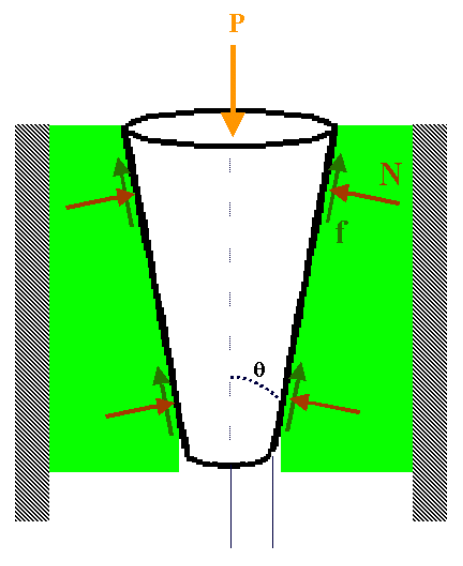

$\mathrm{r}=\mathrm{c}+\mathrm{sz}$

b)

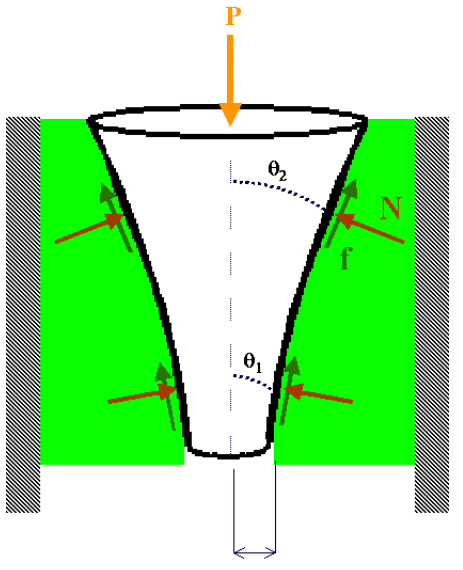

$\mathrm{r}=\mathrm{c}+\mathrm{sz}^{\mathrm{n}}$

c)

Figure 6-4. Schematic diagram showing the forces acting on idealized stems having a) no taper, b) constant taper and c) increasing taper. There is no cement below the tip of the stem to give support.

This process is accelerated in the case of a stem with an increasing taper (Figure 6-4c). For a given displacement, there will be more interference between the stem and cement when the stem taper increases with length than when it is constant. Another consequence of an increasing taper is that as subsidence continues the change in radius 
increases. This means that progressively less subsidence will be needed to generate the forces necessary to restore equilibrium.

The stem used in this study (Figure 6-5) can be considered a combination of a stem with no taper and a stem with an increasing taper angle. The lateral side of the stem has no taper. The medial side has no taper for the distal most $20 \mathrm{~mm}$ of length. Along the rest of the length the medial taper increases with length. As the stem subsides within the cement mantle, the greatest increase in normal force will be in the proximal-medial region. The lateral-medial region will experience a smaller increase in normal force. Proceeding down the stem, there will be a decreasing effect of stem subsidence on normal forces at the stem-cement interface.

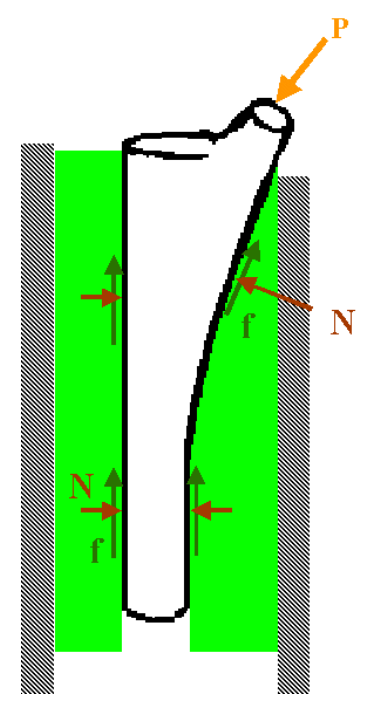

Figure 6-5. Schematic diagram showing stem geometry and forces acting on the stem used in this study. The stem has no taper laterally and distally while it has an increasing taper along the proximal-medial aspect.

This is consistent with the results of a finite element model of this system (Norman, et al., 2001). The model incorporates stem-cement interface debonding and cement creep into the analysis. The normal stresses acting across the stem-cement 
interface along the medial aspect of the stem are highest proximal extent of the cement mantle and decrease distally. The stress is not significantly different after 24 hours of cement creep. This shows that distal displacement serves to maintain an equilibrium normal stress.

This can explain the pattern of strains observed in this study. In single-legged stance and cyclic loading the strains becoming more tensile throughout the tests can be attributed to the effects of stem subsidence. The mixture of compressive and tensile strains on the lateral aspect can be due to the complex physiologic loading. The femur bends in the frontal plane when subjected to stance loading. This bending induces axial tension laterally and axial compression medially. The lateral axial tension may lead to compressive hoop strains in the lateral portion of the cement mantle due to the Poisson effect. The bending stress will be higher distally, near mid-shaft. This can explain why the compressive hoop strains in the distal-lateral region of the cement mantle do not become more tensile throughout loading as is the case for strains in the other three regions of measurement.

The combined effects of stem surface finish and stem geometry determine stem behavior. Stem surface finish determines how much load a stem can sustain before subsidence occurs. A stem with a rough surface can sustain more load than a stem with a smooth surface. However, once a stem starts to subside, the rough stem will generate cement debris that has been shown to be detrimental to long-term survival of the implant. Stem geometry determines how much the stem will subside once a maximum load has been applied. A stem with an increasing taper, at least over part of its profile, will subside less than a stem with a constant taper or no taper at all. Bone cement creep does not diminish the taper lock. Creep of the cement mantle is responsible for stem 
subsidence but stem geometry and interface conditions are the factors that determine if taper lock will occur and stem geometry alone ensures that taper lock is maintained during subsidence. 


\section{CHAPTER 7: Conclusions}

\section{Contributions}

The tests performed on Simplex P bone cement have led to the derivation of a mathematical relationship that describes the creep behavior of this cement. The results show that the amount of creep strain that it experiences is comparable to that of Ostebond cement, another commercial formulation of PMMA that uses a co-styrene co-polymer, and is much less than that experienced by Palacos $R$, a cement that uses a methylmethacrylate co-polymer.

Cement mantle strain measurements verify that bone cement does experience creep under in vivo loading and boundary conditions. Stem displacement measurements indicate that the stem debonds and that the amount of friction between the stem and cement is less than previously assumed.

This work has experimentally shown that a polished, tapered stem with an unsupported distal tip achieves a mechanical taper lock between the stem and cement mantle. The strength of this taper lock is not diminished due to cement creep, dynamic loading or loads with a high relative torsional component such as would be encountered climbing stairs or rising from a chair.

Conversely, it has shown that a stem with identical geometry but a rough surface finish will not debond and will not achieve taper lock fixation. This underscores the necessity of considering the combined effects stem geometry and surface finish instead of as looking at each as a distinct design variable.

The cement mantle damage assessment has indicated that there is a pronounced difference in the number, length and arrangement of cracks that develop in different 
formulations of bone cement. No gross failure of the cement mantle was observed, indicating that the displacement of the stem within the cement mantle was mainly the result of cement creep. These preliminary results indicate that while Osteobond cement experiences less creep than Palacos R, it is more likely to develop cracks that grow into networks of larger cracks, which may lead to gross failure of the cement mantle and stem failure.

\section{Future Work}

The initial results of cement mantle damage assessment indicate that further detailed study of this aspect of cement behavior be investigated with emphasis on determining what characteristics of commercial formulations of bone cement influence creep behavior and damage accumulation.

The stem used in this study should be implanted using other formulations of cement for which creep laws are available. This will make it possible to evaluate the significance of cement creep on stem behavior and determine what role it plays in implant stability.

Various sizes of stems of the type used in this study should be tested. The large size of the stem used in this study precluded the use of bones of small size. Thus all of the specimens were from male donors. Testing various sizes of this stem would provide an opportunity to study the behavior of this stem in specimens more representative of the THA recipient population.

Stems of other geometries should be tested in the same manner as the collarless, tapered stem was tested so that the effects of stem geometry on cement behavior and stem performance can be determined. 
The results of the four studies recommended above might lead to the development of a guideline by which a particular stem can be matched with a certain formulation of bone cement to produce optimum results. For instance, a stem that does not rely on taper-lock fixation for stability might be paired with a cement with high resistance to creep.

Limitations of the testing equipment made it impossible to test the specimens using load cases in which the direction of load application was changing. Being able to test a specimen using load cases that are dynamic in load magnitude and orientation would more closely simulate physiologic loading conditions.

Because pull-out tests were performed on the stems, all of the polished stems tested were completely debonded from the cement mantle before loading. All finite element models developed in the parallel project have only considered cases with uniform bonding conditions at the stem-cement interface. Some effort should be made to investigate the effects of partial debonding of stems at the stem-cement interface. 


\section{REFERENCES}

April, Ernest W., Anatomy, $2^{\text {nd }}$ edition, John Wiley and Sons: New York, 1990.

Baldursson, H., Egund, N., Hansson, L.I., Selvik, G., "Instability and wear of total hip prostheses determined with roentgen stereophotogrammetry," Archives of Orthopaedic and Trauma Surgery, 95(4):257-63, 1979.

Barich, F.C., Brown, T.D. and Callaghan, J.J., "Whole Surface Micromotion of a Noncemented Femoral Component Under Level Walking and Stair Climbing Simulations," Advances in Bioengineering, American Society of Mechanical Engineers Winter Annual Meeting, 28:363-364, 1994.

Barich, F.C., Brown, T.D. and Callaghan, J.J., "Effect of Proximal and Distal Fit on Micromotion of an Uncemented Femoral Component Under Realistic In Vivo Gait Loads," 41st Annual Meeting of the Orthopaedic Research Society, Orlando, FL, p. 268, 1995.

Bergmann, G., Graichen, F. and Rohlmann, A., "Hip Joint Loading Measured During Walking and Running Measured in Two Patients," Journal of Biomechanics, 26:969-990, 1993.

Bergmann, G., Graichen, F. and Rohlmann, A., "Is Staircase Walking a Risk for the Fixation of Hip Implants?” Journal of Biomechanics, 28:535-553, 1995.

Bühler, D.W., Berlemann, U., Frei, H.P. and Nolte, L.P., "Three-Dimensional Motions of Prosthetic Stems: An In Vitro Evaluation of a Novel Measuring Concept," 41st Annual Meeting of the Orthopaedic Research Society, Orlando, FL, p. 734, 1995.

Burke, D., "Stress, Strain, Porosity, and Fatigue of Acrylic Bone Cement," chapter in Advanced Concepts in THR, Harris, W. ed., pp. 22-36, Slack Inc.:Thorofare, N.J., 1985.

Byars, E.F., Snyder, R.D. and Plants, H.L., Engineering Mechanics of Defromable Bodies, $4^{\text {th }}$ edition, Harper and Row: New York, 1983.

Charnley, J., "Anchorage of the Femoral Head Prosthesis to the Shaft of the Femur," Journal of Bone and Joint Surgery, 42B:28-30, 1960.

Charnley, J., "The Bonding of Prosthesis to Bone by Cement," Journal of Bone and Joint Surgery, 46B:518-529, 1964.

Cheal, E.J., Spector, M. and Hayes, W.C., "Role of Loads and Prosthesis Material Properties on the Mechanincs of the Proximal Femur After Total Hip Arthroplasty," Journal of Orthopaedic Research, 10:405-422, 1992. 
Chwirut, D.J., "Long-Term Compressive Creep Deformation and Damage in Acrylic Bone Cement," Jounrnal of Biomedical Materials Research, 18:25-37, 1984.

Collis, D.K. and Mohler, C.G., "Loosening Rates and Bone Lysis with Rough Finished and Polished Stems," Clinical Orthopedics and Related Research, 355:113-122, 1998.

Cowin, S.C. and Hegedus, H., "Bone Remodeling I: Theory of Adaptive Elasticity," Journal of Elasticity, 6:313-326, 1976.

Crowninshield,R.D., Pedersen, D.R. and Brand, R.A., "A Measurement of Proximal Femur Strain with Total Hip Arthroplasty," Journal of Biomechanical Engineering, 102:230-233, 1980.

Crowninshield, R.D. and Tolbert, J.R., "Cement Strain Measurement Surrounding Loose and Well-Fixed Femoral Component Stems," Journal of Biomedical Materials Research, 17:819-828, 1983.

Currey, J., The Mechanical Adaptations of Bone, Princeton University Press: Princeton N.J., 1984.

Dall, D.M., Learmaonta, I.D., Solomon, M.I., Miles, A.W. and Davenport, J.M., "Fracture and Loosening in Charnley Stems," Journal of Bone and Joint Surgery, 75B:259-265, 1993.

Dall, D. M., Grobbelaar, C. J., Learmonth, Ian D., and Dall, George, "Charnley LowFriction Arthroplasty of the Hip: Long-term Results in South Africa," Clinical Orthopaedics and Related Research, 211:85-90, October 1986.

Darlington, M.W. and Turner S., "Creep of Thermoplastics," Chapter in Creep of Engineering Materials, Pomeroy, C.D. ed., pp.197-214, Mechanical Engineering Publications Ltd. : London, 1978.

Davy, D.T., Kotzar, G.M., Brown, R.H., Heiple, K.G., Goldbers, V.M., Heiple, K.G. Jr., Berilla, J. and Burstein, A.H., "Telemetric Force Measurements Across the Hip After Total Arthroplasty," Journal of Bone and Joint Surgery, 70A:45-50, 1988.

Doehring, T.C., Shanbhag, A.S. and Rubash, H.E., "The Effect of Bone/Implant Deformation on In Vitro Femoral Micromotion Measurements," Advances in Bioengineering, American Society of Mechanical Engineers Winter Annual Meeting, 31:181-182, 1995.

Electronic Instrument Research, Ltd. LE-01 Laser Extensometer User's Manual, Irwin, PA.

Evens, F. and Lissner, H., "Stresscoat Deformation Studies of the Femur Under Static Vertical Loading," The Anatomical Record, 100:159-190, 1948. 
Findley, W.N., Lai, J.S. and Onaran, K., Creep and Relaxation of Viscoelastic Materials, North Holland Publishing Co.: New York, 1976.

Fowler, J.L., Gie, G.A., Lee, A.J.C. and Ling, R.S.M., "Experience with the Exeter Total Hip Stem Since 1970," Orthopedic Clinics of North America, 19:477-489, 1988.

Gardiner, R.C. and Hozack, W.J., "Failure of the Cement-Bone Interface: A Consequence of Strengthening the Cement-Prosthesis Interface?" Journal of Bone and Joint Surgery, 76B:49-52, 1994.

Gibbons, D.F. and Buran, K.A., "Microscopic Analysis of Retrieved Polymethylmethacrylate (PMMA) Bone Cement," In Implant Retrieval: Material and Biological Analysis, NBS Special Pub. 601, National Bureau of Standards, Washington, D.C., January, 1991.

Gruen, T.A., McNeice, G.M., Amstutz, H.C., "“Modes of Failure' of Cemented StemType Femoral Components - A Radiographic Analysis of Loosening," Clinical Orthopaedics and Related Research, 141:17-27, June 1979.

Harrigan, T.P., Kareh, J.A., O’Conner, D.O., Burke, D.W. and Harris, W.H., "A Finite Element Study of Failure of Fixation in Cemented Femoral Total Hip Components," Journal of Orthopaedic Research, 10:134-144, 1992.

Harris, W.H., "Will Stress Shielding Limit the Longevity of Femoral Components of Total Hip Replacement?" Clinical Orthopaedics and Related Research, 274:120-123, 1992.

Holm, N.J., "The Relaxation of Some Acrylic Bone Cements," Acta Orthopaedica Scandinavia, 51:727-731, 1980.

Horowitz, S.M., Doty, S.B., Lane, J.M. and Burstein, A.H., "Studies of the Mechanism by Which Mechanical Failure of Polymethylmethacrylate Leads to Bone Resorption," Journal of Bone and Joint Surgery 75A:802-813, 1993.

Huiskes, R., Weinans, H., Grootenboer, H.J., Dalstra, M., Fudala, B. and Sloof, T.J., "Adaptive Bone-Remodeling Theory Applied to Prosthetic Design Analysis," Journal of Biomechanics, 20:1125-1150, 1987.

Huiskes, R., "The Various Stress Patterns of Press-Fit, Ingrown, and Cemented Femoral Stems," Clinical Orthopaedics and Related Research, 261:27-38, December, 1990.

Huiskes, R., "Failed Innovation in Total Hip Replacement," Acta Orthopaedica Scandinavia, 64:239-247, 1993.

Hustosky, Keith, "Axisymmetric Finite Element Analysis of a Total Hip Stem with a Debonded Interface and Unsupported Distal Tip", Master's Thesis, West Virginia University, Morgantown, WV, December, 1993. 
Jacobs, C.R., Simo, J.C., Beaupre, G.B. and Carter, D.B., "Anisotropic Adaptive Bone Remodelling Simulation Based on Principal Stress Magnitudes," $41^{\text {st }}$ Annual Meeting of the Orthopaedic Research Society, Orlando, FL, p. 178, 1995.

Jasty, M., Maloney, W.J., Bragdon, C.R., O’Conner, D.O., Haire, T. and Harris, W.H., "The Initiation of Failure in Cemented Femoral Components of Hip Arthroplasties," Journal of Bone and Joint Surgery, 73B:551-558, 1991.

Jasty, M., O'Conner, D.O., Henshaw, R.M., Harrigan, T.P. and Harris, W.H., "Fit of the Uncemented Femoral Component and the Use of Cement Influence the Strain Transfer to Femoral Cortex," Journal or Orthopaedic Research, 12:648-656, 1994.

Kärrholm, J., Malchau, H., Snorrason, F. and Herberts, P., "Micromotion of Femoral Stems in Total Hip Arthroplasty," Journal of Bone and Joint Surgery, 76A:1692-1705, 1994.

Kärrholm, J., Borssén, B., Löwenhielm, G. and Snorrason, F., "Early Micromotions in Cemented Femoral Stems Subsequently Revised Due to Pain or Osteolysis," 40th Annual Meeting of the Orthopedic Research Society, New Orleans, LA, p. 246, 1994.

Lee, A.J.C., "Differential Movement Between Implant and Bone," Chapter in Implant Bone Interface, Older, J. ed., pp. 131-135, Springer-Verlag: London: 1990.

Lee, A.J.C., Perkins, R.D., Ling, R.S.M., "Time Dependent Properties of Polymethylmehthacrylate Bone Cement," Chapter in Implant Bone Interface, Older, J. ed., pp. 85-90, Springer-Verlag: London: 1990.

Lennox, D.W., Schofield, B.A, McDonald, D.F. and Riley, L.H., "A Histologic Comparison of Aseptic Loosening of Cemented, Press-Fit and Biologic Ingrowth Prostheses," Clinical Orthopaedics and Related Research, 225:171-191, December 1987.

Loudin, James R. "Femoral Prosthetic Subsidence After Low-friction Arthroplasty," Clinical Orthopaedics and Related Research, 211:134-139, 1986.

Loudin, J.R. and Charnley, J., "Subsidence of the Femoral Prosthesis in Total Hip Replacement in Relation to Design of the Stem," Journal of Bone and Joint Surgery, 62B:450453, 1980.

Lu, Z., Ebramzadeh, E., McKellop, H., Zahiri, C. and Sarmiento, A., "The Influence of the Stem Bonding Strength on the Cement Stresses in Total Hip Arthroplasty," 38th Annual Meeting, Orthopedic Research Society, Washington, D.C., p. 377, February, 1992.

Lu, Z. and McKellop, H., "The Effect of Creep on Cement Stress and Subsidence of a Hip Prosthesis," 21st Annual Meeting of the Society of Biomaterials, San Francisco, CA, p.364, 1995. 
Maloney, W.J., Jasty, M., Curke, D.W., O’Conner, D.O., Zalenski, E.B., Bragdon, C. and Harris, W.H., "Biomechanical and Histological Investigation of Cemented Total Hip Arthroplasties: A Study of Autopsy-Retrieved Femurs After In Vivo Cycling," Clinical Orthopaedics and Related Research, 249:129-140, 1989.

Maloney, W.J., Bragdon, C., Sychterz, C., McGovern, T., Jasty, M., Engh, C.A. and Harris, W.H., "Adaptive Bone Remodeling With Well-Fixed Cemented and Cementless Femoral Components," 21st Annual Meeting of the Society of Biomaterials, San Francisco, CA, p.70, 1995.

Manley, M.T., Stern, L.S. and Gurtowski, J., " The Load Carrying and Fatigue Properties of the Stem-Cement Interface with Smooth and Porous Coated Femoral Implants," Journal of Biomedical Materials Research, 19:563-575, 1985.

Mann, K.A., Bartel, D.L., and Wright, T.M., "Cement Stresses in a Femoral Hip Component with Coulomb Friction at the Stem-Cement Interface," 37th Annual Meeting of the Orthopaedic Research Society, Anaheim, CA, p. 107, 1991.

McLeish, R.D. and Charnley, J., "Abduction Forces in the One-Legged Stance," Journal of Biomechanics, 3:191-209, 1970.

McKellop, H., Lu, Z., Ebramzadeh, E. and Sarmiento, A., "Variation of Stress in the Cement Mantle of Total Hip Replacements as a Result of Creep," 40th Annual Meeting of the Orthopedic Research Society, New Orleans, LA, p. 798, 1994.

Mercier, Lionel R., Practical Orthopedics, $4^{\text {th }}$ edition, Mosby: St. Louis, 1995.

MicroStrain, Inc. DVRT Specification Notes. Burlington, VT.

Miles, A.W., "A Preliminary Report on the Stem-Cement Interface and its Influence on the Bone-Cement Interface," Chapter in Implant Bone Interface, Older, J. ed., pp. 137141, Springer-Verlag: London: 1990.

Mohler, C.G., Callaghan, J.J., Collis, D.K. and Johnston, R.C., "Early Loosening of the Femoral Component at the Cement-Prosthesis Interface After Total Hip Replacement," The Journal of Bone and Joint Surgery, 77A:1315-1322, 1995.

Mohler, C.G., Kull, L.R., Martell, J.M., Rosenberg, A.G. and Galante, J.O., "Total Hip Replacement with Insertion of an Acetabular Component without Cement and a Femoral Component with Cement. Four to 7-year Results," The Journal of Bone and Joint Surgery, 77A:86-96, 1995.

Norman, T.L., Hustosky, K., Blaha, J.D. and Anderson, J.D., "2D Axisymmetric Finite Element Analysis of a Debonded Total Hip Stem With an Unsupported Distal Tip," 1993 Advances in Bioengineering, American Society of Mechanical Engineers 1993 Winter Annual Meeting, pp. 243-246, 1993. 
Norman, T.L., Kish, V., Blaha, J.D., Gruen, T.A. and Hustosky K.T., "Creep Characteristics of Hand- and Vacuum-Mixed Acrylic Bone Cement at Elevated Stress Levels," Journal of Biomedical Materials Research, 29:495-501, 1995.

Norman, T.L., Saligrama, V.C., Hustosky, K.T., Blaha, J.D. and Gruen, T.A., "Axisymmetric Finite Element Analysis of a Debonded Total Hip Stem with an Unsupported Distal Tip,” Journal of Biomechanical Engineering, 118:399-404, 1996.

Norman, T.L., Thyagarajan, G., Saligrama, V.C., Gruen, T.A. and Blaha, J.D., "Stem Surface Roughness Alters Creep Induded subsidence and 'Taper-Lock' in a Cemented Femoral Hip Prosthesis," submitted to Journal of Biomechanics, 2001.

Oh, I. and Harris, W.H., "Proximal Strain in the Loaded Femur - An In Vitro Comparison of the Distribution in the Intact Femur and After Insertion of Different Hip-Replacement Femoral Components," Journal of Bone and Joint Surgery, 60A:75-85, 1978.

Oishi, C.S., Walker, R.H. and Colwell, C.W.J., "The Femoral Component in Total Hip Arthroplasty. Six to 8-year Follow-up of 100 Consecutive Patients After Use of Third Generation Cementing Techniques," Journal of Bone and Joint Surgery, 76A:1130-1136, 1994.

Older, John, "Low Friction Arthroplasty: A 10-12-Year Follow-up Study," Clinical Orthopaedics and Related Research, 211:35-42, October 1986.

Rabb, S., Ahmed, A.M. and Provam, J.W., "The Quasi-Static and Fatigue Performance of the Implant/Bone Cement Interface," Journal of Biomedical Materials Research, 15:158$152,1981$.

Rohlmann, A., Mössner, U., Bergmann, G. and Kölbel, R., "Finite-Element-Analysis and Experimental Investigation of Stresses in a Femur," Journal of Biomedical Engineering, 4:241-246, 1982.

Rohlmann, A., Mössner, U., Bergmann, G. and Kölbel, R., "Finite-Element-Analysis and Experimental Investigation in a Femur With Hip Endoprosthesis," Journal of Biomechanics, 16:727-742, 1983.

Saab, Erik, "Creep of Low Viscosity Acrylic Bone Cement", Master's Thesis, West Virginia University, Morgantown, WV, May, 1997.

Saha, S. and Pal, S., "Mechanical Properties of Bone Cement: A Review," Journal of Biomedical Materials Research, 18:435-462, 1984.

Schmalzried, T.P., Zahiri, C.A. and Woolson, S.T., "The Significance of Stem-Cement Loosening of Grit-Blasted Femoral Components," Orthopedics, 23(11):1157-1164, 2000. 
Schulte, K.R., Callahagn, J.J, Kelly, S.S. and Johnston, R.C., "The Outcome of Charnley Total Hip Arthroplasty With Cement After a Minimum Twenty-Year Follow-up," Journal of Bone and Joint Surgery, 75A:961-975, 1993.

Shultz, Travis M., unpublished data, West Virginia University, 2001.

Sporer, S.M., Callaghan, J.J., Olejniczak, J.P., Goetz, D.D. and Johnston, R.C., "The Effects of Surface Roughness and Polymethymethacrylate Precoating on Radiographic and Clinical Results of the Iowa Hip Prosthesis," Journal of Bone and Joint Surgery, 81A:481-492, 1999.

Stauffer, R., "A 10 Year Follow-up Study of THR," Journal of Bone and Joint Surgery, 64A:983-990, 1982.

Sugiyama, H., Whiteside, L.A. and Kaiser, A.D., "Examination of Rotational Fixation of the Femoral Component in Total Hip Arthroplasty," Clinical Orthopaedics and Related Research, 249:124-128, 1989.

Sutherland, C.J., Wilde, A.H., Borden, L.S. and Marks, K.E., "A Ten-Year Follow-Up of One Hundred Consecutive Müller Curved-Stem Total Hip-Replacement Arthroplasties," Journal of Bone and Joint Surgery, 64A:970-82, 1982.

Total Hip Joint Replacement. NIH Consensus Statement, Mar 1-3;4(4):1-11, 1982.

Total Hip Joint Replacement. NIH Consensus Statement, Sep 12-14;12(5):1-31, 1994.

Treharne, R.W. and Brown, N., "Factors Influencing the Creep Behavior of Poly(methylmethacrylate) Cements," Journal of Biomedical Materials Research Symposium, 6:81-88, 1975.

Verdonschot, N. and Huiskes, R., "Creep Behavior of Hand-Mixed Simplex P Bone Cement Under Cyclic Tensile Loading," Journal of Applied Biomaterials, 5:235-243, 1994a.

Verdonschot, N. and Huiskes, R., "Dynamic Creep Behavior of Acrylic Bone Cement," 40th Annual Meeting of the Orthopedic Research Society, New Orleans, LA, p. 590, 1994b.

Verdonschot, N. and Huiskes, R., "Dynamic Creep Behavior of Acrylic Bone Cement," Journal of Biomedical Materials Research, 29:575-581, 1995.

Weber, F.A. and Charnley, J, "A Radiological Study of Fractures of Acrylic Cement in Relation to the Stem of a Femoral Head Prosthesis," Journal of Bone and Joint Surgery, 57B:297-301, 1975.

Weinans, H., Huiskes, R. and Grootenboer, H.J., "Effects of the Material Properties of Femoral Hip Components on Bone Remodeling," Journal of Orthopaedic Research, 10:845-853, 1992. 
Wolff, J., Das gesetz der transformation der knochen. Berlin: A Hirschwald, 1892.

Woolson, S.T. and Haber, D.F., "Primary Total Hip Replacement with Insertion of an Acetabular Cup without Cement and a Femoral Component with Cement. Follow-up Study at an Average of 6 years," The Journal of Bone and Joint Surgery, 78A:698-705, 1996.

Williams, Michael, "Creep Characterization of Hand and Vacuum Mixed Acrylic Bone Cement", Master's Thesis, West Virginia University, Morgantown, WV, August, 1995.

Wroblewski, B.M., "15-21-Year Results of the Charnley Low Friction Arthroplasty," Clinical Orthopaedics and Related Research, 211:30-35, October 1986. 


\section{CURRICULUM VITAE}

\section{KEITH T. HUSTOSKY \\ hustosky@yahoo.com}

\section{$\underline{\text { Education }}$}

West Virginia University, Morgantown, WV

- Ph.D. Mechanical Engineering - August 2002

GPA: 3.2

Advisor: Dr. Timothy L. Norman

Dissertation: Experimental Characterization of the Mechanical Consequences of a Debonded Total Hip Stem with an Unsupported Distal Tip

- M.S. Mechanical Engineering - December 1993

GPA: 3.4

Advisor: Dr. Timothy L. Norman

Thesis: Axisymmetric Finite Element Analysis of an Idealized Total Hip

Stem with an Unsupported Distal Tip

- B.S. Mechanical Engineering - May 1992

GPA: 3.3

- Registered Engineer Intern - State of West Virginia Certificate \#EI6158

\section{$\underline{\text { Experience }}$}

Computer Technician

West Virginia Assistive Technology System

955 Hartman Run Road

Morgantown, WV 26505

April 1996 - August 2002

Responsible for installation, maintenance and upgrading of computers, peripherals and software. Computers include PC's and Macintoshes used for general office work and as demonstration platforms for assistive technologies. Peripherals include printers, modems, scanners and alternative I/O devices such as braillers, speech synthesizers, alternate keyboards, switch inputs and touch screens.

\section{Graduate Research Assistant -}

West Virginia University, Mechanical and Aerospace Engineering Department/Musculoskeletal Research Center

May 1992 - August 2001 
- Experimental Work: Designed and performed experiments to evaluate total hip prosthesis design. Have prepared specimens and performed tests in order to characterize creep behavior of acrylic bone cement. Have designed and performed tests to measure cement mantle strains, distal stem displacement and fixation strength. Experience with design and fabrication of test fixtures, use of servo-hydraulic testing machines, data acquisition systems and statistical analysis.

- Finite Element Modeling: Developed axisymmetric finite element model of an idealized total hip stem to evaluate the behavior of a cemented hip prosthesis with a debonded stem-cement interface and an unsupported distal tip. The models include interface (gap) elements and non-linear creep behavior of the cement.

\section{Computer Skills}

- ANSYS and I-DEAS finite element codes

- Windows, Macintosh and UNIX operating environments

- FORTRAN and BASIC programming

- LabTech Notebook data acquisition software

- JMP Statistical Analysis software

- Microsoft Office

- Corel Office Suite

\section{Relevant Graduate Coursework}

- Numerical Modeling

- Computer Aided Design

- Continuum Mechanics

- Experimental Stress Analysis

- Instrumentation

- Advanced Mechanics of Materials

- Theory of Elasticity
- Inelastic Behavior of Engineering Materials

- Mechanics of Composite Materials

- Advanced Composite Materials

- Fracture Mechanics

- Statistics for Research

- Applied Regression Analysis

\section{Honors/Activities}

- Pi Tau Sigma Mechanical Engineering Honorary

- Dean's List College of Engineering (Fall 1991)

- WVU Scholar's Program

- WVU Presidential Scholarship

- Biomedical Engineering Society (WVU Chapter President 1996, Secretary 1997)

- American Society of Mechanical Engineers

- Society of Automotive Engineers

- WVU SAE Mini-Baja Senior Design Team - 1992

- Safety Judge - SAE Mini-Baja East Competition - 1996 


\section{$\underline{\text { Publications }}$}

Journal Articles

Norman, T. L., Saligrama, V.C., Hustosky, K.T., Blaha, J.D. and Gruen, T.A., "Axisymmetric Finite Element Analysis of a Debonded Total Hip Stem with an Unsupported Distal Tip," Journal of Biomechanical Engineering, vol. 118, pp. 399-404, August 1996.

Norman, T. L., Kish, V., Blaha, J.D., Gruen, T. A. and Hustosky, K., "Creep Characteristics of Hand and Vacuum Mixed Acrylic Bone Cement at Elevated Stress Levels," Journal of Biomedical Materials Research, vol. 29, pp. 495-501, April 1995.

Conference Papers

Hustosky, Keith T., Norman, Timothy L., Kish, Vincent L., Gruen, Thomas A. and Blaha, J.David, "The Effect of Surface Finish on the Behavior of a Tapered Cement Total Hip Stem,” ASB 1999 Annual Meeting.

Gruen, T.A., Kenamond, Carter A., Hustosky, K.T. and Norman, Timothy L., "Can Radiogrammetry Predict the Mechanical Strength of the Proximal Femur? An In Vitro Comparison with Bone Mineral Densitometry," ASB 1999 Annual Meeting.

Hustosky, K.T., Norman, T.L., Kish, V.L., Gruen, T.A. and Blaha, J.D., "Pullout Strength of a Polished, Tapered, Cement Total Hip Stem," 44th ORS Annual Meeting, March, 1998.

Hustosky, K.T., Norman, T.L., Kish, V.L., Blaha, J.D. and Gruen, T.A., "The Effects of Creep on Cement Hoop Stresses and Axial Displacement of a Cemented Femoral Hip Prosthesis In-Vitro," 42nd ORS Annual Meeting, February 1996.

Norman, T. L., Kish, V., Blaha, J.D., Gruen, T. A. and Hustosky, K., "Creep Characterization of Hand and Vacuum Mixed Acrylic Bone Cement at Elevated Stress Levels," AAOS 62nd Annual Meeting, Orlando, Florida, 1994.

Norman, T. L., Hustosky, K. and Blaha, J. D. "Effect of Stem Taper and Creep on Cement Mantle Stress and Subsidence of THA", 1994 Advances in Bioengineering, American Society of Mechanical Engineers Winter Annual Meeting, 1994.

Norman, T. L., Hustosky, K. and Blaha, J. D. " Design of THA for Stem Debonding," 1994 International Society on Research in Orthopaedic and Trauma, 1994. 
Norman, T.L., Hustosky, K., Blaha, J.D. and Anderson, J., "2-D Axisymmetric Finite Element Analysis of a Debonded Total Hip Stem with an Unsupported Distal Tip," 1993 Advances in Bioengineering, American Society of Mechanical Engineers Winter Annual Meeting, 1993.

Norman, T.L., Kish, V., Hustosky, K., and Blaha, J.D., “Creep of Acrylic Bone Cement at High Stress Levels," 1993 Advances in Bioengineering, American Society of Mechanical Engineers Winter Annual Meeting, 1993.

Presentations

"The Effect of Surface Finish on the Behavior of Tapered, Cemented Total Hip Stems," 1999 American Society of Biomechanics Annual Meeting, Pittsburgh, PA, October 1999.

"The Effect of PMMA Creep on Cement Total Hip Stems," Third Annual Research Review, WVU Department of Orthopedics, Morgantown, WV, May 1999.

"Pull-out Strengths of Polished, Tapered Cemented Total Hip Stems," Second Annual Research Review, WVU Department of Orthopedics, Morgantown, WV, April 1998.

"Experimental Evaluation of a Polished, Tapered Cemented Total Hip Stem," First Annual Research Review, WVU Department of Orthopedics, Morgantown, WV, April 1997.

"In Vitro Evaluation of Taper-Lock Fixation," 16th Annual Reunion Day, WVU Department of Orthopedics, Morgantown, WV, October 1995.

"Surface Strain Measurement of a Sawbone Femur Using Resistive Strain Gage Rosettes," Mid-Atlantic Regional Student Conference of the American Institute of Aeronautics and Astronautics, Morgantown WV, April 1994. 